\title{
1. Kinetics of thorium and particle cycling along the U.S. GEOTRACES North Atlantic Transect
}

\author{
Paul Lerner*1, Olivier Marchal ${ }^{1}$, Phoebe J. Lam ${ }^{2}$, Ken Buesseler ${ }^{1}$, and Matthew \\ Charette $^{1}$ \\ ${ }^{1}$ Woods Hole Oceanographic Institution, Woods Hole, MA 02543, USA \\ ${ }^{2}$ University of California Santa Cruz, Santa Cruz, CA 95064, USA
}

\begin{abstract}
The high particle reactivity of thorium has resulted in its widespread use in tracing processes impacting marine particles and their chemical constituents. The use of thorium isotopes as tracers of particle dynamics, however, largely relies on our understanding of how the element scavenges onto particles. Here, we estimate apparent rate constants of Th adsorption $\left(k_{1}\right)$, Th desorption $\left(k_{-1}\right)$, bulk particle degradation $\left(\beta_{-1}\right)$, and bulk particle sinking speed $(w)$ along the water column at 11 open-ocean stations occupied during the GEOTRACES North Atlantic Section (GA03). First, we provide evidence that the budgets of Th isotopes and particles at these stations appear to be generally dominated by sorption reactions, particle degradation, and particle sinking. Rate parameters are then estimated by fitting a Th and particle cycling model to data of dissolved and particulate ${ }^{228,230,234} \mathrm{Th},{ }^{228} \mathrm{Ra}$, particle concentrations , and ${ }^{234,238} \mathrm{U}$ estimates based on salinity, using a nonlinear programming technique.

We find that the adsorption rate constant $\left(k_{1}\right)$ generally decreases with depth across the section: broadly, the time scale $1 / k_{1}$ averages $1.0 \mathrm{yr}$ in the upper $1000 \mathrm{~m}$ and (1.4-1.5) $\mathrm{yr}$
\end{abstract}

${ }^{*}$ Corresponding Author. Address: Department of Marine Chemistry and Geochemistry, Woods Hole Oceanographic Institution, 266 Woods Hole Road, Clark 448 (MS\#25), Woods Hole, MA (Tel:1-508-289-3278)

email address: plerner@whoi.edu 
below. A positive relationship between $k_{1}$ and particle concentration $(P)$ is found, i.e., $k_{1} \propto$ $P^{b}$, where $b \geq 1$, consistent with the notion that $k_{1}$ increases with the number of surface sites available for adsorption. The rate constant ratio, $K=k_{1} /\left(k_{-1}+\beta_{-1}\right)$, which measures the collective influence of rate parameters on Th scavenging, averages 0.2 for most stations and most depths. We clarify the conditions under which $K / P$ is equivalent to the distribution coefficient, $K_{D}$, test that the conditions are met at the stations, and find that $K / P$ decreases with $P$, in line with a particle concentration effect $\left(d K_{D} / d P<0\right)$. In contrast to the influence of colloids as envisioned by the Brownian pumping hypothesis, we provide evidence that the particle concentration effect arises from the joint effect of $P$ on the rate constants for thorium attachment to, and detachment from, particles.

Keywords: GEOTRACES;Thorium;Particle Concentration Effect;single-particle class model;Inverse Method

\section{Introduction}

One of the major questions in marine biogeochemistry concerns the processes controlling the formation, transport, and destruction of marine particles. Thorium can be useful for investigating these processes: thorium is highly particle reactive in seawater, with radioactive isotopes characterized by a wide range of half-lives: $t_{1 / 2}=24.101 \pm 0.025$ days for ${ }^{234} \mathrm{Th}$ (Knight and Macklin, 1948), $1.910 \pm 0.002 \mathrm{yr}$ for ${ }^{228}$ Th (Kirby et al., 2002), and $75,584 \pm 110 \mathrm{yr}$ for ${ }^{230}$ Th (Cheng et al., 2013). Additionally, the sources of these isotopes are well known. ${ }^{234} \mathrm{Th},{ }^{230} \mathrm{Th}$, and ${ }^{228} \mathrm{Th}$ are produced in situ by radioactive decay of ${ }^{238} \mathrm{U},{ }^{234} \mathrm{U}$, and ${ }^{228} \mathrm{Ra}$, respectively. The apparent quasiconservative behavior of uranium (Ku et al., 1977; Delanghe et al., 2002) allows the ${ }^{234} \mathrm{U}$ and ${ }^{238} \mathrm{U}$ activities to be estimated from salinity (Chen et al., 1986; Owens et al., 2011), whereas ${ }^{228} \mathrm{Ra}$ is generally measured (Henderson et al., 2013). The high particle reactivity, widely different halflives, and relatively well understood sources of thorium isotopes have led to their extensive use in tracing processes that affect particles and their chemical constituents such as particulate organic carbon.

The use of thorium isotopes to trace particle dynamics in the North Atlantic has a rich history. Brewer et al. (1980) relied on ${ }^{228,230,234}$ Th (multiple mass numbers written as left superscript denote 
several isotopes) measurements on particulate material caught in sediment traps deployed between 414-5332 $\mathrm{m}$ in the Sargasso Sea $\left(31^{\circ} 32.5^{\prime} \mathrm{N}, 55^{\circ} 55.4^{\prime} \mathrm{W}\right)$ and between $389-5068 \mathrm{~m}$ off the coast of Barbados $\left(13^{\circ} 30.2^{\prime} \mathrm{N}, 54^{\circ} 00.1^{\prime} \mathrm{W}\right)$ to estimate a residence time of Th with respect to scavenging 22 yr. Bacon et al. (1985) found that radionuclides, particularly ${ }^{230} \mathrm{Th}$ and ${ }^{231} \mathrm{~Pa}$, on particles collected in a sediment trap at $3200 \mathrm{~m}$ in the Sargasso Sea showed seasonal variations consistent with the annual cycle of primary production in the overlying surface water. They concluded that, since small particles reside on average for several years in the deep ocean, there must be a continuous exchange of material between the small and large size fractions.

More recently, Murnane (1994a) analyzed thorium isotope and particle concentration data from the (i) Nares Abyssal Plain $\left(23^{\circ} 11^{\prime} \mathrm{N}, 63^{\circ} 28^{\prime} \mathrm{W}\right)$, (ii) station $20\left(23^{\circ} 17^{\prime} \mathrm{N}, 64^{\circ} 09^{\prime} \mathrm{W}\right)$ of the Transient Tracers in the Ocean-North Atlantic Study, and (iii) station $31\left(27^{\circ} \mathrm{N}, 53^{\circ} 32^{\prime} \mathrm{W}\right)$ of the Geochemical Oceans Section Study (GEOSECS). By fitting to the water column data models for the cycling of inert and biogenic particles in small and large size classes, they estimated depthdependent rate constants for the remineralization of biogenic particles and for the aggregation and disaggregation of both biogenic and inert detrital particles. They reported median values between 2.1 and $3.6 \mathrm{yr}^{-1}$ for the aggregation rate constant, 135 and $195 \mathrm{yr}^{-1}$ for the disaggregation rate constant, and 0.2 and $75 \mathrm{yr}^{-1}$ for the remineralization rate constant. However, the errors in the rate parameters were large compared to the estimates themselves, and the authors concluded that the data do not strongly constrain the particle cycling rate constants. The authors also estimated the rate constant for Th adsorption normalized to particle concentration to be $5.0 \pm 1.0 \times 10^{4} \mathrm{~m}^{3} \mathrm{~kg}^{-1}$ $\mathrm{yr}^{-1}$, and the rate constant for Th desorption to be $k_{-1}=3.1 \pm 1.5 \mathrm{yr}^{-1}$. In contrast to the other model parameters, the rate constants for adsorption and desorption were assumed to be vertically uniform in their analysis.

Colley et al. (1995) collected particulate ${ }^{230} \mathrm{Th}$ and ${ }^{210} \mathrm{~Pb}$ intercepted by sediment traps at 3100 $\mathrm{m}$ and $4465 \mathrm{~m}$ in the Porcupine Abyssal Plain $\left(47^{\circ} \mathrm{N}, 19^{\circ} \mathrm{W}\right)$. They found that, below a mass flux of $120 \mathrm{mg} \mathrm{m}^{-2} \mathrm{~d}^{-1}$, the fluxes of these radionuclides were linearly related to the mass flux, and above $120 \mathrm{mg} \mathrm{m}^{-2} \mathrm{~d}^{-1}$, the radionuclide fluxes leveled off. The authors ascribed this lack of correlation at 
high mass flux values to an incomplete interaction of radionuclides with faster settling particulate material. Furthermore, they found that the trap material had the ${ }^{210} \mathrm{~Pb} /{ }^{230} \mathrm{Th}$ signature of the entire water column, suggesting the surface material does not reach the trap unaltered.

Studies from the JGOFS North Atlantic Bloom Experiment (24 April-30 May, 1989) provided insight into various processes affecting particles in the top $300 \mathrm{~m}$ in a mid-latitude oceanic environment. These studies used ${ }^{228,234} \mathrm{Th}$ measured on particles intercepted by in-situ pumps outfitted with 0.5- $\mu \mathrm{m}$ nominal pore size filters (Buesseler et al., 1992) to determine rate constants for Th adsorption (Clegg and Whitfield, 1993), and for particle aggregation, disaggregation, and degradation (Cochran et al., 1993; Murnane et al., 1996). A key finding of both Cochran et al. (1993) and Murnane et al. (1996) was that, over the course of the bloom, the particle aggregation rate constant increased from about 0 to $30 \mathrm{yr}^{-1}$, while the particle disaggregation rate constant increased from about 100 to $500 \mathrm{yr}^{-1}$.

More recently, a large amount of measurements of trace elements and isotopes, including thorium isotopes, have been generated along the US GEOTRACES North Atlantic (GA03) transect (Fig. 1). These measurements, concurrently with measurements of particle concentration, provide a unique opportunity to study trace metal and particle cycling in a range of environments in the North Atlantic. Specifically, the GA03 transect includes stations from near the western margin, the Trans-Atlantic Geotraverse (TAG) hydrothermal vent at the Mid-Atlantic Ridge, the subtropical gyre interior, the Mauritanian upwelling, and the region influenced by Mediterranean Outflow Water near the Iberian Peninsula.

The collection and analysis of radionuclides from the U-Th decay series at GA03 have already been described in several studies. These include studies on the distribution of dissolved and particulate ${ }^{230} \mathrm{Th}$ (Hayes et al., 2015a,b), ${ }^{234} \mathrm{Th}$ (Owens et al., 2015a), and dissolved ${ }^{228} \mathrm{Ra}$ (Charette et al., 2015). Additionally, Lam et al. (2015) have reported measurements of small $(0.8-51 \mu \mathrm{m})$ and large $(\geq 51 \mu \mathrm{m})$ bulk particle concentrations as well as particle phase concentrations (particulate organic carbon, particulate inorganic carbon, biogenic opal, lithogenic material, $\mathrm{MnO}_{2}$, and iron (oxyhydr)oxides obtained along GA03. 
Particularly relevant to the present study, Hayes et al. (2015b) used ${ }^{230} \mathrm{Th}$ data for the dissolved and particulate fractions collected along GA03 to estimate the apparent distribution coefficient $K_{D}=A_{p} /\left(A_{d} P\right)$, where $A_{d}\left(A_{p}\right)$ is the activity measured in the dissolved (particulate) phase and $P$ is particle concentration. They found that $K_{D}$ generally increased with depth and that $\log _{10}\left(K_{D}\right)$ decreased with $\log _{10}(P)$ (slope $=-0.66, r=-0.72$ ). They also noticed that $K_{D}$ was highest for $\mathrm{MnO}_{2}\left(116.5 \pm 54.7 \times 10^{7} \mathrm{~g} / \mathrm{g}\right)$ and relatively small for particulate organic matter (POM) $\left(0.3 \pm 0.2 \times 10^{7} \mathrm{~g} / \mathrm{g}\right)$. A possible reason for the low $K_{D}$ values for POM was that the operationally defined "dissolved" phase $(\leq 0.8 \mu \mathrm{m})$ includes colloidal particles, too fine to be caught by conventional filters but onto which much of the thorium is expected to adsorb (Hayes et al., 2015b). Thus, the fraction of thorium that is adsorbed onto particulate material (both colloidal and larger particles) may potentially be underestimated.

A recent study by Lerner et al. (2016) demonstrated that, at open ocean station GT11-22 of GA03, a model with vertically varying rate parameters fits Th isotope and particle data significantly better than a model with vertically uniform rate parameters. They also found that the adsorption rate constant has a significant positive relationship with particle concentration. Outstanding questions are (i) whether a similar result holds at other stations along GA03 and, more generally, (ii) the extent to which rate parameters of Th and particle cycling vary along this section, and what processes are controlling them.

In this paper, we extend previous studies by documenting the vertical and horizontal variations in apparent kinetic parameters of Th sorption reactions and particle processes in the North Atlantic. A nonlinear least-squares technique is used to fit a 1-D (vertical) single-particle class model of thorium and particle cycling to ${ }^{228,230,234} \mathrm{Th}$ isotope activities in the dissolved and particulate phases, ${ }^{234,238} \mathrm{U}$ activities, ${ }^{228} \mathrm{Ra}$ activities, and particle concentrations, at a number of open-ocean stations occupied during GA03. Particular emphasis is placed on the Th adsorption rate constant $\left(k_{1}\right)$ and on its relationship with particle concentration, thereby complementing the analysis of Hayes et al. (2015b): whereas $K_{D}$ is a measure of the amount of thorium bound to particles relative to the amount of thorium dissolved in seawater, $k_{1}$ is a measure of the specific rate at which thorium 
attaches to particles. Both concepts, $K_{D}$ and $k_{1}$, are thus different and provide distinct perspectives on the scavenging process. Furthermore, our study analyzes jointly three thorium isotopes $\left({ }^{228,230,234} \mathrm{Th}\right)$ in different size fractions, an effort only previously performed by Murnane (1994a) and Murnane et al. (1994b). In this manner, we provide the first look into the spatial variations in the kinetics of thorium and particle cycling in the North Atlantic as constrained by multiple thorium isotopes, their parents, and particle concentrations.

This paper is organized as follows. In section 2, we present (i) the data from the two legs of GA03, (ii) the vertical interpolation of the data that is assumed in our analysis, (iii) the model of particle and Th cycling, (iv) an assessment of the effects of advection, diffusion, and unsteadiness (all neglected in the model), and (v) the inverse method used to combine the data and the model. In section 3, the model is fitted to the data, the consistency of the model with the data is tested, and the rate parameters estimated from the fit are reported. In section 4, the rate parameters are interpreted in the context of the different oceanographic environments spanned by our selected stations, and the relationship of the rate parameters, particularly $k_{1}$, with particle concentration, is explored. Attention is paid to the implications of our results for the interpretation of $K_{D}$ in terms of the kinetics of Th sorption reactions. Moreover, we examine the robustness of the estimated rate parameters to various assumptions in our analysis. Conclusions follow in section 5.

\section{Methods}

\subsection{Hydrographic Setting}

We use data collected aboard the R/V Knorr in October 2010 (leg GT10) and NovemberDecember 2011 (leg GT11; Figure 1). The first leg (GT10) of the transect went from Lisbon to Cape Verde, while the second leg (GT11) ran from Woods Hole to Cape Verde. We consider only the stations highlighted in red (Figure 1). These stations, situated in the open-ocean, are chosen on the assumption that they suffer from a relatively small influence of lateral and vertical transport of thorium isotopes and particles. This assumption is tested in section 2.5.

The hydrography along GA03 is thoroughly described by Jenkins et al. (2015) and briefly summarized here. Across our selected stations, the main thermocline gradually shoals equatorward to 
station GT10-10, at which point deep isotherms below the main thermocline rise to about 200 $\mathrm{m}$ in the region of the Mauritanian upwelling (Figure 2a in Jenkins et al. (2015)). Evidence for upwelling is also seen by the incursion of deep, low salinity water to the near-surface at stations GT10-10 and GT10-09. Additionally, an intrusion of low salinity water at intermediate depths (about $1000 \mathrm{~m}$ ) is apparent in the southeastern part of leg GT11 (Figure 2b in Jenkins et al. (2015)). This feature has been ascribed to Antarctic Intermediate Water shoaling to the southeastern part of the leg, where the Northern Equatorial Current abuts the Northern Equatorial Counter Current (Schmitz and McCartney, 1993; Jenkins et al., 2015). Another noteworthy feature is the presence of high salinity water at intermediate depths of stations GT10-01 and GT10-03, presumably associated with the Mediterranean Outflow Water emanating from the Straits of Gibraltar (Bozec et al., 2011).

Jenkins et al. (2015) conducted a multiple regression analysis to estimate the relative contributions of various water masses along GA03. They show that most of the thermocline waters (above $600 \mathrm{~m}$ ) are comprised of North Atlantic Central Waters. However, a significant proportion ( $\geq 40 \%)$ of thermocline waters in the southeastern segment of leg GT-11 consists of Atlantic Equatorial Water flowing from the south of the subtropical gyre (Schmitz and McCartney, 1993; Stramma et al., 2005; Jenkins et al., 2015). The intermediate waters at the stations considered here are estimated to include Irminger Sea Water, Antarctic Intermediate Water, Mediterranean Outflow Water, Upper Circumpolar Deep Water, and Upper Labrador Sea Water. Stations GT11-22, GT11-24, GT10-10, GT10-11, and GT10-12 are dominated (> 50\%) by Antarctic Intermediate Water between 6001000 m, and Upper Circumpolar Deep Water between 1000-2000 m. West of the Mid-Atlantic Ridge, the intermediate depths are dominated by Irminger Sea Water (between 800-1000 m) and Upper Labrador Sea Water (between 1000-2000 m). The deepwater masses at our selected stations are Classical Labrador Sea Water, Denmark Strait Overflow Water, Iceland-Scotland Overflow Water, and Antarctic Bottom Water. Throughout both legs, Classical Labrador Sea Water is estimated to be the main contributor $(\geq 60 \%)$ to the total water mass between 2000-3000 m. Below 3000 m, Iceland Scotland Overflow water is the main contributor, although Antarctic Bottom Water also 
constitutes a significant portion of the total water mass (around 30\%).

\subsection{Data}

The samples were collected using the following procedures. Particles fractionated into small $(1-51 \mu \mathrm{m})$ and large $(>51 \mu \mathrm{m})$ size classes were obtained by large volume in-situ filtration using a modified dual-flow WTS-LV McLane research pump equipped with 142-mm "mini-MULVFS" filter holders (Bishop et al., 2012). Samples for particulate ${ }^{228} \mathrm{Th}$, dissolved ${ }^{228} \mathrm{Th}$, and dissolved ${ }^{228} \mathrm{Ra}$ were collected by large volume in situ filtration. The dissolved ${ }^{230} \mathrm{Th}$ and ${ }^{234} \mathrm{Th}$ samples were gathered using 30-L Niskin bottles. Bottles collecting ${ }^{234}$ Th samples below $1000 \mathrm{~m}$ were attached individually to the pump wire at the depths of the in situ pumps. Bottles collecting dissolved ${ }^{230} \mathrm{Th}$ samples at all depths and ${ }^{234} \mathrm{Th}$ samples above $1000 \mathrm{~m}$ were mounted on the ODF/SIO rosette on a separate cast. These data can be found in the GEOTRACES Intermediate Data Product (The GEOTRACES group, 2015).

In this paper, we use data collected below 85-187 m; data from shallower depths are not used because the model considered in this study does not account for particle production. The shallowest depth varies with station $(85-187 \mathrm{~m})$, and is chosen so that data extrapolation is avoided (Table 1). We restrict our analysis to depths below the primary production zone, defined as the upper layer in the water column where net primary production (the difference between gross primary production and phytoplankton respiration) is positive. Following Owens et al. (2015a), it is defined as the depth where in vivo fluorescence, as measured by the CTD, reaches $10 \%$ of its maximum value. This definition is based on a study by Marra et al. (2014) in the Northwest Atlantic, which found that the compensation depth generally occurred at or below the in vivo fluorescence maximum.

For convenience, the subscript $d(p)$ is used to designate Th isotope activity in dissolved (small and large particulate) form, and $P$ designates bulk particle concentration. The following studies have reported and discussed methods and (or) data for radionuclide activities and particle concentrations used here: Lam et al. (2015) for particle concentrations, Maiti et al. (2012) and Owens et al. (2015b) for total ${ }^{234} \mathrm{Th}$ and ${ }^{234} \mathrm{Th}_{p}$, Anderson et al. (2012), Shen et al. (2012), and Hayes et al. (2015a) for ${ }^{230} \mathrm{Th}_{d, p}$, Maiti et al. (2015) for ${ }^{228} \mathrm{Th}$, and Henderson et al. (2013) and Charette 
et al. (2015) for ${ }^{228} \mathrm{Ra}$. The tabulated ${ }^{228} \mathrm{Th}_{d, p}$ can be found on BCO-DMO (Charette et al., 2014). Finally, ${ }^{234} \mathrm{Th}_{d}$, which was not measured directly, is calculated by subtracting ${ }^{234} \mathrm{Th}_{p}$ from total ${ }^{234} \mathrm{Th}$, and its error is derived by error propagation neglecting error covariances (Bevington and Robinson, 1992).

The radioactive parents of ${ }^{234} \mathrm{Th}$ and ${ }^{230} \mathrm{Th}$, which were also not measured, are estimated as follows. The parent ${ }^{238} \mathrm{U}$ is estimated from salinity, measured at the Scripps Oceanographic Data Facility, using the empirical equation derived by Owens et al. (2011),

$$
{ }^{238} \mathrm{U}=0.0786( \pm 0.00446) S-0.315( \pm 0.158),
$$

where ${ }^{238} \mathrm{U}$ is in dpm L $\mathrm{L}^{-1}$ and $S$ is on the Practical Salinity Scale of 1978 . The uncertainties of ${ }^{238} \mathrm{U}$ are taken as the root mean square error of the linear regression of ${ }^{238} \mathrm{U}$ against salinity (Owens et al., 2011). On the other hand, ${ }^{234} \mathrm{U}$ is estimated from ${ }^{238} \mathrm{U}$ by assuming a ${ }^{234} \mathrm{U} /{ }^{238} \mathrm{U}$ ratio of 1.147 (Andersen et al., 2010), and its uncertainty is obtained by multiplying the uncertainties in ${ }^{238} \mathrm{U}$ by 1.147 .

Notice that ${ }^{230} \mathrm{Th}_{p}$ present in marine particulate material may have two distinct origins: ${ }^{230} \mathrm{Th}$ adsorbed in situ onto the surfaces of particles and ${ }^{230} \mathrm{Th}$ locked in the mineral lattices of particles (Roy-Barman et al., 2009; Hayes et al., 2013, 2015a). Since we are only interested in the adsorption of thorium onto particles, we estimate the fraction of ${ }^{230} \mathrm{Th}$ adsorbed onto particles using equations (2-3) in Hayes et al. (2015b). For these estimates, measurements of dissolved and particulate ${ }^{232} \mathrm{Th}$ are required. As for ${ }^{230} \mathrm{Th}_{p}$, particulate ${ }^{232} \mathrm{Th}$ was measured on particles collected with a modified dual-flow WTS-LV McLane research pump. Subsamples of filters fixed on the pump were acid digested, co-precipitated with Fe after dissolution, and subject to inductively coupled plasma mass spectrometry (ICP-MS). Dissolved ${ }^{232}$ Th collected in Niskin bottles was also measured by ICPMS. Within our selected stations and depths (Table 1), these corrections never amount to more than $30 \%$ of total ${ }^{230} \mathrm{Th}_{p}$, the largest correction accounting to $30 \%$ near the surface at station GT11-24. For simplicity, estimates of ${ }^{230} \mathrm{Th}_{p}$ in the adsorbed fraction are simply referred to as ${ }^{230} \mathrm{Th}_{p}$ in the remainder of this paper. 
Whereas particle and radionuclide samples were collected in both small $(1-51 \mu \mathrm{m})$ and large $(>$ $51 \mu \mathrm{m})$ size classes, only data for bulk particles $(P)$ and bulk particulate radionuclides $\left({ }^{228,230,234}{ }^{2} h_{p}\right)$ are used in this paper. At some stations, ${ }^{234} \mathrm{Th}$ in the large size fraction is only available above about $1000 \mathrm{~m}$ (the precise depth varies between stations). ${ }^{230} \mathrm{Th}$ in the large size fraction is only available at a few depths at stations GT11-14, GT11-22, GT10-12, and GT10-11. Finally, ${ }^{228} \mathrm{Th}$ in the large size fraction is only available at a few depth ranges at stations GT10-10, GT10-11, and GT10-12 (samples from multiple depths were combined for better detectability). In order to obtain bulk particle data for each Th isotope at a given station, the ratio of large $\left({ }^{234} \mathrm{Th}_{p, l}\right)$ to small particulate ${ }^{234} \mathrm{Th}\left({ }^{234} \mathrm{Th}_{p, s}\right)$ is calculated from the ${ }^{234} \mathrm{Th}_{p, l}$ and ${ }^{234} \mathrm{Th}_{p, s}$ data that are available at that station. Then, from the measured activities on the small size fraction, this ratio is applied to derive (i) ${ }^{234} \mathrm{Th}_{p, l}$ at depths where it was not measured and (ii) ${ }^{228,230} \mathrm{Th}_{p, l}$ at stations where it was not measured. At stations where ${ }^{230} \mathrm{Th}_{p, l}$ was measured, the average ratio of ${ }^{230} \mathrm{Th}_{p, l}$ to ${ }^{230} \mathrm{Th}_{p, s}$ is applied to the ${ }^{230} \mathrm{Th}$ activities measured on the small size fraction to derive ${ }^{230} \mathrm{Th}_{p, l}$ at depths where it was not measured. Similarly, at stations where ${ }^{228} \mathrm{Th}_{p, l}$ within certain depth ranges was measured, the average ratio of ${ }^{228} \mathrm{Th}_{p, l}$ to ${ }^{228} \mathrm{Th}_{p, s}$ is used to estimate ${ }^{228} \mathrm{Th}_{p, l}$ at all depths. At all stations and depths, the measured or calculated ${ }^{228,230,234} \mathrm{Th}_{p, l}$ is added to the measured ${ }^{228,230,234} \mathrm{Th}_{p, s}$ to obtain total particulate Th for each isotope (e.g., ${ }^{228} \mathrm{Th}_{p}={ }^{228} \mathrm{Th}_{p, s}+{ }^{228} \mathrm{Th}_{p, l}$ ). Errors in ${ }^{228,230,234} \mathrm{Th}_{p}$ were calculated by error propagation omitting error covariances.

\subsection{Vertical Interpolation}

The depths at which radiochemical and particle data are available do not generally coincide. To facilitate our analysis, the measured (or calculated) values of $P,{ }^{228,230,234} \mathrm{Th}_{d, p},{ }^{234,238} \mathrm{U}$, and ${ }^{228} \mathrm{Ra}$ are interpolated onto an irregular grid for which each grid point is at a depth where at least one measurement is available (see Table 1 for the depth range at each station). The grid is defined such that no data extrapolation is needed. That is, at each station, the shallowest depth of the grid is chosen such that neither thorium isotope activities nor particle concentrations need to be extrapolated beyond that depth (and likewise for the deepest depth).

We use a minimum variance interpolation technique (e.g., Wunsch (2006)) which is described 
in detail in Lerner et al. (2016). The parameters of the interpolation procedure are the variance of the water property being interpolated, $\sigma_{M}^{2}$, and the length scale characterizing its vertical covariance along the water column, $l_{z}$. The parameter $\sigma_{M}^{2}$ is the maximum tolerable variance in the gridded (interpolated) data: when the interpolation depth is far from the measurement depth, the error in the interpolated value approaches $\sigma_{M}$. On the other hand, $l_{z}$ is a length scale that determines the property covariance along the water column. Specifically, if the distance between two depths increases by $l_{z}$, the property covariance between both depths is reduced by a factor of $1 / e$. Following Lerner et al. (2016), we set $\sigma_{M}^{2}=0.5 \sigma_{D}^{2}$ and $l_{z}=1000 \mathrm{~m}$, where $\sigma_{D}^{2}$ is the variance in a particular data set (e.g., the variance in the ${ }^{230} \mathrm{Th}_{d}$ data) at a given station.

To assess the vertical interpolation, we interpolate the data at the sampling depths and calculate the interpolation residuals normalized to measurement errors for all data used in this study (Figure 2a). A normalized residual is defined as

$$
r_{i}=\left(\hat{x}_{i}-x_{d, i}\right) / \sigma_{d, i},
$$

where $\hat{x}_{i}$ is the gridded value at sampling depth level $i, x_{d, i}$ is the measured value at this level, and $\sigma_{d, i}$ is the error in the measurement at this level. For $\sigma_{M}^{2}=0.5 \sigma_{D}^{2}$ and $l_{z}=1000 \mathrm{~m}$, the fraction of normalized residuals less than 2 in absolute magnitude is 0.96 (Figure 2a). Thus, over $95 \%$ of the gridded values agree with the data within $2 \sigma_{d, i}$, which supports the interpolation.

Table 1: Depth range of the radionuclide and particle concentration data considered in this study

\begin{tabular}{|l|c|}
\hline Station & Depth range $(\mathrm{m})$ \\
\hline GT11-10 & $185-3006$ \\
\hline GT11-12 & $185-5485$ \\
\hline GT11-14 & $135-4000$ \\
\hline GT11-16 & $114-3600$ \\
\hline GT11-18 & $187-4362$ \\
\hline GT11-20 & $186-5420$ \\
\hline GT11-22 & $125-4243$ \\
\hline GT11-24 & $90-3458$ \\
\hline GT10-10 & $100-3200$ \\
\hline GT10-11 & $85-3200$ \\
\hline GT10-12 & $90-3500$ \\
\hline
\end{tabular}




\subsection{Model of Thorium and Particle Cycling}

We consider a single-particle class model for thorium and particle cycling that includes balance equations for ${ }^{228,230,234} \mathrm{Th}_{d}$, bulk ${ }^{228,230,234} \mathrm{Th}_{p}$, and bulk particles (Figure 3 ). The model equations for the thorium isotopes include the production by their radioactive parents, the radioactive decay, the adsorption onto particles, the desorption from particles, the release from particles via particle degradation, and the effect of particle sinking. The equations for particle concentration include the degradation of particles and the effect of particle sinking. The equations are (Nozaki et al., 1981; Bacon and Anderson, 1982):

$$
\begin{aligned}
T\left(A_{d}\right) & =\lambda A_{\pi}+\left(k_{-1}+\beta_{-1}\right) A_{p}-\left(k_{1}+\lambda\right) A_{d} \\
T\left(A_{p}\right)+w \frac{\partial A_{p}}{\partial z} & =k_{1} A_{d}-\left(\beta_{-1}+k_{-1}+\lambda\right) A_{p} \\
T(P)+w \frac{\partial P}{\partial z} & =-\beta_{-1} P .
\end{aligned}
$$

Here, $A_{d}\left(A_{p}\right)$ represents the thorium isotope activity in the dissolved (particulate) phase (in units of $\left.\mathrm{dpm} \mathrm{m} \mathrm{m}^{-3}\right), A_{\pi}$ is the activity of the parent isotope $\left(\mathrm{dpm} \mathrm{m}^{-3}\right), P$ is the particle concentration $\left(\mathrm{mg} \mathrm{m}^{-3}\right), \lambda$ is the radioactive decay constant $\left(\mathrm{yr}^{-1}\right)$, and $k_{1}, k_{-1}$, and $\beta_{-1}$ are the rate constants for Th adsorption, Th desorption, and particle degradation, respectively $\left(\mathrm{yr}^{-1}\right)$. The particle sinking speed is $w\left(\mathrm{~m} \mathrm{yr}^{-1}\right)$, and $z$ is depth $(\mathrm{m})$. Notice that the presence of vertical derivatives require boundary conditions, which we take as the values of $P$ and $A_{p}$ at the shallowest depth of the grid at each station (Table 1). Finally, the term $T(\cdot)$ in each equation represents the effects of unsteadiness, advection, and diffusion, i.e.,

$$
T\left(A_{d}\right) \equiv \frac{\partial A_{d}}{\partial t}+\boldsymbol{u} \cdot \nabla A_{d}-\nabla \cdot\left(\boldsymbol{k} \nabla A_{d}\right)
$$

where $\mathbf{u}$ is the vector velocity and $\boldsymbol{k}$ a diffusion tensor.

Several assumptions are made in the governing equations (3a-3c). We assume steady state and 
omit the effects of transport by advection and diffusion, i.e., $T(\cdot)=0$. Furthermore, Th sorption reactions and particle degradation are described using first order kinetics. Some models also assume no significant contribution to the dissolved and particulate pools of thorium isotopes from lithogenic sources. While this assumption should be reasonable for ${ }^{228,234} \mathrm{Th}$ far from sedimentary sources, ${ }^{230} \mathrm{Th}$ may have a sizeable lithogenic contribution in the vicinity of mineral dust sources (Hayes et al., 2013). Here, the lithogenic contribution is removed from the data (see section 2.2), and our model (equations 3a-3c) only considers the ${ }^{230} \mathrm{Th}$ fraction that takes part in sorption reactions.

\subsection{Effects of Advection, Diffusion, and Unsteadiness}

In this section, we assess our assumption of a negligible contribution of advection, diffusion, and unsteadiness in the Th isotope and particle budgets at our selected stations along GA03. To this end, we rely on the Th and particle data along legs GT10 and GT11 together with other observational estimates in the North Atlantic. The advection fluxes are estimated from (i) the horizontal and vertical velocities inferred for November 2011 from a least-squares fit of an ocean general circulation model to oceanic and atmospheric observations (ECCO v4 non-linear inverse solution; Forget et al. (2015)), and (ii) the horizontal and vertical concentration gradients measured along the two legs. For example, the vertical advection flux of $A_{d}$ at depth $z$ of the ECCO grid and at station GT11-24 is estimated as $u \partial A_{d} / \partial l$, where $\partial A_{d} / \partial l$ is the concentration gradient evaluated using an upstream scheme, $A_{d}$ is obtained by vertically interpolating data on the ECCO grid at station GT11-24 and its upstream station (GT11-22), $l$ is the geodesic distance between the two stations, and $u$ is the magnitude of the horizontal velocity component at depth $z$, closest to station GT11-22, and along the line joining the two stations. Similarly we estimate the vertical advection flux of $A_{d}$ at a given depth of the ECCO grid and at a given station as $\omega \partial A_{d} / \partial z$, where $\partial A_{d} / \partial z$ is the vertical concentration gradient evaluated from $A_{d}$ interpolated at that depth and the depth immediately above, and $\omega$ is the vertical velocity at that depth. The horizontal diffusion flux of $A_{d}$ is estimated by evaluating $K_{h} \partial^{2} A_{d} / \partial l^{2}$ using a 2nd-order central difference scheme, where the horizontal diffusivity $K_{h}=1000 \mathrm{~m}^{2} \mathrm{~s}^{-1}$ is taken from a tracer release experiment in the 
North Atlantic (Ledwell et al., 1998). Note that our horizontal flux estimates only consider fluxes along the transect, and do not take into account fluxes of Th isotopes or particles in cross-transect directions. The vertical diffusion of $A_{d}, K_{z} \partial^{2} A_{d} / \partial z^{2}$, where $K_{z}$ is the vertical diffusivity, is evaluated using a similar scheme. We restrict our estimates of vertical diffusion to stations GT1124, GT10-11, and GT10-10, which are nearby the African continental rise (Figure 1), where Toole et al. (1994) reported diffusivities $K_{z}=10^{-5} \mathrm{~m}^{2} \mathrm{~s}^{-1}$ using microstructure data. Finally, we assess the unsteadiness terms $\partial(\cdot) / \partial t$ at the cross-over station of GA03 (station GT10-12 of leg 1 and station GT11-24 of leg 2). Specifically, data from these stations are interpolated on the ECCO grid, and differences between interpolated values at the same depth are divided by the time interval between the two occupations of the cross-over station. Note that our estimates of $\partial(\cdot) / \partial t$ have limited usefulness, particularly for the short-lived ${ }^{234} \mathrm{Th}$ as this time interval exceeds the ${ }^{234} \mathrm{Th}$ half-life by one order of magnitude.

Figures 4 and 5 show our estimates of the magnitude of the various terms in $T(\cdot)$ for the Th isotopes and the particles (depth averages are shown). For reference, these figures also include prior estimates of terms that are retained in the balance equations (3a-3c) (horizontal lines in Figures 4 and 5). These terms are the production flux $\lambda A_{\pi}$ for ${ }^{228,234} \mathrm{Th}_{d}$, the adsorption flux $k_{1} A_{d}$ for ${ }^{230} \mathrm{Th}_{d}$ and ${ }^{228,230,234} \mathrm{Th}_{p}$, and the degradation flux $\beta_{-1} P$ for $P$. They are estimated using the interpolated thorium isotope and particle concentrations $\left({ }^{234,238} \mathrm{U},{ }^{228} \mathrm{Ra}^{228,230,234} \mathrm{Th}_{d, p}\right.$, and $\left.P\right)$ and, where appropriate, prior estimates of the rate parameters. For the prior adsorption and degradation fluxes, we take the smallest and largest values of $k_{1}\left(0.1\right.$ and $\left.1 \mathrm{yr}^{-1}\right)$ and $\beta_{-1}\left(1\right.$ and $\left.100 \mathrm{yr}^{-1}\right)$ reported in previous syntheses (Marchal and Lam, 2012; Lerner et al., 2016). A term in $T(\cdot)$ would appear negligible, in the depth-average sense, if its vertical average has an order of magnitude less than that of the retained term in the same equation. We find that (horizontal and vertical ) diffusion and advection, as well as the unsteadiness term, appear generally negligible for the balance equations of ${ }^{228,230,234} \mathrm{Th}_{d, p}$ and $P$ (Figures 4 and 5).

We illustrate the vertical variations in the missing terms for ${ }^{230} \mathrm{Th}_{d}$ at the crossover station (Figure 6), the only station for which all terms in the ${ }^{230} \mathrm{Th}_{d}$ governing equations can be estimated. 
Consistent with the vertical averages (Figure 4b), it is seen that the missing terms appear to be generally small compared to prior estimates of $k_{1}^{230} \mathrm{Th}_{d}$. Some of these terms exceed the minimum estimate of the adsorption flux in the top $300 \mathrm{~m}$. Between 300 and $500 \mathrm{~m}$, horizontal diffusion appears to be significant. Between 500 and $1500 \mathrm{~m}$, the unsteadiness term occasionally exceeds the prior estimates of the minimum adsorption rate. Finally, below $1500 \mathrm{~m}$, only the unsteadiness term appears significant compared to the minimum adsorption rate.

In summary, our results show that, at most of our selected stations, advection and diffusion fluxes appear to be generally smaller by at least one order of magnitude than retained terms in the Th isotope and particle budgets. Likewise, the unsteadiness term appears generally negligible at the cross-over station. Although our estimates of missing terms are very crude, they do suggest that a 1-D (vertical) model that neglects advection, diffusion, and unsteadiness may provide a generally plausible description of Th and particle cycling at our selected stations. As a result, we proceed in the remainder of this paper by neglecting $T(\cdot)$ in the model equations $(3 \mathrm{a}-3 \mathrm{c})$. At least at some stations and in some depth intervals, the effects of transport and unsteadiness do seem to be important, and they will be discussed in Section 4 .

\subsection{Inverse method}

We fit the single-particle class model (equations $3 \mathrm{a}-3 \mathrm{c}$ with $T(\cdot)=0$ ) to the radiochemical and particle data (interpolated values) at our selected stations (Figure 1) using an inverse method. The fit is obtained by adjusting the rate parameters of the model $\left(k_{1}, k_{-1}, \beta_{-1}\right.$, and $\left.w\right)$ as well as the radiochemical and particle concentration data themselves, given the uncertainties in the prior estimates of the rate parameters as well as in the data. Prior estimates of $k_{1}, k_{-1}, \beta_{-1}$ and $w$ are obtained from previous observational estimates of these rate parameters in different oceanic environments (Table 2). By allowing the interpolated values to change within a range consistent with their uncertainties, this approach aims to prevent, or at least reduce, a possible bias in the rate parameter estimates (for a discussion, see Lam and Marchal (2014)).

The inverse method used to fit the model to the data is a nonlinear programming technique (Waltz et al., 2006), which operates as follows. Let $\boldsymbol{x}$ be a vector describing the state of the Th and 
Table 2: Prior estimates of rate parameters of Th and particle cycling assumed in this study

\begin{tabular}{|l|c|c|c|}
\hline parameter & prior estimate & prior estimate error & sources \\
\hline$k_{1}\left(\mathrm{y}^{-1}\right)$ & 0.5 & 5 & $\mathrm{a}, \mathrm{b}, \mathrm{c}, \mathrm{d}, \mathrm{e}$ \\
\hline$k_{-1}\left(\mathrm{y}^{-1}\right)$ & 2 & 5 & $\mathrm{a}, \mathrm{b}, \mathrm{c}, \mathrm{d}, \mathrm{e}$ \\
\hline$\beta_{-1}\left(\mathrm{y}^{-1}\right)$ & 1 & 10 & $\mathrm{a}, \mathrm{b}, \mathrm{f}, \mathrm{g}$ \\
\hline $\mathrm{w}\left(\mathrm{m} \mathrm{y}^{-1}\right)$ & 700 & 400 & $\mathrm{~h}, \mathrm{i}, \mathrm{j}, \mathrm{k}, \mathrm{l}, \mathrm{m}$ \\
\hline
\end{tabular}

a. Nozaki et al. (1987). b. Bacon and Anderson (1982). c. Murnane et al. (1990). d. Murnane (1994a). e. Murnane et al. (1994b).

f. Clegg et al. (1991). g. Cochran et al. (1993). h. Krishnaswami et al. (1976). i. Krishnaswami et al. (1981).

j. Rutgers van der Loeff and Berger (1993). k. Rutgers van der Loeff and Berger (1993). 1.Scholten et al. (1995). m. Venchiarutti et al. (2008).

particle cycles at a given (selected) station of GA03 according to the model. The elements of $\boldsymbol{x}$ are the Th isotope activities in dissolved and particulate forms, the parent activities $\left({ }^{234} \mathrm{U},{ }^{238} \mathrm{U},{ }^{228} \mathrm{Ra}\right)$, the particle concentration, as well as the rate parameters $\left(k_{1}, k_{-1}, \beta_{-1}, w\right)$, at all depths of the interpolation grid for that station. We seek a vector $\boldsymbol{x}$ that is consistent with the data and the prior estimates of the rate parameters given their respective error statistics, while satisfying the model equations (3a-3c) perfectly. This vector is found at a minimum of the objective function:

$$
\boldsymbol{J}(\boldsymbol{x})=\left(\boldsymbol{x}-\boldsymbol{x}_{0}\right)^{\prime} \boldsymbol{C}_{0}^{-1}\left(\boldsymbol{x}-\boldsymbol{x}_{0}\right)
$$

subject to the hard constraint $f(x)=0$, where $f(x)=0$ represents equations (3a-3c) (with $T(\cdot)=0$ ) discretized at all depths of the grid (a first-order backward finite-difference scheme is used to discretize $w \partial A_{p} / \partial z$ and $\left.w \partial P / \partial z\right)$. Here, $\boldsymbol{x}_{0}$ is a vector including prior estimates of the elements in $\boldsymbol{x}$ (in our study, $\boldsymbol{x}_{0}$ includes the interpolated values obtained from the data and prior estimates of the rate parameters), $C_{0}$ is the error covariance matrix for the prior estimates (the diagonal elements of $\boldsymbol{C}_{0}$ are the squared errors in the estimates and the off-diagonal elements of $C_{0}$ are the covariances between the errors), and the prime designates the transpose. The function (5) therefore represents the deviation of the state vector from its prior estimate, where $\boldsymbol{C}_{0}$ plays the role of a weighting factor: the elements of $\boldsymbol{x}_{0}$ with small (large) uncertainties contribute strongly (modestly) to the objective function.

We ensure that the Th and particle equations in $f(x)=0$ have a comparable effect in the 
inversion, independent of the choice of units, by normalizing the elements of $\boldsymbol{x}$ by their prior values in $\boldsymbol{x}_{\mathbf{0}}$ before the inversion; $\boldsymbol{C}_{\mathbf{0}}$ is modified accordingly. Additionally, each model equation is normalized by the root of the sum of the squared terms in that equation (row scaling; Wunsch (2006)). Details about the iterative method used to find a minimum of $J(x)$ subject to $f(x)=0$ and about the estimation of the solution error are reported in appendix A.

\section{Results}

In this section, we present the solution of the inverse problem stated in section 2.6. We first describe the goodness of fit of the Th and particle cycling model to the radiochemical and particle data at our selected stations along the GA03 transect. Emphasis is then placed on estimated radiochemical activities and particle concentrations and on the estimated rate parameters at these stations.

We find that at each station, a converging solution $(\hat{\boldsymbol{x}})$ is obtained: at the solution point, the gradient of $\boldsymbol{J}(\boldsymbol{x})$ vanishes, and the change in $\hat{\boldsymbol{x}}$ (normalized values) between subsequent iterations has an Euclidean norm of less than $10^{-10}$. In order to check whether the model equations are reasonably satisfied by the solution $\hat{\boldsymbol{x}}$, the residual of each equation, $f_{i}(\hat{\boldsymbol{x}})=\epsilon_{i}$, is calculated and compared with the maximum term in the corresponding equation. We find that the residual $\epsilon_{i}$ amounts to less that $10^{-4}$ (in absolute magnitude) of the maximum term for each equation, indicating that the model equations are satisfied to at least the 4th order.

\subsection{Goodness of Fit}

Two measures of goodness of fit of the model to the data are considered for each station. One measure is the fraction (noted $\phi$ below) of the fit residuals normalized to the measurement error that are lower than 2 in absolute magnitude. A normalized fit residual is defined as

$$
r_{i}=\frac{\hat{x}_{i}-x_{d, i}}{\sigma_{d, i}}, i=1,2, \ldots, n
$$

Here $\hat{x}_{i}$ is the estimated value of the $i$ th variable $\left({ }^{228,230,234} \mathrm{Th}_{d, p},{ }^{234,238} \mathrm{U},{ }^{228} \mathrm{Ra}\right.$, or $\left.P\right)$ in the vector $\hat{\boldsymbol{x}}$ that is obtained from the fit, $x_{d, i}$ is the measured (not interpolated) value of this variable, 
$\sigma_{d, i}$ is the error in this measured value, and $n$ is the number of measured values. The second measure considered is the arithmetic average of the normalized fit residuals:

$$
B=\frac{1}{n} \sum_{i=1}^{n} \frac{\hat{x}_{i}-x_{d, i}}{\sigma_{d, i}}
$$

Note that $\phi$ and $B$ provide different information about the model fit to the data: $\phi$ reflects the ability of the model to explain the data with no regard for possible over- or under-estimation, while $B$ is an indicator of systematic errors in the model.

We find that the model fits $82 \%$ of the data at our selected stations within 2 standard deviations ( $\phi=0.82$ ), with an overall bias $B=0.07$ (Figure $2 \mathrm{~b}$ ). Among our selected stations, the value of $\phi$ ranges from 0.76 to 0.84 , and the value of $B$ ranges from -0.24 to 0.32 (Table 3 ). Note the remarkably small range of $\phi$ across the stations, which suggests that the model has about the same aptitude to explain the data. Moreover, both negative and positive values of $B$ are found, i.e., no noticeable bias of the model seems to occur across the stations.

Table 3: Measures of goodness of fit of the model to data at selected stations of GA03.

\begin{tabular}{|l|c|c|}
\hline & $\phi$ & $B$ \\
\hline all stations & 0.82 & 0.07 \\
\hline GT11-10 & 0.76 & -0.1 \\
\hline GT11-12 & 0.84 & 0.04 \\
\hline GT11-14 & 0.81 & -0.22 \\
\hline GT11-16 & 0.81 & 0.29 \\
\hline GT11-18 & 0.82 & 0.19 \\
\hline GT11-20 & 0.82 & 0.13 \\
\hline GT11-22 & 0.82 & -0.24 \\
\hline GT11-24 & 0.82 & 0.32 \\
\hline GT10-12 & 0.82 & 0.06 \\
\hline GT10-11 & 0.82 & 0.07 \\
\hline GT10-10 & 0.82 & 0.07 \\
\hline
\end{tabular}

\subsection{Radiochemical Activities and Particle Concentrations}

In this section we present the interpolated Th isotope activities and particle concentrations as well as the residuals between the posterior estimates $\left(\hat{x}_{i}\right)$ and interpolated values $\left(x_{I, i}\right)$, normalized 
to the error in the interpolated values $\left(\sigma_{I, i}\right)$.

$$
R_{i}=\frac{\hat{x}_{i}-x_{I, i}}{\sigma_{I, i}}, i=1,2, \ldots, n
$$

where $n$ is the number of estimated or interpolated values. These normalized residuals (Figure 7a-10a and 7c-10c) are generally less than 2 in absolute magnitude, indicating that the general features in the (interpolated) data (Figure $7 b-10 b$ and 7d-10d) are broadly replicated within $2 \sigma_{I, i}$. For ${ }^{230} \mathrm{Th}_{d, p}$, these features include the general increase with depth, and the ${ }^{230} \mathrm{Th}_{d}$ deficit and ${ }^{230} \mathrm{Th}_{p}$ excess near the TAG hydrothermal vent at station GT11-16. For ${ }^{228} \mathrm{Th}_{p}$, they include maxima at the surface and near the seafloor, and minima at mid-depth. Similarly, the posterior estimates successfully capture the general decrease of ${ }^{234} \mathrm{Th}_{p}$ with depth and an excess in deep water at station GT11-16. Finally, both the data and posterior estimates show a general decrease of particle concentration with depth, and a larger concentration of particles near the surface waters at the easternmost stations (GT11-24, GT10-10, GT10-11, and GT10-12) relative to other stations.

Nonetheless, notable differences between the posterior estimates and the interpolated data are also apparent. For ${ }^{228} \mathrm{Th}_{d}$, the number of posterior estimates that deviate notably from the interpolated values is remarkably large compared to the other thorium isotopes. Most of these large deviations occur at stations GT11-22, GT11-24, GT10-10, GT10-11 and GT10-12. At each of these stations, over $40 \%$ of the posterior estimates exceed the interpolated data by more than 2 standard deviations. In addition, at the crossover station GT11-24/GT10-12, over 30\% of the ${ }^{234} \mathrm{Th}_{d}$ normalized residuals are greater than 2 in absolute magnitude. These deviations are discussed in section 4.1. For ${ }^{228} \mathrm{Th}_{p},{ }^{230} \mathrm{Th}_{d, p}$, and ${ }^{234} \mathrm{Th}_{p}$, less than $20 \%$ of the normalized residuals are greater than 2 in absolute magnitude at each station. Thus, despite inconsistencies, both measures of goodness of fit $(\phi$ and $B$ ) and the distribution of the normalized residuals (Figure 2b) show that the model generally is successful at reproducing the data gathered at our selected stations.

\subsection{Rate Parameters}

In this section we present the posterior estimates of the rate parameters $\left(k_{1}, k_{-1}, \beta_{-1}\right.$, and $\left.w\right)$ at our selected stations (Figure 11). Conspicuously, the adsorption rate constant $k_{1}$ tends to decrease 
with depth at most of the stations. Some of the highest values of $k_{1}$ are estimated above $500 \mathrm{~m}$ at the four easternmost stations (station GT11-22, GT11-24, GT10-10, and GT10-11). Furthermore, $k_{1}$ displays a spectacular enhancement in deep water near the TAG hydrothermal vent (station GT11-16). The desorption rate constant, $k_{-1}$, on the other hand, does not exhibit a consistent vertical trend, except at stations GT11-24, GT10-12, GT10-10, and GT10-11, where $k_{-1}$ appears to decrease with depth. As with $k_{1}$, near-surface values of $k_{-1}$ at stations GT11-24, GT10-12, GT1010, and GT10-11 are high relative to the other stations. The rate constant of particle degradation, $\beta_{-1}$, shows generally both higher values and higher vertical variability above $1000 \mathrm{~m}$. Finally, estimates of particle sinking speed, $w$, tend to be larger and display enhanced vertical variability below $2000 \mathrm{~m}$. One notable exception is at the TAG hydrothermal vent, where estimates of $w$ are low relative to those at the other stations.

The vertical profiles of estimated $k_{1}$ at our selected stations (Figure 12) reveal features that are more difficult to discern in the section plot (Figure 11). For example, it is seen that stations GT1122, GT11-24, GT10-12, GT10-11, and GT10-10 exhibit the highest values of $k_{1}$ near the surface. These stations also portray the steepest vertical gradients in $k_{1}$ in the upper $1000 \mathrm{~m}$. Additionally, at the easternmost stations GT11-24, GT10-12, GT10-11, and GT10-10, $k_{1}$ values below $1000 \mathrm{~m}$ are higher than those below the same depth at all other stations. There is a notable exception to this pattern at station GT11-16, where a very large value of $k_{1}\left(21 \mathrm{yr}^{-1}\right)$ is estimated below 3000 $\mathrm{m}$, near the TAG hydrothermal vent.

\section{Discussion}

\subsection{Misfit to the interpolated values}

In this section, we discuss the model misfits to the data, with emphasis on ${ }^{228} \mathrm{Th}$ and ${ }^{234} \mathrm{Th}$. Consider first ${ }^{228} \mathrm{Th}$. Many of the normalized residuals greater than 2 in absolute magnitude stem from the misfit to the ${ }^{228} \mathrm{Th}_{d}$ data. Particularly, at each station east of GT11-20, over $40 \%$ of the ${ }^{228} \mathrm{Th}_{d}$ data are overestimated by more than 2 standard deviations. To examine the depths where these large residuals occur, we show the vertical profiles of the interpolated and posterior estimates of ${ }^{228} \mathrm{Th}_{d}$ in Figure 13. At each of these stations, most of the posterior estimates differ by more 
than two standard deviations from the interpolated values above $1000 \mathrm{~m}$ as well as near the seafloor. The greatest misfit between data and model clearly occurs in the top $1000 \mathrm{~m}$ at station GT10-10. Speculatively, these misfits arise from the missing terms in the ${ }^{228} \mathrm{Th}_{d}$ balance equations (Figure 3), since our estimates of the magnitude of these terms (depth averages) are close to the posterior estimates of radioactive production of ${ }^{228} \mathrm{Th}_{d}$ by ${ }^{228} \mathrm{Ra}$. At station GT10-10, where the misfits in the top $1000 \mathrm{~m}$ are the most pronounced (Figure 13), the largest estimated missing term is vertical advection (our missing term estimates are depth-averages, and terms that appear smaller (Figure 3) may still influence of ${ }^{228} \mathrm{Th}_{d}$ at certain depths). That the posterior ${ }^{228} \mathrm{Th}$ values overestimate the ${ }^{228} \mathrm{Th}_{d}$ data (interpolated values in the upper $1000 \mathrm{~m}$ at GT10-10) suggests that a process which tends to decrease ${ }^{228} \mathrm{Th}_{d}$ is missing in the model. Such a process could be, for example, the upwelling of ${ }^{228} \mathrm{Th}_{d}$-poor waters below $1000-2000 \mathrm{~m}$ to above $1000 \mathrm{~m}$ (as suggested by the relatively shallow ${ }^{228} \mathrm{Th}_{d}$ maximum at GT10-10), or unsteadiness.

Consider then ${ }^{234} \mathrm{Th}$. Figure 14 shows profiles of ${ }^{238} \mathrm{U}$ and total ${ }^{234} \mathrm{Th}\left({ }^{234} \mathrm{Th}_{t o t}={ }^{234} \mathrm{Th}_{d}+{ }^{234} \mathrm{Th}_{p}\right)$ at the crossover station GT10-12/GT11-24. These profiles suggest the source of misfits to the ${ }^{234} \mathrm{Th}_{d}$ data. At both stations, the data indicate deviations of total ${ }^{234} \mathrm{Th}_{t o t}$ from secular equilibrium (Owens et al., 2015a). For example, at station GT10-12, ${ }^{234} \mathrm{Th}_{t o t}$ in the top $700 \mathrm{~m}$ exceeds the value expected from secular equilibrium, in contrast to the model which produce ${ }^{234} \mathrm{Th}_{t o t}$ activities close to ${ }^{238} \mathrm{U}$ activities. To understand the misfits consider the sum of equations (3a-3b) (section 2.4):

$$
T\left(A_{t o t}\right)+w \frac{\partial A_{p}}{\partial z}=\lambda\left(A_{\pi}-A_{t o t}\right)
$$

Since the model does not consider terms in $T\left(A_{t o t}\right)$, this equation reduces to $w \frac{\partial A_{p}}{\partial z}=\lambda\left(A_{\pi}-\right.$ $\left.A_{\text {tot }}\right)$. If the vertical gradient in ${ }^{234} \mathrm{Th}_{p}$ is small, then $w$ must be relatively large in order to allow departure from secular equilibrium and hence to allow the model to fit the (interpolated) ${ }^{234} \mathrm{Th}_{t o t}$ (and ${ }^{238} \mathrm{U}$ ) data. Yet, the posterior estimates of $w$ are also determined from the other data (e.g., ${ }^{228,230} \mathrm{Th}_{p}$ and $P$ ). Rather than increase $w$ the posterior estimates of ${ }^{234} \mathrm{Th}_{d}$ and ${ }^{238} \mathrm{U}$ are modified compared to their prior values, so that secular equilibrium is obtained. This interpretation would explain the relatively large misfits to ${ }^{234} \mathrm{Th}_{t o t}$ (and thus ${ }^{234} \mathrm{Th}_{d}$ ) and ${ }^{238} \mathrm{U}$ data at the crossover 
station.

\subsection{Variation in Rate Parameters}

\subsubsection{Th Adsorption}

Across all selected stations of GA03, with the exception of station GT11-16, $k_{1}$ tends to decrease with depth (Figure 11). One possible explanation for this trend is that particle concentration also generally decreases with depth (see Figure 10). A decrease in particle concentration reflects a decrease in the number of surface sites onto which thorium can adsorb. To describe this process, Honeyman et al. (1988) developed a simple kinetic model of the interaction between metals and the surface sites of particles. Their model assumes that $k_{1}$ is proportional to the sum of all surface sites not associated with the metal. It also assumes that particle concentration can be taken as a surrogate for the number of surface sites. These assumptions suggest the following, more general relationship between $k_{1}$ and $P$ :

$$
k_{1}=k_{1, c} P^{b},
$$

where $k_{1, c}$ and $b$ are positive constants. Clearly, $b=1$ would indicate a linear dependence of $k_{1}$ on particle concentration.

To test (9), we examine the relationship between the adsorption rate constant and particle concentration at our selected stations. Figure $15 \mathrm{a}-\mathrm{c}$ shows scatter plots of $\ln k_{1}$ vs. $\ln P$ interpolated, inverted, or measured. The light dashed lines are 1:1 lines, corresponding to $k_{1} \propto P(b=1)$. In Figure 15c, the solid line is the best fit derived by ordinary least squares (OLS), and the dark dashed line is the best fit derived by weighted least squares (WLS), which accounts for the error (co)variances in the $k_{1}$ posterior estimates (since our interpolation procedure introduces correlation among interpolated or inverted $P$ values, we apply OLS and WLS only to the relationship between $\ln k_{1}$ and $\ln P_{m}$, where $P_{m}$ denotes measured particle concentration). We exclude station GT11-16 in order to prevent the large values of $k_{1}$ at that station from influencing the regressions. Table 4 lists the slope, the linear Pearson correlation coefficient $(r)$ and associated $p$ value for OLS 
Table 4: Results from ordinary (OLS) and weighted (WLS) least squares regressions of $\ln \left(k_{1}\right)$ against $\ln \left(P_{m}\right)$

\begin{tabular}{|l|c|c|c|c|c|}
\hline & $\hat{b} \pm \sigma_{\hat{b}}\left({ }^{a}\right)$ & $r$ & $p$ for $r$ & $\tau$ & $p$ for $\tau$ \\
\hline OLS & $1.44 \pm 0.18$ & 0.71 & $<0.001$ & 0.58 & $<0.001$ \\
\hline WLS & $1.62 \pm 0.24$ & 0.70 & $<0.001$ & 0.58 & $<0.001$ \\
\hline OLS w/ smoothing & $0.95 \pm 0.13$ & 0.69 & $<0.001$ & 0.54 & $<0.001$ \\
\hline WLS w/ smoothing & $1.02 \pm 0.12$ & 0.69 & $<0.001$ & 0.54 & $<0.001$ \\
\hline
\end{tabular}

$a . \hat{b}$ is the slope estimate and $\sigma_{\hat{b}}$ is its standard error

and WLS ( $r$ for WLS estimated following Buse (1973)), and the Kendall tau rank correlation coefficient $(\tau)$ and associated $p$ value (Kendall and Gibbons, 1990). For both OLS and WLS, the slope is significantly greater than 1 by at least 1 standard error, and the coefficient $r$ indicates that the (positive) relationship between $k_{1}$ and $P_{m}$ is highly significant $(p<0.001$ ). Similarly, the nonparametric coefficient $\tau$ and its $p$-value indicate a significant positive monotonic relationship between $k_{1}$ and $P_{m}$. While Bacon and Anderson (1982) did not report a slope, the positive, linear relationship between $k_{1}$ and $P$ reported here is consistent with that found by these authors using data from the Panama and Guatemala basins. On the other hand, our slope estimates contrast with the value of $0.58\left(r^{2}=0.93\right)$ found by Honeyman et al. (1988) using field data spanning a large range in particle concentration from $O\left(10 \mathrm{mg} \mathrm{m}^{-3}\right)$ to $O\left(10^{9} \mathrm{mg} \mathrm{m}^{-3}\right)$. We speculate on the reasons for this difference in Section 4.2.5. The effect of the errors in $P_{m}$ on the regression of $\ln k_{1}$ vs. $\ln P_{m}$, which are accounted for neither in OLS nor in WLS, is discussed in Appendix B. We also examine the effects of smoothing on the regression of $\ln k_{1}$ vs. $\ln P_{m}$ in Appendix C.

Particle composition may also influence $k_{1}$. For example at the easternmost stations (stations GT11-22 and GT11-24 of leg 1, and stations GT10-12, GT10-11, and GT10-10 of leg 2), the particles are composed mostly of organic matter above $500 \mathrm{~m}$, whereas nearly equal proportions of POM and particulate lithogenic material are observed below $500 \mathrm{~m}$ (Lam et al., 2015). Multiple studies have suggested that marine POM contains organic ligands for which thorium has a high affinity (Hirose and Tanoue, 1998; Quigley et al., 2002; Hirose, 2004). If POM adsorbs Th more strongly than lithogenic particles, then the decrease in $k_{1}$ from near surface waters, where POM is highest, to deep waters, where the lithogenic fraction is higher, may even be larger than expected from just a decrease in particle concentration (i.e., not taking into account any change in particle composition). 
Another apparent example of an effect of particle composition on $k_{1}$ arises from the large values of $k_{1}$ in deep waters at station GT11-16 (Figure 12d). This station is located in the vicinity of the TAG hydrothermal vent, where the fraction of iron (oxyhydr)oxides in the particles is the highest across the entire GA03 transect (Lam et al., 2015). Thorium has been shown to strongly bind to iron oxides. For instance, Quigley et al. (2002) showed that the distribution coefficient for thorium bound to $\mathrm{Fe}_{2} \mathrm{O}_{3}, 10^{5.1} \mathrm{~L} \mathrm{~kg}^{-1}$, was within the range $\left(10^{5}-10^{6.8} \mathrm{~L} \mathrm{~kg}^{-1}\right)$ of the distribution coefficients for Th onto colloidal organic matter collected in the Gulf of Mexico (Baskaran et al., 1992), Chesapeake and Galveston Bay (Guo et al., 1997), and off the continental shelf of New England (Moran and Buesseler, 1993). Similarly, Guo et al. (2002) found that the distribution coefficient for ${ }^{234} \mathrm{Th}$ bound to $\mathrm{Fe}_{2} \mathrm{O}_{3}$ was $10^{5.83} \mathrm{~L} \mathrm{~kg}^{-1}$, larger than the coefficients for $\mathrm{CaCO}_{3}$, humic material, chitin, and $\mathrm{SiO}_{2}$, and exceeded only by $\mathrm{MnO}_{2}$ and acid polysaccharides. In experiments with natural seawater, Lin et al. (2014) found the distribution coefficient for $\mathrm{Fe}_{2} \mathrm{O}_{3}$ to be $10^{5.59} \mathrm{~L} \mathrm{~kg}^{-1}$, greater than the coefficients for $\mathrm{CaCO}_{3}, \mathrm{Al}_{2} \mathrm{O}_{3}, \mathrm{TiO}_{2}$, and $\mathrm{SiO}_{2}$, and comparable to the coefficient for colloidal organic matter from the Gulf of Mexico added to natural seawater $\left(10^{5.86} \mathrm{~L} \mathrm{~kg}^{-1}\right)$. In their analysis of samples collected along GA03, Hayes et al. (2015b) found that $K_{D}$ for iron (oxyhydr)oxides is two orders of magnitude higher than for $\mathrm{POM}, \mathrm{CaCO}_{3}$, opal, or lithogenic particles. Fe K-edge-ray absorption spectroscopy of the TAG particles confirmed that the high iron was in the form of 6-line ferrihydrite (Ohnemus and Lam, 2015), a poorly crystalline iron oxyhydroxide with specific surface area and scavenging capacity 10-20 times higher than for $\mathrm{Fe}_{2} \mathrm{O}_{3}$ (Borggaard, 1983). Therefore, it seems that the large values of $k_{1}$ near the TAG hydrothermal vent are due to the high concentrations of ferrihydrite at this site.

\subsubsection{Th Desorption and Particle Degradation}

In general, the rate constants for Th desorption do not appear to exhibit vertical trends as pronounced as $k_{1}$ (Figures 11), although estimates of $k_{-1}$ do seem larger near the surface at some stations (e.g., GT11-24, GT10-12, GT10-11, and GT10-10; Figure 11). Nonetheless, both the mean and standard deviation of $k_{-1}$ across all stations and depths appear larger in the mesopelagic 
zone (ca. 100-1000 m) than below (Figure 16b; Table 5). As with $k_{1}$, a potentially important influence on $k_{-1}$ is particle composition. Speculatively, the large values in $k_{-1}$ in near-surface waters of the easternmost stations (GT10-11 and GT10-10) may be due to the tendency for biogenic opal to contribute to a larger fraction of total particle concentration than at other stations (Lam et al., 2015): assuming biogenic opal has a smaller affinity for thorium than particulate organic matter (Östhols, 1995; Chase et al., 2002; Quigley et al., 2002; Guo et al., 2002; Luo and Ku, 2004; Roberts et al., 2009; Chuang et al., 2014; Lin et al., 2014), thorium might more easily desorb from biogenic opal than POM.

The particle degradation rate constant, $\beta_{-1}$, shows generally larger values above $1000 \mathrm{~m}(1.87$ $\left.\mathrm{yr}^{-1}\right)$ than below $\left(0.21 \mathrm{yr}^{-1}\right)$, although the errors preclude a strong inference (Figure 16c; Table 5). These values may occur due to increased microbial respiration of particles in the mesopelagic zone, where the highest rates of bacterial production and particle degradation rates have been found (Reinthaler et al., 2006; Dehairs et al., 2008; Steinberg et al., 2008; McDonnell et al., 2015).

Zooplankton feeding may also contribute to particle loss, although this process is likely to mostly affect aggregates greater that $0.5 \mathrm{~mm}$ in size (Lampitt et al., 1993; Dilling et al., 1998; Stemmann et al., 2004). Besides, $\beta_{-1}$ exhibits increased vertical variability in the top $1000 \mathrm{~m}$ : the standard deviation of our $\beta_{-1}$ estimates amounts to $2.67 \mathrm{yr}^{-1}$ above $1000 \mathrm{~m}$ and $0.40 \mathrm{yr}^{-1}$ below (Table 5). Whether this apparent variability is due to variability in microbial activity, particle lability, or biases from processes not incorporated in the model remains unclear.

\subsubsection{Rate Constant Ratio}

We describe the collective effect of the rate parameters $k_{1}, k_{-1}$, and $\beta_{-1}$ on Th scavenging using the rate constant ratio

$$
K=k_{1} /\left(k_{-1}+\beta_{-1}\right) .
$$

This ratio reflects the importance of the specific rate at which thorium attaches to particles relative to the specific rate at which thorium is removed from particles through Th desorption and 
particle degradation (Lerner et al., 2016). It is calculated using the estimates of $k_{1}, k_{-1}$, and $\beta_{-1}$ obtained by inversion at each station, and its error is determined by error propagation considering error covariances. To prevent the occurrence of very large $K$ values, we restrict our calculations to cases where $k_{-1}+\beta_{-1}>0.1 \mathrm{yr}^{-1}$. This value is determined from the probability density function of our estimates of $\left(k_{-1}+\beta_{-1}\right)$, which reveals two modes: one mode below $10^{-2} \mathrm{yr}^{-1}$ containing $7 \%$ of our estimates, and one mode above $1 \mathrm{yr}^{-1}$ containing $93 \%$ of our estimates (not shown). Thus, by retaining cases where $k_{-1}+\beta_{-1}>0.1 \mathrm{yr}^{-1}$, the majority of $(K)$ values are considered.

We find that $K$ is generally less than 1 (Figure 17a), suggesting that the specific rate at which thorium is attached to particles is generally less than that at which it is lost from particles due to desorption and (or) particle degradation. We cannot discern a vertical trend in $K$ and its variability: the mean of $K$ in the top $1000 \mathrm{~m}$ is 0.20 with a standard deviation of 0.30 , while the mean of $K$ below $1000 \mathrm{~m}$ is 0.19 with a standard deviation of 0.20 (Table 5). To remove the potential influence of the few $K$ values larger than 1, we also estimate these means and standard deviations for $K<1$ (Figure 17a). For this subset of values, $K$ has a mean of 0.20 and a standard deviation of 0.11 above $1000 \mathrm{~m}$, and a mean of 0.15 and standard deviation of 0.06 below $1000 \mathrm{~m}$. In addition, we account for the influence of the TAG hydrothermal vent by estimating these means and standard deviations excluding station GT11-16. This subset of values yields a mean $K$ of 0.20 and standard deviation of 0.31 above $1000 \mathrm{~m}$, and a mean of 0.15 and standard deviation of 0.05 below 1000 m (Table 5). Considering these two subsets of $K$, a vertical pattern is suggested, with $K$ in the mesopelagic zone being larger and displaying stronger variability than below.

The choice of whether to apply a smoothing constraint also impacts the estimates of the rate parameters and $K$. The effects of smoothing on the estimates of $k_{-1}, \beta_{-1}$, and $K$ are examined in Appendix C.

\subsubsection{Relationship to Distribution Coefficient}

The rate constant ratio $K$, introduced in the previous section, can be related under certain circumstances to the distribution coefficient, $K_{D}=A_{p} /\left(A_{d} P\right)$, which is generally used to describe 
Table 5: Mean and standard deviation (s.d.) of $k_{1}, k_{-1}, \beta_{-1}, K$, and $w$ for the inversion without smoothing.

\begin{tabular}{|c|c|c|c|c|c|c|c|c|}
\hline & $k_{1}\left(\mathrm{yr}^{-1}\right)$ & $k_{-1}\left(\mathrm{yr}^{-1}\right)$ & $\beta_{-1}\left(\mathrm{yr}^{-1}\right)$ & $K$ & $K^{a}$ & $K^{b}$ & $K / P_{m}(\mathrm{~g} / \mathrm{g})$ & $\mathrm{w}\left(\mathrm{m} \mathrm{yr}^{-1}\right)^{c}$ \\
\hline mean above $1000 \mathrm{~m}$ & 1.11 & 5.10 & 1.87 & 0.20 & 0.18 & 0.20 & $2 \times 10^{7}$ & 851 \\
\hline s.d. above $1000 \mathrm{~m}$ & 0.84 & 4.57 & 2.67 & 0.30 & 0.08 & 0.31 & $1.1 \times 10^{7}$ & 389 \\
\hline mean below $1000 \mathrm{~m}$ & 0.71 & 2.45 & 0.21 & 0.19 & 0.15 & 0.15 & $3 \times 10^{7}$ & 990 \\
\hline s.d. below $1000 \mathrm{~m}$ & 2.21 & 1.81 & 0.40 & 0.20 & 0.06 & 0.05 & $8.5 \times 10^{6}$ & 656 \\
\hline
\end{tabular}

a. Excluding $K$ values $>1$.

b. Excluding station GT11-16.

$c$. For $w$, means and standard deviations are those above and below $2000 \mathrm{~m}$

the partitioning of metals between the particulate and dissolved forms (Section 1). To elucidate the conditions under which $K$ and $K_{D}$ are related, consider the balance equation for dissolved Th (eq. 3a). Assuming that radioactive production, radioactive decay, and $T(\cdot)$ are negligible terms (for future reference, the first two assumptions are labeled A1 and A2, respectively), we get $0=\left(k_{-1}+\beta_{-1}\right) A_{p}-k_{1} A_{d}$, i.e.,

$$
A_{p} / A_{d}=k_{1} /\left(k_{-1}+\beta_{-1}\right) .
$$

Thus, under assumptions A1, A2, and negligible $T(\cdot)$, the distribution coefficient, $K_{D}$, would be equivalent to $K$ normalized to particle concentration, $K / P$.

Alternatively, consider the balance equation for particulate Th (eq. 3b). Assuming that the effects of particle sinking, radioactive decay, and $T(\cdot)$ are negligible (first two assumptions labeled as $\mathrm{A} 3$ and $\mathrm{A} 4$, respectively), we obtain $0=k_{1} A_{d}-\left(k_{-1}+\beta_{-1}\right) A_{p}$, so $K_{D}$ would again be equivalent to $K / P$. Clearly, the approximate expression (11) could only hold when both sets of assumptions, (A1-A2) and (A3-A4) (together with negligible $T(\cdot))$ simultaneously hold (otherwise, a mathematical inconsistency would arise). Under such circumstances, expression (11) would provide a framework for interpreting the partitioning of Th between the solid and dissolved phases in terms of the relative importance of kinetic rate constants (for a related discussion see Honeyman et al. (1988)).

Stimulated by this development, we compare $K_{D}$ obtained from ${ }^{230} \mathrm{Th}$ and $P$ data (interpolated values are used since ${ }^{230} \mathrm{Th}$ and $P$ data do not generally occur at the same depth) with $K$ normalized by measured particle concentration $\left(K / P_{m}\right)$. We calculate $K_{D}$ values from ${ }^{230} \mathrm{Th}_{d, p}$ data because (i) Hayes et al. (2015b) estimated $K_{D}$ using ${ }^{230} \mathrm{Th}_{d, p}$ and $P_{m}$ from all stations and 
depths along GA03, providing a basis for comparison, and (ii) assumptions (A1-A4) are most likely to hold for ${ }^{230} \mathrm{Th}$, since radioactive decay of ${ }^{230} \mathrm{Th}_{d, p}$ and production of ${ }^{230} \mathrm{Th}$ by ${ }^{234} \mathrm{U}$ are generally small compared to the effects due to ${ }^{230} \mathrm{Th}_{d}$ adsorption, ${ }^{230} \mathrm{Th}_{p}$ desorption, and (or) particle degradation (not shown; Lerner et al. (2016)). Likewise, we estimate $K / P_{m}$ at our selected stations, where the influences of advection and diffusion appear generally negligible (Section 2.5). Whereas assumptions A1, A2, and A4 also hold at all these stations, the effect of ${ }^{230} \mathrm{Th}_{p}$ sinking (A3) may not be negligible below $3000 \mathrm{~m}$ at station GT11-16 (not shown). Therefore, we restrict our estimation of $K / P_{m}$ to all our selected stations except GT11-16. With this restriction, we find that values of $K_{D}$ and $K / P_{m}$ are generally not significantly different given their respective error estimates (Figure 18a-b). Although our estimates of $K_{D}$ and $K / P_{m}$ are not independent (both are constrained from the same ${ }^{230} \mathrm{Th}_{d, p}$ and $P$ data), the comparison is encouraging.

Previous studies were also able to successfully relate a rate constant ratio to $K_{D}$ for thorium. Jannasch et al. (1988), using ${ }^{230} \mathrm{Th}$ from Puget Sound, found a strong correlation between $k_{1} / P$ and $K_{D}\left(r^{2}=0.88\right)$. Honeyman and Santschi (1989) expressed $K_{D}$ as $k_{1, c} P^{b} /\left(k_{-1} P\right)$, and found that this relationship holds for a constant $k_{-1}$, with $b$ varying from 1 at low particle concentration $\left(<10^{2} \mathrm{mg} \mathrm{m}^{-3}\right)$ to 0.3 at high particle concentration $\left(>10^{4} \mathrm{mg} \mathrm{m}^{-3}\right)$.

We examine the potential differences in $K / P_{m}$ between the mesopelagic zone and below across our selected stations, except GT11-16 (Table 5; Figure 17(c)). The mean $K / P_{m}$ in the top 1000 $\mathrm{m}$ is $2 \times 10^{7} \mathrm{~g} / \mathrm{g}$ with a standard deviation of $1.1 \times 10^{7} \mathrm{~g} / \mathrm{g}$, while the mean $K / P_{m}$ below $1000 \mathrm{~m}$ is $3 \times 10^{7} \mathrm{~g} / \mathrm{g}$ with a standard deviation of $8.5 \times 10^{6} \mathrm{~g} / \mathrm{g}$. These values, combined with the vertical profile in Figures 17 (c), do no appear to suggest consistent vertical patterns in $K / P_{m}$ and its variance.

\subsubsection{Particle Concentration Effect}

The particle concentration effect usually refers to a negative relationship between the distribution coefficient, $K_{D}$, and particle concentration, $P$ (e.g., Honeyman et al. (1988)). For our selected stations, we find a rank correlation coefficient $\tau=-0.64$ with $p<0.001$ for the relationship be- 
tween $K_{D}$ and $P_{m}$ (Figure 18c). A comparable result holds for the relationship between $K / P_{m}$ and $P_{m}(\tau=-0.51, p<0.001$, Figure 18d). These negative relationships are qualitatively consistent with the negative correlation $r=-0.72$ between $K_{D}$ and $P$ found by Hayes et al. (2015b) using ${ }^{230} \mathrm{Th}_{d, p}$ and $P$ data from all GA03 stations and depths, excluding samples (i) with $>60 \%$ POM, (ii) with significant Fe and Mn (oxyhydr)oxide content, and (ii) from benthic nepheloid layers (note that $\tau$ and $r$ cannot be easily compared; we refrain from calculating a value of $r$ here given the indication of a variable relationship between $\log _{10} K_{D}$ and $\log _{10} P_{m}$ for $P_{m}<9 \mathrm{mg} \mathrm{m}^{-3}$ and $P_{m}>9 \mathrm{mg} \mathrm{m}^{-3}$; Figure $\left.18 \mathrm{c}\right)$.

Thus, both $K_{D}$ and $K / P_{m}$ exhibit a significantly negative relationship with particle concentration at open-ocean stations of GA03. A proposed explanation for the particle concentration effect is that the rate of adsorption of trace metals onto filterable particles depends on the rate of coagulation of colloidal (e.g., <0.8 $\mu \mathrm{m}$ ) particles (Honeyman and Santschi, 1989; Baskaran et al., 1992, 1996; Hayes et al., 2015b). This hypothesis posits that $k_{1} \propto P^{b}$ with $b<1$ and that Th desorption and particle degradation are independent of particle concentration. That is, if colloidal coagulation limits the rate of thorium adsorption onto particles, then a given increase in particle concentration would result in an increase in $k_{1}$ that is less than that expected from a linear relationship between $k_{1}$ and $P$ (Honeyman et al., 1988). However, our results suggest that $k_{1} \propto P^{b}$ with $b \geq 1$ (section 4.2.1), although $K / P_{m}$ decreases with $P$. The cause of this conundrum obviously lies in the fact that the specific rate of Th loss from particles due to Th desorption and particle degradation is not independent of particle concentration, as previously postulated (e.g., Honeyman et al. (1988)), but may also vary, in this case increase, with particle concentration. To test this possibility, we examine the relationship between $\ln \left(k_{-1}+\beta_{-1}\right)$ and $\ln P_{m}$, neglecting again values of $\left(k_{-1}+\beta_{-1}\right)$ less than $0.1 \mathrm{yr}^{-1}$ (Figure 19). A positive relationship is apparent, with a slope of $0.99 \pm 0.18$ for OLS and $1.21 \pm 0.13$ for WLS, confirming that the specific rate of Th loss from particles due to Th desorption and particle degradation tends to increase with particle abundance.

Thus, although we observe a particle concentration effect at our selected stations, we find that this effect may not strictly comply to the Brownian-pumping model (Honeyman and Santschi, 
1989). Rather, the variation of $K_{D}$ or $K / P$ with $P$ would arise from two distinct relationships. The first relationship, $k_{1} \propto P^{b}$ with $b \geq 1$, contradicts (i) the proposal by Honeyman et al. (1988) that $b<1$ if there is a particle concentration effect due to colloidal coagulation limiting the rate at which thorium appears on filterable $(>0.8 \mu \mathrm{m})$ particles, as well as (ii) their value $b=0.51$ derived from oceanic field data corresponding to $P \geq 10 \mathrm{mg} \mathrm{m}^{-3}$. Recall that their proposal relies on the notion that the number of surface sites available for metal attachment can be approximated by the particle concentration (section 4.2.1). This assumption may not hold universally as, for example, particles with the same concentration may be characterized by different surface-to-volume ratios or different shapes. The lack of a particle concentration effect in the relationship between $k_{1}$ and measured $P$ (i.e., $b \geq 1$ ) may suggest a low abundance of colloids, relatively low colloidal reactivity of Th compared to its filterable particle reactivity, or a short residence time of colloids with respect to aggregation, such that colloidal aggregation does not limit the rate of appearance of thorium onto filterable particles (Moran and Buesseler, 1993). In fact, Honeyman and Santschi (1989) suggested that a particle concentration effect should not exist for particle concentration below $10^{2} \mathrm{mg} \mathrm{m}^{-3}$, a concentration level which is much larger than those considered in this study (Figure 10).

While Th isotope measurements on the colloidal fraction are not available for the GA03 transect, Hayes et al. (2017) found that colloidal ${ }^{230}$ Th was a small portion $(<6 \%)$ of "dissolved" ${ }^{230} \mathrm{Th}$ and ${ }^{232} \mathrm{Th}$ in the upper $1000 \mathrm{~m}$ at $27^{\circ} 12^{\prime} \mathrm{N}, 62^{\circ} 58^{\prime} \mathrm{W}$, about $500 \mathrm{~km}$ south of Bermuda. The presence of small concentrations of colloidal ${ }^{230,232} \mathrm{Th}$ appears consistent with the relationship between $k_{1}$ and $P$ found in our study, which does not require an influence of colloids as described in the Brownian-pumping model. However, it is unclear whether the low colloidal ${ }^{230,232}$ Th activities reported by Hayes et al. (2017) are due to a low abundance of colloids, or to a relatively small affinity of Th for colloids compared to filterable particles. Furthermore, extrapolation of their results to the entire set of stations considered here may be inappropriate.

The second relationship is $\left(k_{-1}+\beta_{-1}\right) \propto P^{d}$ (Figure 19) with $d>0$, again contrasting with the assumption of Honeyman et al. (1988) that the rate constant for Th loss from particles is in- 
dependent of $P$. This apparent association of $\left(k_{-1}+\beta_{-1}\right)$ with $P_{m}$ pertains to $93 \%$ of the rate constants estimated in this paper, as it relies on $\left(k_{-1}+\beta_{-1}\right)$ estimates higher than $0.1 \mathrm{yr}^{-1}$. A positive relationship between $\left(k_{-1}+\beta_{-1}\right)$ and $P_{m}$ is somewhat surprising, given that neither of these rate parameters is expected to be directly influenced by particle concentration. For example, Honeyman et al. (1988) proposed that the apparent desorption rate constant of a particle-reactive metal could be expressed as

$$
k_{-1}=k_{-1, c}[X],
$$

where $k_{-1, c}$ is a positive constant and [X] is the seawater concentration of the ion with which thorium is exchanging on the surface of a particle. In this proposed relationship (and in contrast to $\left.k_{1}\right), k_{-1}$ is independent of particle concentration.

The apparent relationship between $\left(k_{-1}+\beta_{-1}\right)$ and particle concentration found in this study may reflect the covariance of particle concentration with particle composition in the upper 1000 m. For example, it has been shown that the fraction of total particulate matter composed of labile POM rapidly attenuates with depth in the mesopelagic zone, which mimics the downward decrease of particle concentration (Wakeham et al., 1997; Hedges et al., 2000; Lutz et al., 2002; Sheridan et al., 2002; Collins et al., 2015). A decrease with depth in the relative abundance of labile POM would then result in a corresponding decrease in $\beta_{-1}$. However such reasoning is speculative, and the apparent relationship between $\left(k_{-1}+\beta_{-1}\right)$ and particle concentration remains an intriguing result of this study.

\subsection{Importance of Missing Terms}

In section 2.4, we assessed the influence of (lateral and vertical) advection and diffusion (as well as non-steady state conditions for the cross-over station) on the Th isotope and particle budgets at our selected stations along GA03. Here we revisit this assessment based on the dominant posterior flux in the corresponding balance equation as obtained by inversion (section 3). As for the prior fluxes, the posterior fluxes are the adsorption rate of thorium onto particles, the production rate from the radioactive parent, and the degradation rate of particles (Figures 4-5). Reassuringly, 
the posterior fluxes are always larger than the estimates of the missing terms. At some stations, horizontal diffusion and unsteadiness terms are within or close to within 1 standard deviation of the posterior estimates of radioactive ${ }^{228} \mathrm{Th}_{d}$ production. These missing terms, then, may contribute to the budget of ${ }^{228} \mathrm{Th}_{d}$.

One should probably re-iterate that the rate parameters reported in this study are estimated under the assumption that the effects of advection, diffusion, and unsteadiness are all negligible. Hence, these parameters may suffer from some bias due to the exclusion of these terms. While our results, with the possible exception of ${ }^{228} \mathrm{Th}_{d}$, suggest that the neglected processes do not, to the first-order, influence thorium isotopes and particles at our selected stations (Figures 4-5), a significant impact of these terms cannot be ruled out with complete confidence.

\section{Conclusion}

Radiochemical and particle data from the GEOTRACES section GA03 are combined with a single-particle class model in order to estimate the lateral and vertical distributions of $\left(k_{1}, k_{-1}\right.$, $\left.\beta_{-1}, w\right)$ in the open North Atlantic. We provide evidence that advection by the mean flow, turbulent diffusion, and unsteadiness have generally a small influence on the Th and particle budgets at the stations considered in this paper. The model displays a good fit to the data $(\phi=0.82$, $B=0.07)$, and the posterior estimates of the radiochemical activities and particle concentrations generally replicate the (vertically interpolated) data. The rate parameters exhibit some discernible spatial patterns. Most notably, $k_{1}$, the adsorption rate constant, tends to decrease with depth, and many of its highest values occur in the top $500 \mathrm{~m}$ of the water column at the easternmost stations (GT11-24, GT10-12, GT10-11, and GT10-10). One exception is at station GT11-16 near the TAG hydrothermal vent, where $k_{1}$ reaches its absolute maximum of $21 \mathrm{yr}^{-1}$. Notable features in the distributions of the other rate parameters include (i) larger values of $k_{-1}$ in the top $500 \mathrm{~m}$ of the easternmost stations and (ii) larger variability of $\beta_{-1}$ in the top $1000 \mathrm{~m}$. We speculate on a number of processes that may influence $k_{-1}$ and $\beta_{-1}$, including microbial activity and changes in particle composition.

We find a positive relationship between $k_{1}$ and particle concentration, $P, k_{1}=k_{1, c} P^{b}$ with 
$b \geq 1$, supporting the notion that $k_{1}$ increases with the number of surface sites available for adsorption, but opposing the assertion that colloids affect the apparent rate at which Th attaches to filterable particles as envisioned by the Brownian-pumping model (Honeyman and Santschi, 1989). We also find a negative relationship between the distribution coefficient for ${ }^{230} \mathrm{Th}, K_{D}$, and particle concentration, indicative of a particle concentration effect. We clarify the conditions under which $K_{D}$ is equivalent to the rate constant ratio, $K=k_{1} /\left(k_{-1}+\beta_{-1}\right)$, normalized to particle concentration, and find that these conditions are met at all our selected stations except GT11-16. We think that this result is significant, for it suggests that a kinetic interpretation of $K_{D}$ is generally warranted at these stations. Interestingly, the relationship between $K / P$ and $P$ appears to be partly driven by a positive relationship between $\left(k_{-1}+\beta_{-1}\right)$ and $P$, in contrast with a previous interpretation of the particle concentration effect (e.g. Honeyman et al. (1988); Honeyman and Santschi (1989)).

Importantly, if these relationships between $k_{1}$ and $\left(k_{-1}+\beta_{1}\right)$ on the one hand and $P$ on the other hand are robust, then they suggest that Th adsorption onto particles and Th release from particles, due to the combined effects of desorption and particle degradation, are not first order processes with respect to particle concentration. Notice that these findings do not challenge the model considered in this study (which systematically relies on first order kinetics), since the specific rate constants for sorption and particle processes inferred here are apparent ones (e.g. Honeyman et al. (1988)). In our study, they are allowed to vary with both location and depth. A dependence of $k_{1}$ on $P$, for example, is not formally incorporated into the model but emerges from the quantitative combination of the model and the data. It is established a posteriori, not posited a priori.

While we emphasize relationships between rate parameters and particle concentration, we stress that these parameters may also be influenced by other properties. Future studies should focus on (i) quantifying the effects of particle composition on rate parameters for thorium and particle cycling, and (ii) examining the effect of microbial and zooplankton activities on these rate parameters. Finally, the approach of data analysis used in this study should be applicable to study the geochemical behavior of other particle-reactive metals in the ocean, such as protactinium, whose 
long-lived isotope ${ }^{231} \mathrm{~Pa}$, paired with ${ }^{230} \mathrm{Th}$ and measured on sediment samples, is taken as as an indicator of paleo-productivity or paleo-circulation(Henderson and Anderson, 2003). A better understanding of the scavenging of both radionuclides is needed in order to properly interpret bulk sediment ${ }^{231} \mathrm{~Pa} /{ }^{230} \mathrm{Th}$ records in terms of palaeoceanographic phenomena (e.g., Burke et al. (2011); Hayes et al. (2015a)) and to improve their representation in ocean circulation-biogeochemistry models (e.g., Siddall et al. (2005); Dutay et al. (2009)).

\section{Acknowledgement}

We acknowledge the U.S. National Science Foundation for providing funding for this study (grant OCE-1232578) and for U.S. GEOTRACES North Atlantic section ship time, sampling, and data analysis. The U.S. NSF also supported the generation of ${ }^{230}$ Th data (OCE-0927064 to LDEO, OCE-O092860 to WHOI, and OCE-0927754 to UMN) and ${ }^{228,234}$ Th data (OCE-0925158 to WHOI). We thank the chief scientists of the GA03 section (Ed Boyle, Bill Jenkins, and Greg Cutter) as well as the captain, the crew, and the scientific party on the R/V Knorr, which completed this section. We are also grateful to the scientists and staff involved in the collection and analysis of the thorium isotope and particle data. We also thank Andrew Solow (WHOI) for directing us to MATLAB constrained optimization routine FMINCON. 


\section{Appendix A}

This appendix provides further details about our method of data inversion. The vector $\boldsymbol{x}$ that yields a minimum of $J(\boldsymbol{x})$ subject to $\boldsymbol{f}(\boldsymbol{x})=\mathbf{0}$ is derived as follows (Byrd et al., 2000; Waltz et al., 2006). Equation (5) is replaced by a sequence of subproblems of the form:

$$
J_{\mu}(\boldsymbol{x}, \boldsymbol{s})=J(\boldsymbol{x})-\mu \sum_{i=1}^{m} \ln \left(s_{i}\right) .
$$

Here, $\mu>0$ is a barrier parameter, $\ln$ is the natural logarithm, and $s>0$ is a vector of "slack" variables. The function (A.1) is minimized subject to the equality constraints $f(x)=0$ and the inequality constrains $g(x) \geq 0$. In our study, $f(x)=0$ represents the model equations, whereas $\boldsymbol{g}(\boldsymbol{x})=\boldsymbol{x}$ represents our desire to avoid the inference of negative values for the radiochemical activities, the particle concentrations, and the rate parameters. The slack variables are used to replace the inequality constraints with equality constraints, i.e., $g(x)+s=0$. A solution is then obtained by finding a stationary point of the following function:

$$
L(\boldsymbol{x}, \boldsymbol{s}, \boldsymbol{\lambda})=J_{\mu}(\boldsymbol{x}, \boldsymbol{s})+\boldsymbol{\lambda}_{f}^{\prime} \boldsymbol{f}(\boldsymbol{x})+\boldsymbol{\lambda}_{g}^{\prime}(\boldsymbol{g}(\boldsymbol{x})+\boldsymbol{s}) .
$$

Here, $L(\boldsymbol{x}, \boldsymbol{s}, \boldsymbol{\lambda})$ is the Lagrangian associated with (A.1), and $\boldsymbol{\lambda}=\left[\boldsymbol{\lambda}_{f}^{\prime}, \boldsymbol{\lambda}_{h}^{\prime}\right]^{\prime}$ is a vector of Lagrange multipliers. The solution is found using an Interior Point algorithm, which relies on one of two methods. The first method is the "direct step" (Waltz et al., 2006), whereby a solution is found by linearizing equation (A.2) at some reference point $\left(\boldsymbol{x}_{k}, \boldsymbol{s}_{k}\right)$, where $k$ is an iterate index. This method may fail due to nonconvexity or rank deficiencies in the (i) Jacobians (matrices of firstorder partial derivatives of $\boldsymbol{f}(\boldsymbol{x})$ and $\boldsymbol{g}(\boldsymbol{x})$ with respect to $\boldsymbol{x}$ ) or (ii) the Hessian (matrix of secondorder partial derivatives of $L(\boldsymbol{x}, \boldsymbol{s}, \boldsymbol{\lambda})$ with respect to $\boldsymbol{x})$. In this case, the Interior Point algorithm relies on a second method, which involves a trust region. For details regarding these methods, we refer the reader to the relevant literature (Byrd et al., 1999, 2000; Waltz et al., 2006).

We apply the Interior Point algorithm using the constrained nonlinear programming solver FMINCON, which is part of Matlab's optimization toolbox (Matlab, 2016). Among the optional 
852

inputs to the algorithm is the gradient of the objective function (5), which we provide as:

$$
\nabla_{\boldsymbol{x}} J(\boldsymbol{x})=2 \boldsymbol{C}_{0}^{-1}\left(\boldsymbol{x}-\boldsymbol{x}_{0}\right)
$$

The other user-defined inputs are listed in table A.1. These options are used for all inversions discussed in this paper.

The posterior uncertainties in $\boldsymbol{x}$ are estimated from the square root of the diagonal elements of the posterior error covariance matrix (Tarantola and Valette, 1982)

$$
\boldsymbol{C}_{k+1}=\boldsymbol{C}_{0}-\boldsymbol{C}_{0} \boldsymbol{F}_{k}^{\prime}\left(\boldsymbol{F}_{k} \boldsymbol{C}_{0} \boldsymbol{F}_{k}^{\prime}\right)^{-1} \boldsymbol{F}_{k} \boldsymbol{C}_{0}
$$

Here, $\boldsymbol{F}_{k}$ is a matrix whose elements are the partial derivatives of the model equations with respect to the elements of $\boldsymbol{x}$ at the solution point, i.e., the element in the $i$ th row and $j$ th column of $\boldsymbol{F}_{k}$ is $\partial f_{i} / \partial x_{j}$ evaluated at $\boldsymbol{x}=\hat{\boldsymbol{x}}_{k}$, where $\hat{\boldsymbol{x}}_{k}$ denotes the solution (subscript $k$ is dropped in the text). The matrix inversions in (A.3-A.4) are performed using LU decomposition.

\section{Appendix B}

The OLS and WLS regressions of $\ln k_{1}$ against $\ln P_{m}$ do not account for the uncertainties in the measurements of particle concentration. Specifically, in the regression problem,

$$
\ln \left(k_{1}\right)=a+b \ln \left(P_{m}\right)+\epsilon
$$

both $b$ and $P_{m}$ should be treated as unknowns. Here, $a=\ln k_{1, c}$ is the intercept, $b$ is the slope, and $\epsilon$ is a regression error. In order to estimate $(a, b)$ taking uncertainties in $P_{m}$ into account, we use the Algorithm of Total Inversion (ATI; Tarantola and Valette (1982)). Thus, we construct a prior estimate of a vector $\boldsymbol{x}$ of unknowns, which is $\boldsymbol{x}_{0}$. The elements of $\boldsymbol{x}_{0}$ contain measurements of $P_{m}$ (more specifically, $\ln \left(P_{m}\right)$ ) and prior estimates of $a$ and $b$. We then minimize the objective 
Table A1: Optional Inputs for Matlab's Constrained Nonlinear programming solver FMINCON

\begin{tabular}{|c|c|}
\hline & Input \\
\hline Maximum iterations & 10,000 \\
\hline Maximum Objective Function Evaluations & $40,000,000$ \\
\hline User supplied objective function gradient & On \\
\hline Objective Function Tolerance & $10^{-3}$ \\
\hline Tolerance on hard constraint & $10^{-4}$ \\
\hline CheckGradients & False \\
\hline DiffMaxChange & Inf \\
\hline DiffMinChange & 0 \\
\hline FiniteDifferenceStepSize & $\left(\sqrt{2^{-52}}\right)$ \\
\hline FiniteDifferenceType & forward \\
\hline OptimalityTolerance & $10^{-6}$ \\
\hline SpecifyConstraintGradient & false \\
\hline StepTolerance & $10^{-10}$ \\
\hline TypicalX & a vector $[1 \ldots .1]$ with length equal to the number of elements in $\boldsymbol{x}$ \\
\hline UseParallel & false \\
\hline Hessian Approximation & BroydenFletcherGoldfarbShanno algorithm \\
\hline HonorBounds & true \\
\hline Initial Barrier Parameter & 0.1 \\
\hline Initial Trust Region Radius & $\sqrt{N}$, where $N$ is the number of elements in $\boldsymbol{x}$ \\
\hline Maximum Projected Conjugate Gradients & $2 \times(N-E)$, where $E$ is the number of inequality constraints \\
\hline Subproblem Algorithm & factorization \\
\hline Tolerance for Projected Conjugate Gradient & $10^{-10}$ \\
\hline Relative Tolerance for Projected Conjugate Gradient & 0.01 \\
\hline
\end{tabular}

function

$$
J(\boldsymbol{x})=\left(\boldsymbol{x}-\boldsymbol{x}_{0}\right)^{\prime} \boldsymbol{C}_{0}^{-1}\left(\boldsymbol{x}-\boldsymbol{x}_{0}\right)+\boldsymbol{f}(\boldsymbol{x})^{\prime} \boldsymbol{C}_{f}^{-1} \boldsymbol{f}(\boldsymbol{x}) .
$$

Here, the error covariance matrix $C_{0}$ is taken as diagonal, and its diagonal elements are based on the variances in the measurements of $P$ (Aitchison and Brown, 1957) and in the prior estimates of $a$ and $b$. The vector $\boldsymbol{f}(\boldsymbol{x})$ contains the regression equations (B.1), and $\boldsymbol{C}_{f}$ is a matrix whose elements are based on the posterior error statistics of $\ln k_{1}$ derived by inversion (section 2.5).

The prior estimates of $a$ and $b$ are taken from Honeyman et al. (1988): $a_{0}=-9.2 \pm 9.2$ and $b_{0}=0.51 \pm 0.51$, where we subjectively assumed $100 \%$ relative error for both coefficients. We find that the slope of $\ln k_{1}$ vs. $\ln P_{m}$ is $\hat{b}=3.1 \pm 0.1$ (Figure B.1). Although this value is significantly larger than the slopes derived from OLS and WLS (Table 4), the slopes estimated from the three regression methods (OLS, WLS, and ATI) are all $\mathcal{O}(1)$. 


\section{Appendix C}

\section{C.1 Effect of Smoothing}

In our recent study (Lerner et al., 2016), a vertical smoothing constraint on the rate parameters, $\gamma \boldsymbol{x}^{\prime} \boldsymbol{S}^{-1} \boldsymbol{x}$, was added to the objective function (5). The motivation for adding a vertical smoothing constraint was twofold: (i) to reduce the occurrence of negative values in the solution, since the method used to fit the model to the data did not prevent inference of negative values, and (ii) to reduce large variations of the rate parameters on small vertical scales, which do not appear geochemically plausible. In this section, we describe the influence of smoothing on the rate parameter estimates at our selected stations.

Adsorption Rate Constant We consider the results of regressing $\ln k_{1}$ against $\ln P_{m}$ for the case where $\gamma \boldsymbol{x}^{\prime} \boldsymbol{S}^{-1} \boldsymbol{x}$ (with $\gamma=1$ ) is added to the objective function (5) (Figure 15d-f). Table 4 lists the slopes of OLS and WLS, as well as the Pearson and Kendall correlation coefficients.

The regressions of $\ln k_{1}$ obtained by inversion with smoothing vs. $\ln P_{m}$ consistently yield smaller slopes compared with the corresponding regressions based on $\ln k_{1}$ obtained by inversion without smoothing. Given that vertical smoothing tends to reduce the vertical variations in the rate parameters, this result is not surprising. On the other hand, the regressions based on $\ln k_{1}$ obtained by inversion with and without smoothing are comparable in that all slopes are on the order of 1 (Table 4).

Other Rate Parameters Figure 16e-h show $k_{-1}, \beta_{-1}$ and $w$ estimates at all depths and all selected stations obtained by inversion with the smoothing constraint $(\gamma=1)$. Compared with the solution without smoothing, the vertical variability in $\beta_{-1}$ and $w$ is drastically reduced. Without smoothing, the standard deviation of our posterior estimates of $k_{-1}, \beta_{-1}$, and $w$ (all selected stations and all depths) is $3.76 \mathrm{yr}^{-1}, 2.12 \mathrm{yr}^{-1}$, and $548 \mathrm{~m} \mathrm{yr}^{-1}$, respectively. With smoothing, these values amount to $1.81 \mathrm{yr}^{-1}, 0.15 \mathrm{yr}^{-1}$, and $383 \mathrm{~m} \mathrm{yr}^{-1}$, respectively. The large vertical variations of $\beta_{-1}$ apparent in the upper $1000 \mathrm{~m}$ inferred from the inversion without smoothing (2.67 $\mathrm{yr}^{-1}$; Table 5) are reduced for the inversion with smoothing $\left(0.15 \mathrm{yr}^{-1}\right.$; Table C.1). Similarly, the 
large vertical variations of $w$ below $2000 \mathrm{~m}$ inferred without smoothing (656 $\mathrm{m} \mathrm{yr}^{-1}$; Table 5) are smaller for the inversion with smoothing (465 $\mathrm{m} \mathrm{yr}^{-1}$; Table C.1).

We consider the effect of smoothing on the rate constant ratio $K$ (Figure 17b). With smoothing, the standard deviation of $K$ decreases from 0.25 to 0.13 (all selected stations and depths). Interestingly, the mean values of $K$ above and below 1000 m estimated without smoothing (respectively, 0.20 and 0.19 for $K$; Table 5) show little change from those estimated with smoothing (respectively, 0.21 and 0.17; Table C.1). In our previous analysis of station GT11-22 data (Lerner et al., 2016), we found that $K$ exhibits a mean of 0.27 (standard deviation of 0.09 ) above $1000 \mathrm{~m}$, and a mean of 0.14 (standard deviation of 0.02 ) below $1000 \mathrm{~m}$. We compare these values with those obtained from our inversion without smoothing. We find that $K$ averages 0.18 (standard deviation of 0.10 ) above $1000 \mathrm{~m}$, and 0.12 (standard deviation of 0.02 ) below $1000 \mathrm{~m}$. These results show that our previous inference of higher $K$ in the mesopelagic zone than below at GT11-22 (Lerner et al., 2016) was due, at least in part, to the effects of smoothing. Finally, notice that the absence a of clear vertical pattern in $K / P_{m}$ persist with smoothing (Fig 17d), as expected.

The decision to apply vertical smoothing (or not) in field data inversion is largely driven by prior knowledge of the property gradients along the water column. Presumably, the availability of measurements with high vertical resolution (e.g., tens of meters) would preclude the need for smoothing, since in this scenario the sampling would be dense enough that adding further assumptions about vertical property gradients would be superfluous. Trace metal and particle measurements at stations occupied along GEOTRACES transects are $O(100-1000) \mathrm{m}$ apart along the water column. Absent prior knowledge about thorium isotope activity or particle concentration gradients on shorter spatial scales, it is difficult to recommend whether or not to use smoothing in the analysis of GEOTRACES data.

\section{C.2 Effect of Algorithm}

Previous studies have reported that estimates of rate constants of Th and particle cycling may depend on the specific method used to fit the model to the data (Murnane, 1994a; Athias et al., 2000a,b). Lerner et al. (2016) combined Th isotope and particle data at station GT11-22 with the 
Table C.1: Mean and standard deviation (s.d.) of $k_{1}, k_{-1}, \beta_{-1}, K$, and $w$ for the inversion with smoothing

\begin{tabular}{|c|c|c|c|c|c|c|c|c|}
\hline & $k_{1}\left(\mathrm{yr}^{-1}\right)$ & $k_{-1}\left(\mathrm{yr}^{-1}\right)$ & $\beta_{-1}\left(\mathrm{yr}^{-1}\right)$ & $K$ & $K^{a}$ & $K^{b}$ & $K / P_{m}(\mathrm{~g} / \mathrm{g})$ & $\mathrm{w}\left(\mathrm{m} \mathrm{yr}^{-1}\right)^{b}$ \\
\hline mean above $1000 \mathrm{~m}$ & 0.73 & 3.22 & 0.33 & 0.21 & 0.21 & 0.21 & $2.3 \times 10^{7}$ & 942 \\
\hline s.d. above $1000 \mathrm{~m}$ & 0.39 & 1.87 & 0.15 & 0.08 & 0.08 & 0.08 & $9.5 \times 10^{6}$ & 274 \\
\hline mean below $1000 \mathrm{~m}$ & 0.46 & 2.76 & 0.24 & 0.17 & 0.17 & 0.14 & $2.8 \times 10^{7}$ & 1051 \\
\hline s.d. below $1000 \mathrm{~m}$ & 0.33 & 1.73 & 0.13 & 0.16 & 0.08 & 0.04 & $7.5 \times 10^{6}$ & 465 \\
\hline
\end{tabular}

a. Excluding $K$ values $>1$.

a. Excluding station GT11-16

$c$. For $w$, means and standard deviations are those above and below $2000 \mathrm{~m}$.

Table C.2: Regression of $\ln k_{1}$ against $\ln P$, with $k_{1}$ estimated from four different inversions at GT11-22

\begin{tabular}{|l|c|c|c|c|c|}
\hline & $\hat{b} \pm \sigma_{\hat{b}}$ & $r$ & $p$ for $r$ & $\tau$ & $p$ for $\tau$ \\
\hline ATI w/ smoothing, total ${ }^{230} \mathrm{Th}_{p}$ & $0.60 \pm 0.05$ & 0.80 & $<0.001$ & 0.73 & $<0.001$ \\
\hline ATI w/ smoothing, adsorbed ${ }^{230} \mathrm{Th}_{p}$ & $0.58 \pm 0.06$ & 0.81 & $<0.001$ & 0.71 & $<0.001$ \\
\hline FMINCON w/ smoothing & $0.58 \pm 0.06$ & 0.84 & $<0.001$ & 0.68 & $<0.001$ \\
\hline FMINCON no smoothing & $1.6 \pm 0.09$ & 0.78 & $<0.001$ & 0.62 & $<0.001$ \\
\hline
\end{tabular}

Th and particle cycling model (3) (with $T(\cdot)=0$ ) using a different algorithm (Algorithm of Total Inversion, or ATI) than implemented here (FMINCON; Appendix A). In order to document the effect of the nature of the algorithm, we compare the results of regressing $\ln k_{1}$ vs. $\ln P$ ( $P$ obtained from the inversion) for the case where $k_{1}$ (as well as other variables in $\boldsymbol{x}$ for station GT11-22) are estimated from ATI and FMINCON, both with smoothing (Figure C.1; Table C.2). Whereas the present study uses adsorbed ${ }^{230} \mathrm{Th}$, Lerner et al. (2016) used particulate ${ }^{230} \mathrm{Th}$ (which also comprises ${ }^{230} \mathrm{Th}$ locked in the mineral lattices of lithogenic particles). Thus, for this comparison, we run the inversion using FMINCON with particulate ${ }^{230} \mathrm{Th}$ as well as adsorbed ${ }^{230} \mathrm{Th}$, so that changes in the regression results due to changes in the data used may also be documented.

For the results with smoothing, the slopes of $\ln k_{1}$ vs. $\ln P$ are not significantly different at the level of 1 standard error (Table 7). The result obtained using FMINCON without smoothing (section 3) is also included for reference. These findings suggest that the nature of the algorithm used to invert the data does not significantly influence our inference about a dependence of $k_{1}$ upon particle concentration. 


\section{References}

Aitchison, J., and J. A. C. Brown (1957), The Lognormal Distribution (With Special Reference to Its Uses in Economics), 168 pp., Cambridge University Press, New York.

Andersen, M. B., C. H. Stirling, B. Zimmermann, and A. N. Halliday (2010), Precise determination of the open ocean ${ }^{234} \mathrm{U} /{ }^{238} \mathrm{U}$ composition, Geochemistry, Geophysics, Geosystems, 11(12).

Anderson, R. F., M. Q. Fleisher, L. F. Robinson, R. L. Edwards, J. Hoff, S. B. Moram, M. Rutgers van der Loeff, A. L. Thomas, M. Roy-Barman, and R. François (2012), GEOTRACES intercalibration of ${ }^{230} \mathrm{Th},{ }^{232} \mathrm{Th},{ }^{231} \mathrm{~Pa}$, and prospects for ${ }^{10} \mathrm{Be}$, Limnology and Oceanography Methods, $10,179-213$.

Athias, V., P. Mazzega, and C. Jeandel (2000a), Nonlinear Inversions of a Model of the Oceanic Dissolved-Particulate Exchanges, Inverse Methods in Global Biogeochemical Cycles (eds. P. Kasibhatla, M. Heimann, P. Rynar, M. Mahowald, R. G.Prinn, and D. E. Hartley), Geophysical Monograph, 114, Am. Geophys. Union. 205-222.

Athias, V., P. Mazzega, and C. Jeandel (2000b), Selecting a global optimization method to estimate the oceanic particle cycling rate constants, Journal of Marine Research, 58(5), 675-707.

Bacon, M. P., and R. F. Anderson (1982), Distribution of thorium isotopes between dissolved and particulate forms in the deep sea, Journal of Geophysical Research: Oceans (1978 to 2012), 87(C3), 2045-2056.

Bacon, M. P., C. A. Huh, A. P. Fleer, and W. G. Deuser (1985), Seasonality in the flux of natural radionuclides and plutonium in the deep Sargasso Sea, Deep Sea Research Part A. Oceanographic Research Papers, 32(3), 273-286.

Baskaran, M., P. H. Santschi, G. Benoit, and B. D. Honeyman (1992), Scavenging of thorium isotopes by colloids in seawater of the Gulf of Mexico, Geochimica et Cosmochimica Acta, 56(9), 3375-3388. 
Baskaran, M., P. H. Santschi, L. Guo, T. S. Bianchi, and C. Lambert (1996), ${ }^{234}$ Th: ${ }^{238}$ U disequilibria in the Gulf of Mexico: the importance of organic matter and particle concentration, Continental Shelf Research, 16(3), 353-380.

Bevington, P. R., and D. K. Robinson (1992), Data Reduction and Error Analysis for the Physical Sciences, McGraw-Hill, New York.

Bishop, J. K., P. J. Lam, and T. J. Wood (2012), Getting good particles: Accurate sampling of particles by large volume in-situ filtration, Limnology and Oceanography: Methods, 10(9), 681710.

Borggaard, O. K. (1983), Iron oxides in relation to aggregation of soil particles, Acta Agriculturae Scandinavica, 33(3), 257-260.

Bozec, A., M. S. Lozier, E. P. Chassignet, and G. R. Halliwell (2011), On the variability of the Mediterranean Outflow Water in the North Atlantic from 1948 to 2006., Journal of Geophysical Research: Oceans, 116(C9), 1-18.

Brewer, P. G., Y. Nozaki, D. W. Spencer, and A. P. Fleer (1980), Sediment trap experiments in the deep North Atlantic: isotopic and elemental fluxes, Journal of Marine Research, 38(4), 703729.

Buesseler, K. O., M. P. Bacon, J. K. Cochran, and H. D. Livingston (1992), Carbon and nitrogen export during the JGOFS North Atlantic Bloom Experiment estimated from ${ }^{234} \mathrm{Th}:{ }^{238} \mathrm{U}$ disequilibria, Deep Sea Research Part A. Oceanographic Research Papers, 39(7-8), 1115-1137.

Burke, A., O. Marchal, L. I. Bradtmiller, J. F. McManus, and R. François (2011), Application of an inverse method to interpret ${ }^{231} \mathrm{~Pa} /{ }^{230} \mathrm{Th}$ observations from marine sediments, Paleoceanography, 26(1), 1-17.

Buse, A. (1973), Goodness of fit in generalized least squares estimations, The American Statistician, 27(3), 106-108. 
Byrd, R. H., M. E. Hribar, and J. Nocedal (1999), An interior point algorithm for large-scale nonlinear programming, SIAM Journal on Optimization, 9(4), 877-900.

Byrd, R. H., J. C. Gilbert, and J. Nocedal (2000), A trust region method based on interior point techniques for nonlinear programming, Mathematical Programming, 89(1), 149-185.

Charette, M. A., W. S. Moore, P. J. Morris, and P. B. Henderson (2014), Gt10$11 \mathrm{Ra}$ and $\mathrm{Th}$, Biological and chemical oceanography data system, BCO DMO, WHOI, http://data.bco-dmo.org/jg/info/BCO/GEOTRACES/ NorthAtlanticTransect/Ra_Th_GT10\%7Bdir=data.bco-dmo.org/jg/ dir/BCO/GEOTRACES/NorthAt lanticTransect/, data=data.bco-dmo.org: $80 / \mathrm{jg} / \mathrm{serv} /$ RESTRICTED/GEOTRACES/NorthAtlanticTransect/Ra_Th_ GT10_joined.html0\%7D?, accessed: 5 April, 2014.

Charette, M. A., P. J. Morris, P. B. Henderson, and W. S. Moore (2015), Radium isotope Distributions during the U.S. GEOTRACES North Atlantic cruises, Marine Chemistry, 177, 184-195.

Chase, Z., R. F. Anderson, M. Q. Fleisher, and P. W. Kubik (2002), The influence of particle composition and particle flux on scavenging of $\mathrm{Th}, \mathrm{Pa}$ and $\mathrm{Be}$ in the ocean, Earth and Planetary Science Letters, 204(1), 215-229.

Chen, J. H., L. R. Edwards, and G. J. Wasserburg (1986), ${ }^{238} \mathrm{U},{ }^{234} \mathrm{U}$ and ${ }^{232} \mathrm{Th}$ in seawater, Earth and Planetary Science Letters, 80, 241-251.

Cheng, H., R. L. Edwards, C. Shen, V. J. Polyak, Y. Asmerom, J. Woodhead, J. Hellstrom, Y. Wang, X. Kong, C. Spötl, X. Wang, and E. C. Alexandar Jr. (2013), Improvements in ${ }^{230}$ Th dating, ${ }^{230} \mathrm{Th}$ and ${ }^{234} \mathrm{U}$ half-life values, and U-Th isotopic measurements by multi-collector inductively coupled plasma mass spectrometry., Earth and Planetary Science Letters, 371, 82-91.

Chuang, C. Y., P. H. Santschi, Y. Jiang, Y. F. Ho, A. Quigg, L. D. Guo, M. Ayranov, and D. Schumann (2014), Important role of biomolecules from diatoms in the scavenging of particle-reactive 
radionuclides of thorium, protactinium, lead, polonium and beryllium in the ocean: a case study with Phaeodactylum tricornutum, Limnology and Oceanography, 59(4), 1256-1266.

Clegg, S. L., and M. Whitfield (1993), Application of a generalized scavenging model to time series ${ }^{234} \mathrm{Th}$ and particle data obtained during the JGOFS North Atlantic Bloom Experiment, Deep Sea Research Part I: Oceanogrpahic Research Papers, 40(8), 1529-1545.

Clegg, S. L., M. P. Bacon, and M. Whitfield (1991), Application of a generalized scavenging model to thorium isotope and particle data at equatorial and high-latitude sites in the Pacific Ocean, Journal of Geophysical Research: Oceans (1978 to 2012), 962(C11), 20,655-20,670.

Cochran, K. J., K. O. Buesseler, M. P. Bacon, and H. D. Livingston (1993), Thorium isotopes as indicators of particle dynamics in the upper ocean: Results from the JGOFS North Atlantic Bloom Experiment., Deep Sea Research Part I: Oceanographic Research Papers, 40(8), 15691595.

Colley, S., J. Thomson, and P. P. Newton (1995), Detailed ${ }^{230} \mathrm{Th},{ }^{232} \mathrm{Th}$ and ${ }^{210} \mathrm{~Pb}$ fluxes recorded by the $1989 / 90$ BOFS sediment trap time-series at $48^{\circ} \mathrm{N}, 20^{\circ} \mathrm{W}$, Deep Sea Research Part I: Oceanographic Research Papers, 42(6), 833-848.

Collins, J. R., B. R. Edwards, K. Thamatrakoln, J. E. Ossolinski, G. R. DiTullio, K. D. Bidle, S. C. Doney, and B. A. Van Mooy (2015), The multiple fates of sinking particles in the North Atlantic Ocean, Global Biogeochemical Cycles, 29(9), 1471-1494.

Dehairs, F., S. Jacquet, N. Savoye, B. A. Van Mooy, K. O. Buesseler, J. K. Bishop, C. H. Lamborg, M. Elskens, W. Baeyens, P. W. Boyd, K. L. Casciotti, and C. Monnin (2008), Barium in twilight zone suspended matter as a potential proxy for particulate organic carbon remineralization: Results for the North Pacific, Deep Sea Research Part II: Topical Studies in Oceanography, 55(14), $1673-1683$.

Delanghe, D., E. Bard, and B. Hamelin (2002), New TIMS constraints on the uranium-238 and 
uranium-234 in seawaters from the main ocean basins and the Mediterranean Sea, Marine Chemistry, 80(1), 79-93.

Dilling, L., J. Wilson, D. Steinberg, and A. Alldredge (1998), Feeding by the euphausiid Euphausia pacifica and the copepod Calanus pacificus on marine snow., Marine Ecology Progress Series, $170,189-201$.

Dutay, J. C., F. Lacan, M. RoyBarman, and L. Bopp (2009), Influence of particle size and type on ${ }^{231} \mathrm{~Pa}$ and ${ }^{230} \mathrm{Th}$ simulation with a global coupled biogeochemical-ocean general circulation model: A first approach, Geochemistry, Geophysics, Geosystems, 10(1), 1-26.

Forget, G., J. M. Campin, P. Heimbach, C. N. Hill, R. M. Ponte, and C. Wunsch (2015), ECCO version 4: an integrated framework for non-linear inverse modeling and global ocean state estimation, Geosci. Model Dev., 8, 3071-3104.

Guo, L., P. H. Santschi, and M. Baskaran (1997), Interactions of thorium isotopes with colloidal organic matter in oceanic environments, Colloids and Surfaces A: Physicochemical and Engineering Aspects, 120(1-3), 255-271.

Guo, L., M. Chen, and C. Gueguen (2002), Control of Pa/Th ratio by particulate chemical composition in the ocean, Geophysical Research Letters, 29(20), 1-4.

Hayes, C. T., R. F. Anderson, S. L. Jaccard, R. François, M. Q. Fleisher, M. Soon, and R. Gersonde (2013), A new perspective on boundary scavenging in the North Pacific Ocean, Earth and Planetary Science Letters, 369, 86-97.

Hayes, C. T., R. F. Anderson, M. Q. Fleisher, K. F. Huang, L. F. Robinson, Y. Lu, H. Cheng, L. R. Edwards, and B. S. Moran (2015a), ${ }^{230} \mathrm{Th}$ and ${ }^{231} \mathrm{~Pa}$ on GEOTRACES GA03, the U.S. GEOTRACES North Atlantic transect, and implications for modern and paleoceanographic chemical fluxes, Deep Sea Research Part II: Topical Studies in Oceanography, 116, 29-41. 
Hayes, C. T., R. F. Anderson, M. Q. Fleisher, S. W. Vivancos, P. J. Lam, D. C. Ohnemus, K. F. Huang, L. F. Robinson, Y. Lu, H. Cheng, R. L. Edwards, and B. S. Moran (2015b), Intensity of Th and Pa scavenging partitioned by particle chemistry in the North Atlantic Ocean, Marine Chemistry, 170, 49-60.

Hayes, C. T., J. Rosen, D. McGee, and E. A. Boyle (2017), Thorium distributions in high and low dust regions and the significance for iron supply, Global Biogeochemical Cycles, 38(2), $328-347$.

Hedges, J. I., G. Eglinton, P. G. Hatcher, D. L. Kirchman, C. Arnosti, S. Derenne, R. P. Evershed, I. Kögel-Knabner, J. W. de Leeuw, R. Littke, W. Michaelis, and J. Rullkötter (2000), The molecularly-uncharacterized component of nonliving organic matter in natural environments, Organic Geochemistry, 31(10), 945-958.

Henderson, G. M., and R. F. Anderson (2003), The U-series toolbox for paleoceanography, $R e$ views in Mineralogy and Geochemistry, 52(1), 493-531.

Henderson, P. B., P. J. Morris, W. S. Moore, and M. A. Charette (2013), Methodological advances for measuring low-level radium isotopes in seawater, Journal of Radioanalytical and Nuclear Chemistry, 296(1), 357-362.

Hirose, K. (2004), Chemical speciation of thorium in marine biogenic particulate matter, The Scientific World Journal, 4, 67-76.

Hirose, K., and E. Tanoue (1998), The vertical distribution of the strong ligand in particulate organic matter in the North Pacific, Marine Chemistry, 59(3), 235-252.

Honeyman, B. D., and P. H. Santschi (1989), A Brownian-pumping model for oceanic trace metal scavenging: evidence from Th isotopes, Journal of Marine Research, 47(4), 951-992.

Honeyman, B. D., L. S. Balistrieri, and J. W. Murray (1988), Oceanic trace metal scavenging: 
the importance of particle concentration, Deep Sea Research Part A. Oceanographic Research Papers, 35(2), 227-246.

Jannasch, H. W., B. D. Honeyman, and L. S. Balistrieri (1988), Kinetics of trace element uptake by marine particles, Geochimica et Cosmochimica Acta, 52(2), 567-577.

Jenkins, W. J., W. M. Smethie, and E. A. Boyle (2015), Water mass analysis for the U.S. GEOTRACES North Atlantic Sections, Deep Sea Research Part II: Topical Studies in Oceanography, 116, 6-20.

Kendall, M., and J. D. R. Gibbons (1990), Rank Correlation Methods, Oxford University Press, Oxford.

Kirby, H. W., G. R. Grove, and D. L. Timma (2002), Neutron-capture cross section of actinium227, Physical Review, 102(4), 1140-1141.

Knight, G. B., and R. L. Macklin (1948), Half-Life of $\mathrm{UX}_{1}\left(\mathrm{Th}_{234}\right)$, Physical Review, 74(10), $1540-1541$.

Krishnaswami, S., D. Lal, B. L. K. Somayajulu, R. F. Weiss, and H. Craig (1976), Large-volume in-situ filtration of deep Pacific waters: Mineralogical and radioisotope studies, Earth and Planetary Science Letters, 32(2), 1-B32.

Krishnaswami, S., M. M. Sarin, and B. L. K. Somayajulu (1981), Chemical and radiochemical investigations of surface and deep particles of the Indian Ocean, Earth and Planetary Science Letters, 51(1), 81-96.

Ku, T. L., K. G. Knauss, and G. G. Mathieu (1977), Uranium in open ocean: concentration and isotopic composition, Deep Sea Research, 24(12), 31-39.

Lam, P., and O. Marchal (2014), Insights into particle dynamics from the geochemical composition of suspended and sinking particles, Annual Review of Marine Science, 7(1), 12.1-12.26. 
Lam, P. J., D. C. Ohnemus, and M. E. Auro (2015), Size-fractionated major particle composition and concentrations from the U.S. GEOTRACES North Atlantic Zonal Transect, Deep-Sea Research II, 116, 303-320.

Lampitt, R. S., K. F. Wishner, C. M. Turley, and M. V. Angel (1993), Marine snow studies in the Northeast Atlantic Ocean: distribution, composition and role as a food source for migrating plankton, Marine Biology, 116(4), 689-702.

Ledwell, J. R., A. J. Watson, and C. S. Law (1998), Mixing of a tracer in the pycnocline, Journal of Geophysical Research: Oceans, 103(C10), 21,499-21,529.

Lerner, P., O. Marchal, P. J. Lam, R. F. Anderson, K. Buesseler, M. A. Charette, R. L. Edwards, C. T. Hayes, K. F. Huang, Y. Lu, L. F. Robinson, and A. Solow (2016), Testing models of thorium and particle cycling in the ocean using data from station GT11-22 of the US GEOTRACES North Atlantic Section, Deep Sea Research Part I: Oceanographic Research Papers, 113, 57-79.

Lin, P., L. Guo, and M. Chen (2014), Adsorption and fractionation of thorium and protactinium on nanoparticles in seawater, Marine Chemistry, 162, 50-59.

Luo, S., and T. L. Ku (2004), On the importance of opal, carbonate, and lithogenic clays in scavenging and fractionating ${ }^{230} \mathrm{Th},{ }^{230} \mathrm{~Pa}$ and ${ }^{10} \mathrm{Be}$ in the ocean, Earth and Planetary Science Letters, $220(1), 201-211$.

Lutz, M., R. Dunbar, and K. Caldeira (2002), Regional variability in the vertical flux of particulate organic carbon in the ocean interior, Global Biogeochemical Cycles, 16(3), 1-18.

Maiti, K., K. O. Buesseler, S. M. Pike, C. Benitez-Nelson, P. Cai, W. Chen, K. Cochran, M. Dai, F. Dehairs, B. Gasser, R. P. Kelley, P. Masque, L. A. Miller, J. C. Miquel, S. B. Moran, P. J. Morris, F. Peine, F. Planchon, A. A. Renfo, M. Rutgers van der Loeff, P. H. Santschi, R. Turnewitsch, J. T. Waples, and C. Xu (2012), Intercalibration studies of short-lived thorium-234 in the water column and marine particles, Limnology and Oceanography: Methods, 10(9), 631-644. 
Maiti, K., M. A. Charette, K. O. Buesseler, K. Zhou, P. Henderson, W. S. Moore, P. Morris, and L. Kipp (2015), Determination of particulate and dissolved ${ }^{228} \mathrm{Th}$ in seawater using a delayed coincidence counter, Marine Chemistry, 177, 196-202.

Marchal, O., and P. J. Lam (2012), What can paired measurements of Th isotope activity and particle concentration tell us about particle cycling in the ocean?, Geochimica et Cosmochimica Acta, 90, 126-148.

Marra, J. F., V. P. Lance, R. D. Vaillancourt, and B. R. Hargreaves (2014), Resolving the ocean's euphotic zone, Deep Sea Research Part I: Oceanographic Research Papers, 83, 45-50.

Matlab (2016), Optimization Toolbox (r2016a), User's guide, The Mathworks, Inc., http:// wWw. mathworks.com/help/optim/, accessed: 22 July, 2016.

McDonnell, A. M., P. W. Boyd, and K. O. Buesseler (2015), Effects of sinking velocities and microbial respiration rates on the attenuation of particulate carbon fluxes through the mesopelagic zone, Global Biogeochemical Cycles, , 29(2), 175-193.

Moran, S. B., and K. O. Buesseler (1993), Size-fractionated ${ }^{234}$ Th in continental shelf waters off New England: Implications for the role of colloids in oceanic trace metal scavenging, Journal of Marine Research, 51(4), 893-922.

Murnane, R. J. (1994a), Determination of thorium and particulate matter cycling parameters at station P: A reanalysis and comparison of least squares techniques, Journal of Geophysical Research: Oceans (1978 to 2012), 99(C2), 3393-3405.

Murnane, R. J., J. L. Sarmiento, and M. P. Bacon (1990), Thorium isotopes, particle cycling models, and inverse calculations of model rate constants, Journal of Geophysical Research: Oceans (1978 to 2012), 95(C9), 16,195-16,206.

Murnane, R. J., J. K. Cochran, and J. L. Sarmiento (1994b), Estimates of particle and thorium 
cycling rates in the northwest Atlantic Ocean, Journal of Geophysical Research: Oceans (19782012), 99(C2), 3373-3392.

Murnane, R. J., J. K. Cochran, K. O. Buesseler, and M. P. Bacon (1996), Least-squares estimates of thorium, particle, and nutrient cycling rate constants from the JGOFS North Atlantic Bloom Experiment, Deep Sea Research Part I: Oceanographic Research Papers), 43(2), 239-258.

Nozaki, Y., Y. Horibe, and H. Tsubota (1981), The water column distributions of thorium isotopes in the western North Pacific, Earth and Planetary Science Letters, 54(2), 203-216.

Nozaki, Y., H.-S. Yang, and M. Yamada (1987), Scavenging of thorium in the ocean, Journal of Geophysical Research: Oceans (1978 to 2012), 92(C1), 772-778.

Ohnemus, D. C., and P. J. Lam (2015), Cycling of lithogenic marine particulates in the US GEOTRACES North Atlantic Zonal transect, Deep Sea Research II, 116, 283-302.

Östhols, E. (1995), Thorium adsorption onto amorphous silica, Geochimica et Cosmochimica Acta, 59(3), 1235-1249.

Owens, S. A., K. O. Buesseler, and K. W. W. Sims (2011), Re-evaluating the ${ }^{238}$ U-salinity relationship in seawater: Implications for the ${ }^{238} \mathrm{U}{ }^{234} \mathrm{Th}$ disequilibrium method, Marine Chemistry, 126(1), 31-39.

Owens, S. A., S. Pike, and K. O. Buesseler (2015a), Thorium-234 as a tracer of particle dynamics and upper ocean export in the Atlantic Ocean, Physical Review, 116, 42-59.

Owens, S. A., K. O. Buesseler, and S. Pike (2015b), Thorium-234 as a tracer of particle dynamics and upper ocean export in the Atlantic Ocean, Deep Sea Research-II, 116, 42-59.

Quigley, M. S., P. H. Santschi, C. C. Hung, L. Guo, and B. D. Honeyman (2002), Importance of acid polysaccharides for ${ }^{234} \mathrm{Th}$ complexation to marine organic matter, Limnology and Oceanography, 47(2), 367-377. 
Reinthaler, T., H. Van Aken, C. Veth, J. Arstegui, C. Robinson, P. J. t. B. Williams, P. Lebaron, and G. J. Herndl (2006), Prokaryotic respiration and production in the meso and bathypelagic realm of the eastern and western North Atlantic basin, Limnology and Oceanography, 51(3), $1262-1273$.

Roberts, K. A., C. Xu, C. C. Hung, M. H. Conte, and P. H. Santschi (2009), Scavenging and fractionation of thorium vs. protactinium in the ocean, as determined from particle-water partitioning experiments with sediment trap material from the Gulf of Mexico and Sargasso Sea, Earth and Planetary Science Letters, 286(1), 131-138.

Roy-Barman, M., C. Lemaître, S. Ayrault, C. Jeandel, M. Souhaut, and J. C. Miquel (2009), The influence of particle composition on Thorium scavenging in the Mediterranean Sea, Earth and Planetary Science Letters, 286(3), 526-534.

Rutgers van der Loeff, M., and G. W. Berger (1993), Scavenging of ${ }^{230} \mathrm{Th}$ and ${ }^{231} \mathrm{~Pa}$ near the Antarctic polar front in the South Atlantic, Deep Sea Research Part I: Oceanographic Research Papers, 40(2), 339-357.

Schmitz, W. J., and M. S. McCartney (1993), On the North Atlantic circulation, Reviews of Geophysics, 31(1), 29-49.

Scholten, J. C., M. Rutgers Van Der Loeff, and M. A (1995), Distribution of ${ }^{230} \mathrm{Th}$ and ${ }^{231} \mathrm{~Pa}$ in the water column in relation to the ventilation of the deep Arctic basins, Deep Sea Research Part II: Topical Studies in Oceanography, 42(6), 1519-1531.

Shen, C. C., C. C. Wu, H. Cheng, R. L. Edwards, Y. T. Hsieh, S. Gallet, C. C. Chang, T. Y. Li, D. D. Lam, A. Kano, M. Hori, and C. Spotl (2012), High-precision and high-resolution carbonate ${ }^{230}$ Th dating by MC-ICP-MS with SEM protocols, Geochimica et Cosmochimica Acta, 99, 7186.

Sheridan, C. C., C. Lee, S. G. Wakeham, and J. K. B. Bishop (2002), Suspended particle organic 
composition and cycling in surface and midwaters of the equatorial Pacific Ocean, Deep Sea Research Part I: Oceanographic Research Papers, 49(11), 1983-2008.

Siddall, M., G. M. Henderson, N. R. Edwards, M. Frank, S. A. Müller, T. F. Stocker, and F. Joos (2005), ${ }^{231} \mathrm{~Pa} /{ }^{230} \mathrm{Th}$ fractionation by ocean transport, biogenic particle flux and particle type, Earth and Planetary Science Letters, 237(1), 135-155.

Steinberg, D. K., B. A. Van Mooy, K. O. Buesseler, P. W. Boyd, T. Kobari, and D. M. Karl (2008), Bacterial vs. zooplankton control of sinking particle flux in the ocean's twilight zone, Limnology and Oceanography, 53(4), 1327.

Stemmann, L., G. A. Jackson, and D. Ianson (2004), A vertical model of particle size distributions and fluxes in the midwater column that includes biological and physical processes-Part I: model formulation, Deep Sea Research Part I: Oceanographic Research Papers, 51(7), 865-884.

Stramma, L., H. Sabine, and J. Schafstall (2005), Water masses and currents in the upper tropical Northeast Atlantic off Northwest Africa, Journal of Geophysical Research: Oceans (1978 to 2012), 110(C12), 1-18.

Tarantola, A., and B. Valette (1982), Generalized nonlinear inverse problems solved using the least squares criterion, Reviews of Geophysics, 20(2), 219-232.

The GEOTRACES group (2015), The GEOTRACES Intermediate Data Product 2014, Marine Chemistry, 177, Part 1, 1-8.

Toole, J. M., R. W. Schmitt, and K. L. Polzin (1994), Estimates of diapycnal mixing in the abyssal ocean, Science, 264(5162), 1120-1123.

Venchiarutti, C., C. Jeandel, and M. Roy-Barman (2008), Particle dynamics study in the wake of Kerguelen Island using thorium isotopes, Deep Sea Research Part I: Oceanographic Research Papers, 55(10), 1343-1363. 
Wakeham, S. G., C. Lee, J. I. Hedges, P. J. Hernes, and M. J. Peterson (1997), Molecular indicators of diagenetic status in marine organic matter, Geochimica et Cosmochimica Acta, 61(24), 55635369.

Waltz, R. A., J. L. Morales, J. Nocedal, and D. Orban (2006), An interior algorithm for nonlinear optimization that combines line search and trust region steps, Mathematical Programming, 107(3), 391-408.

Wunsch, C. (2006), Discrete inverse and state estimation problems: with geophysical fluid applications, Cambridge University Press, Cambridge. 


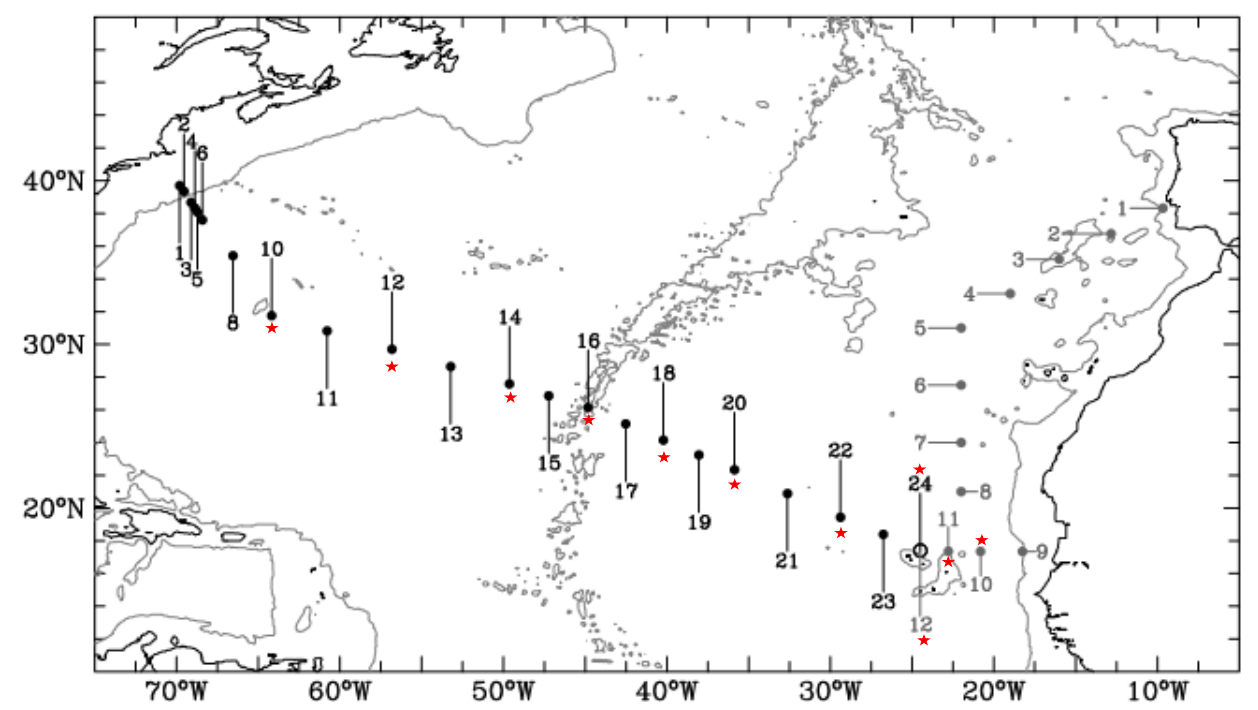

Figure 1: Stations occupied by the R/V Knorr during the GEOTRACES North Atlantic section (GA03). The grey dots show the stations occupied during the first leg (October 2010) and the black dots show the stations occupied during the second leg (November-December 2011). The open circle is both station GT10-12 of the first leg and station GT11-24 of the second leg. The data analyzed in this paper occur at stations marked by red asterisks. The solid lines show the coastline (black) and the 3000-m isobath (grey). 

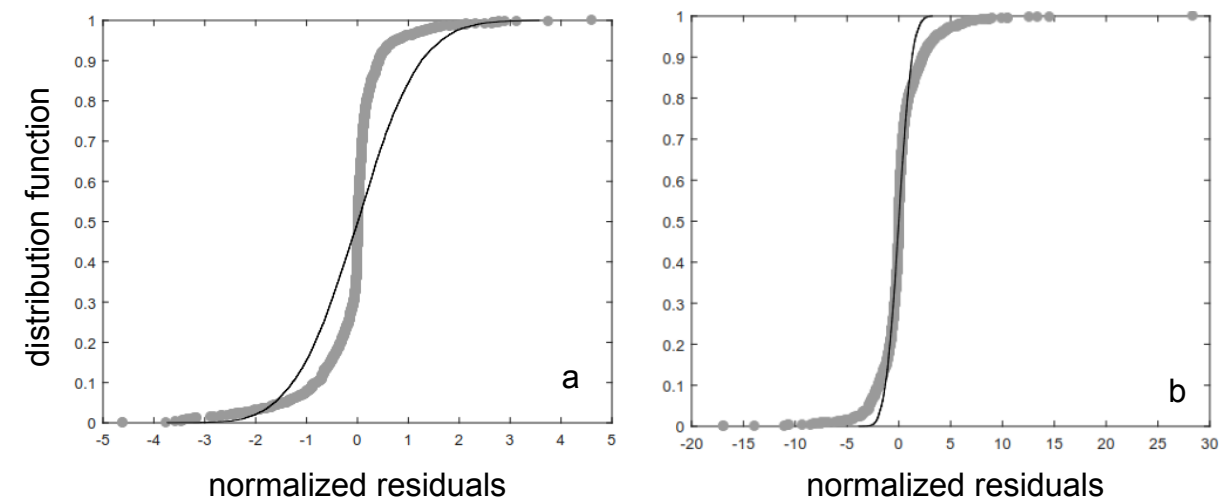

Figure 2: Distribution function of residuals normalized to the errors in the data. The gray circles are the normalized residuals, and the black curve is the standard normal distribution. Panel (a) shows the residuals for the interpolation (Section 2.3), and panel (b) shows the residuals for the inversion (Section 3.1). 


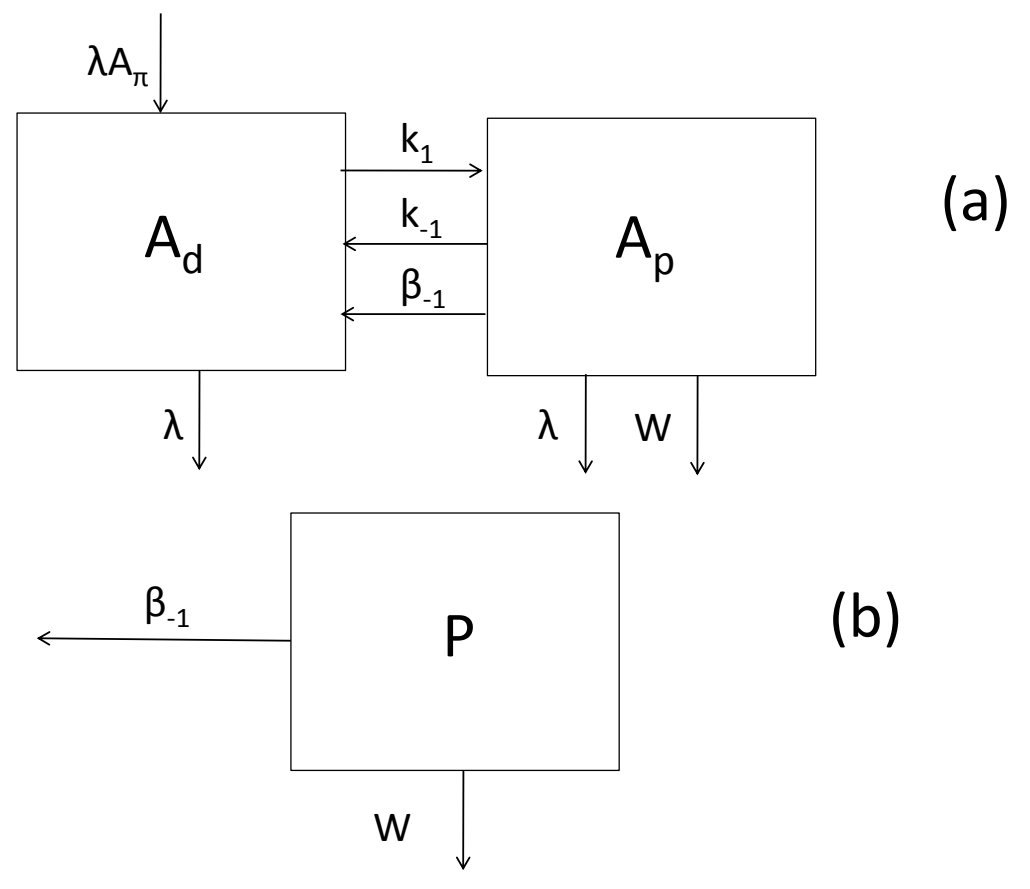

Figure 3: Schematic diagram of the single-particle class model of Th cycling (a) and particle cycling (b). 'A' and 'P' represent, respectively, the Th isotope activity and the particle concentration. Subscript 'd' designates the dissolved fraction and subscript 'p' designates the particulate fraction. $\mathrm{A}_{\pi}$ is the activity of the parent isotope. The other symbols represent the rate parameters of solid-solution exchange $\left(k_{1}\right.$ for adsorption, $k_{-1}$ for desorption) and particle processes $\left(\beta_{-1}\right.$ for particle degradation, and $w$ for particle sinking). $\lambda$ is the radioactive decay constant. 

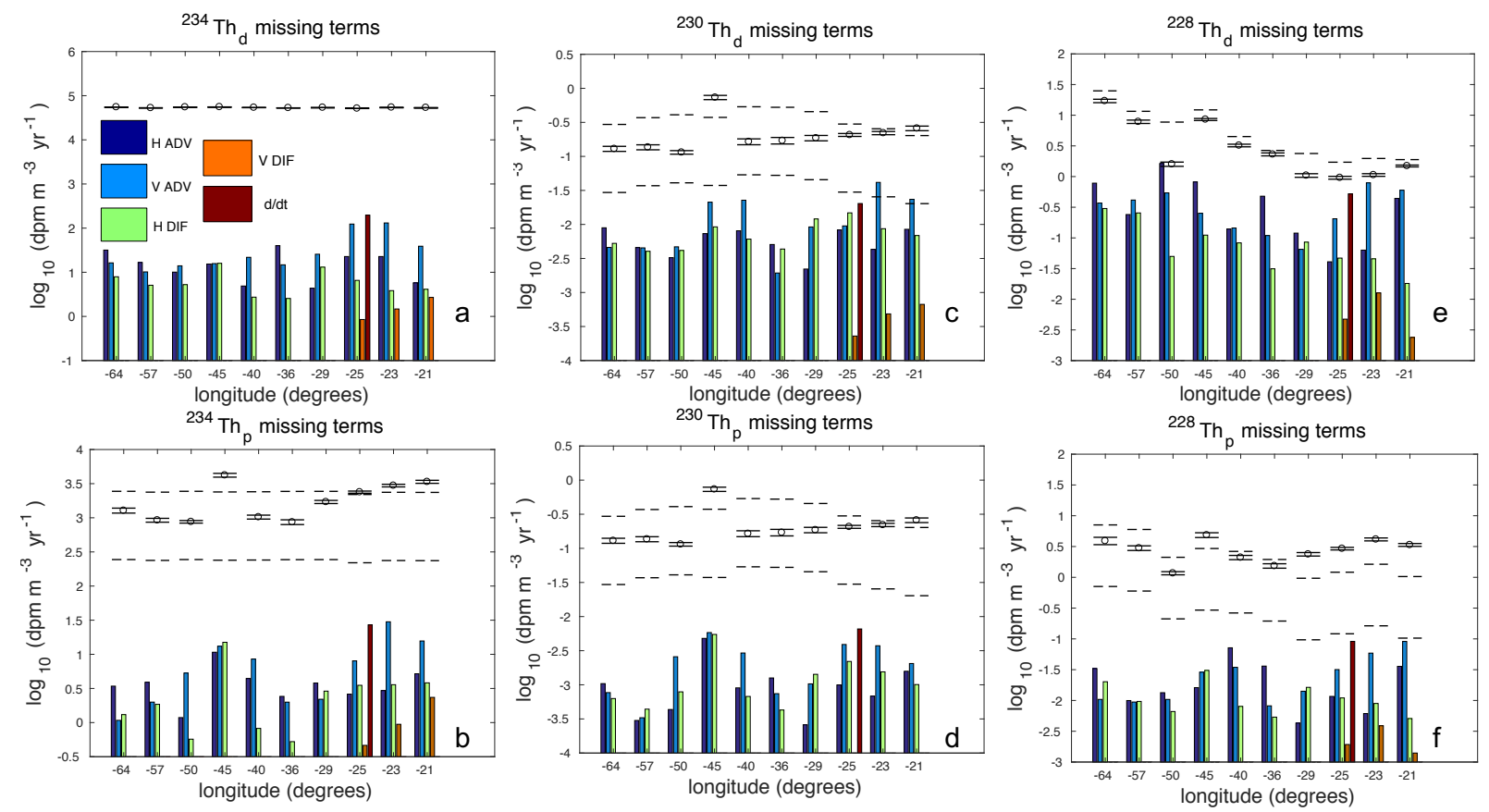

Figure 4: Estimates of the magnitude of the terms missing in the ${ }^{228,230,234} \mathrm{Th}$ dissolved (a-c) and particulate (d-f) balance equations (vertical averages). The x-axis is longitude, and the $y$-axis is the base-10 logarithm of the magnitude of the missing term. The legends in panel (a) apply to all panels. In panels (a, e), the dashed lines are the prior estimates of the radioactive production rates, and the open circles are the posterior estimates of these rates ( \pm 1 standard deviation). Note that in (a), prior and posterior estimates of production rates are barely distinguishable. In panel (b, c, $\mathrm{d}, \mathrm{f}$ ), the dashed lines are prior estimates of the adsorption rate, and the open circles are posterior estimates of the adsorption rate $( \pm 1$ standard deviation). In all panels, the following abbreviations are used: "H ADV" for horizontal advection, "V ADV" for vertical advection, "H DIF" for horizontal diffusion, "V DIF" for vertical diffusion, and "d/dt" for the unsteadiness. 


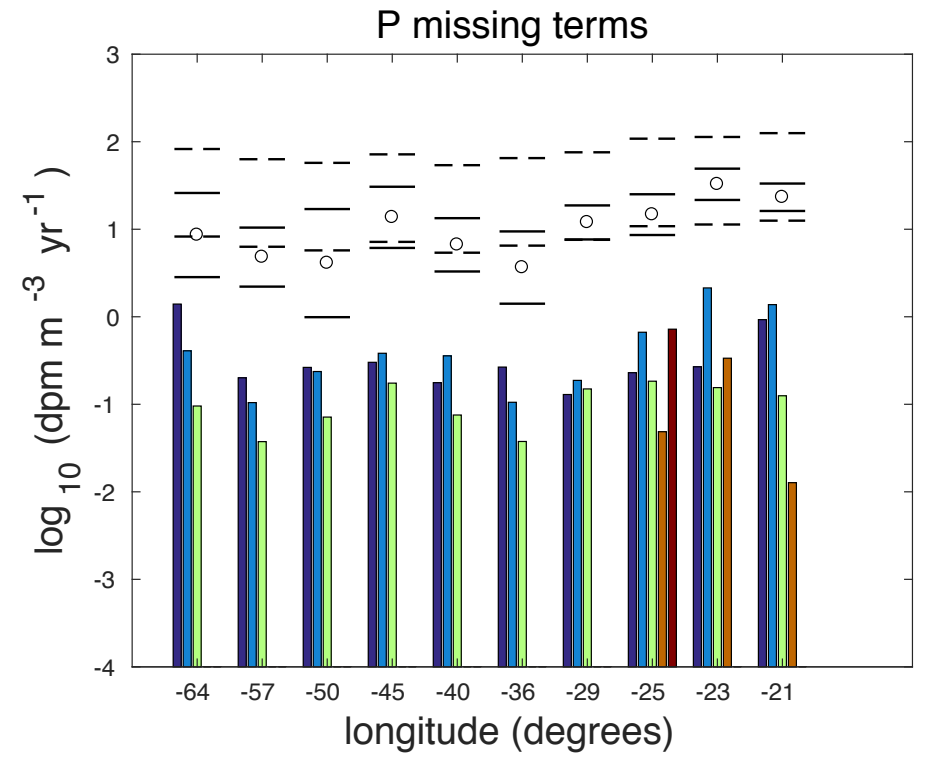

Figure 5: Same as Figure 4, but for $P$. The dashed lines are prior estimates of particle degradation rates, and the open cirlces are the posterior estimates of these rates $( \pm 1$ standard deviation). 


\section{${ }^{230} \mathrm{Th}_{\mathrm{d}}$ flux $\left(\mathrm{dpm} / \mathrm{m}^{3} / \mathrm{yr}\right)$}

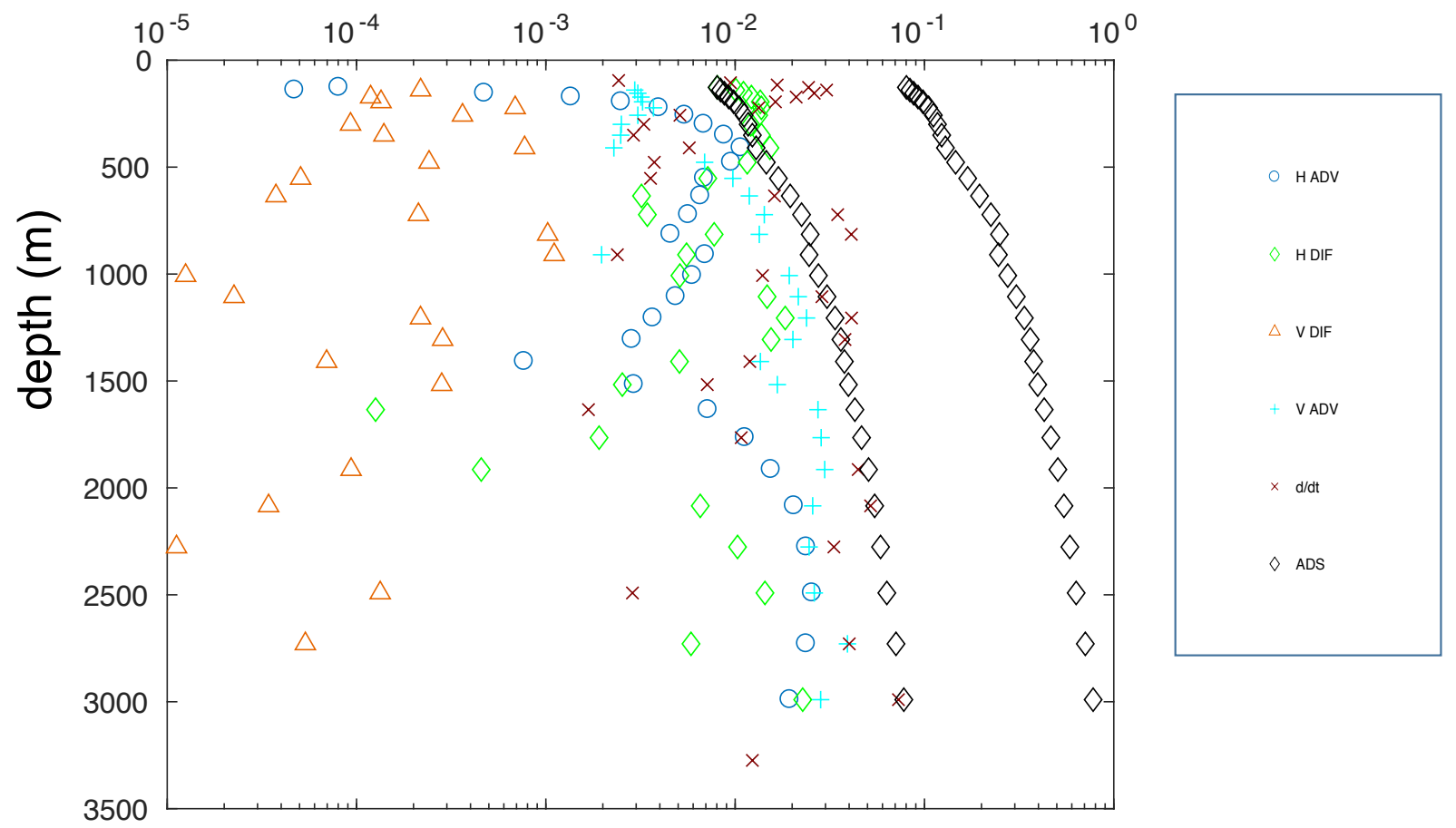

Figure 6: Estimates of the magnitude of the missing terms in the ${ }^{230} \mathrm{Th}_{d}$ balance equations for station GT11-24. In the legend, the following abbreviations are used: "H ADV" for horizontal advection (dark blue circles), "V DIF" for vertical diffusion (light blue crosses), "H DIF" for horizontal diffusion (green squares), "V ADV" for vertical advection (orange triangles), and "d/dt" for unsteadiness (brown crosses). For comparison, "ADS" denotes the prior estimates of Th adsorption rates (minimum and maximum estimates, black diamonds). 
${ }^{234} \mathrm{Th}_{\mathrm{d}}$ normalized residuals

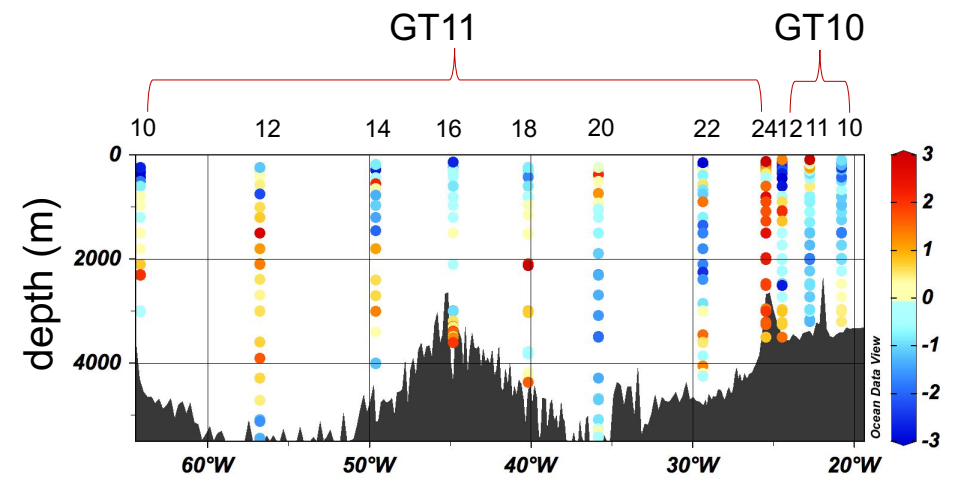

a

${ }^{234} \mathrm{Th}_{\mathrm{p}}$ normalized residuals

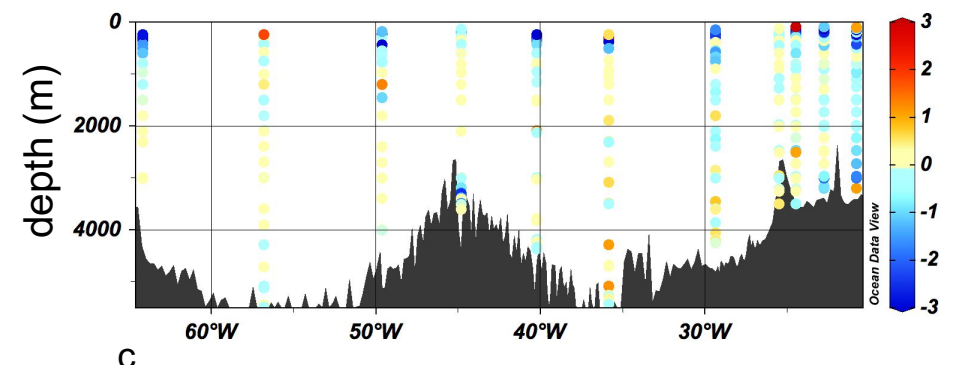

${ }^{234} \mathrm{Th}_{\mathrm{d}}$ (interpolated from data)

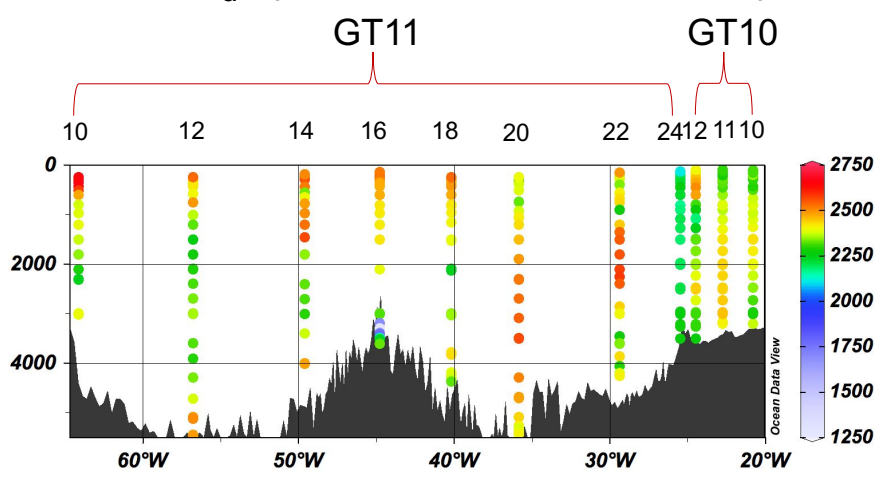

b

${ }^{234} \mathrm{Th}_{\mathrm{p}}$ (interpolated from data)

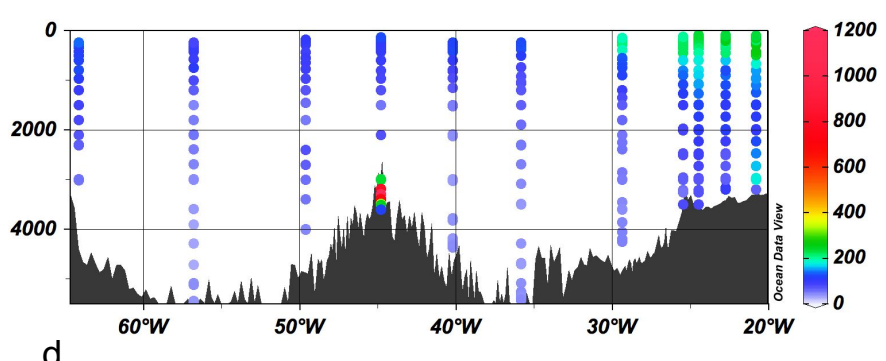

Figure 7: Section plots of ${ }^{234} \mathrm{Th}_{d, p}$. In panels (a, c), the colors show the difference of the posterior estimates and interpolated values, normalized to the interpolated values. Note that the minimum and maximum of the colorbar represent all values $\leq 3$ and all values $\geq 3$, respectively. In panels (b, d), the colors show the activities of interpolated ${ }^{234} \mathrm{Th}$ in $\mathrm{dpm} \mathrm{m}{ }^{-3}$. The third and fourth stations from the right of each panel (GT1012 and GT11-24, respectively) are actually at the same geographic location $\left(17^{\circ} 23^{\prime} \mathrm{N}\right.$, $\left.24^{\circ} 30^{\prime} \mathrm{W}\right)$. 
${ }^{230} \mathrm{Th}_{\mathrm{d}}$ normalized residuals
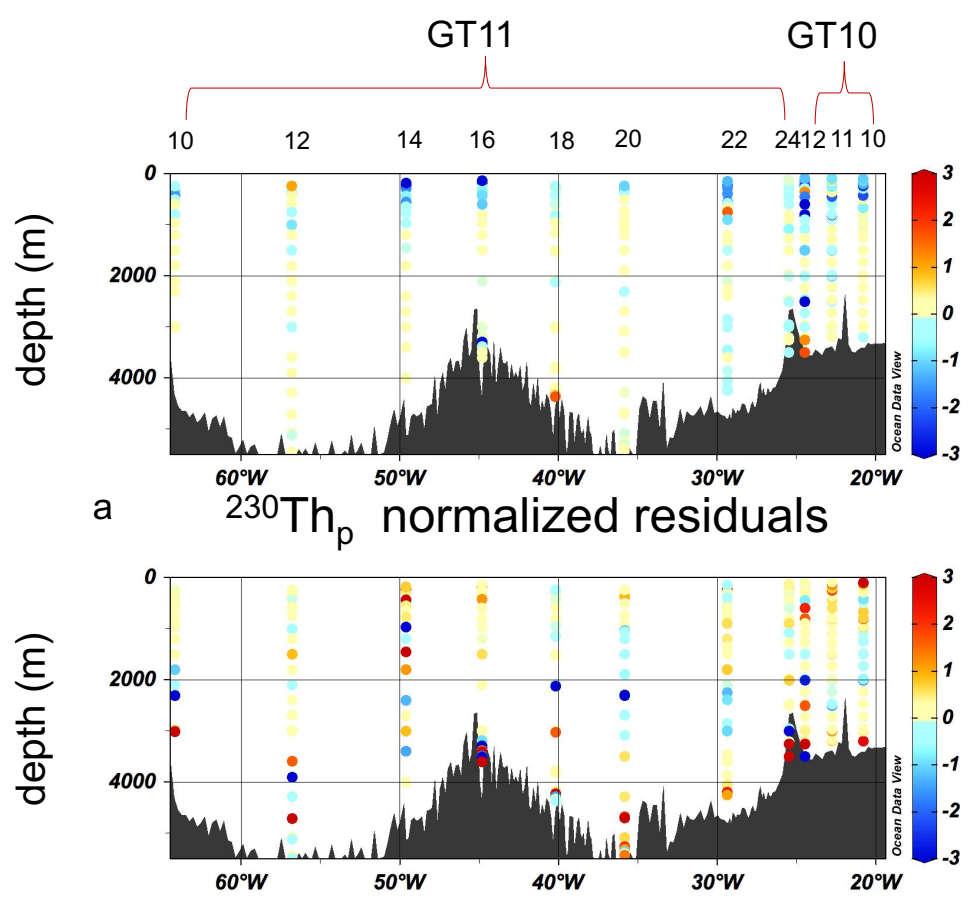

C
${ }^{230} \mathrm{Th}_{\mathrm{d}}$ (interpolated from data)
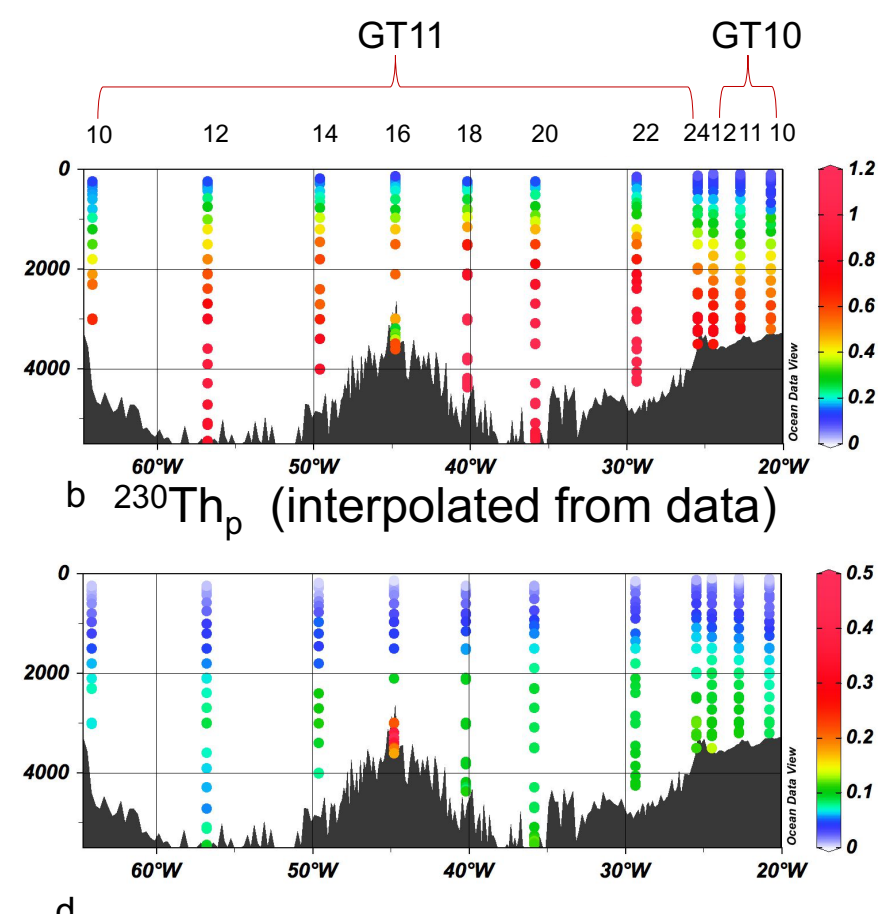

Figure 8: Same as Figure 7, but for ${ }^{230} \mathrm{Th}\left(\mathrm{dpm} \mathrm{m}^{-3}\right)$. 
${ }^{228} \mathrm{Th}_{\mathrm{d}}$ normalized residuals
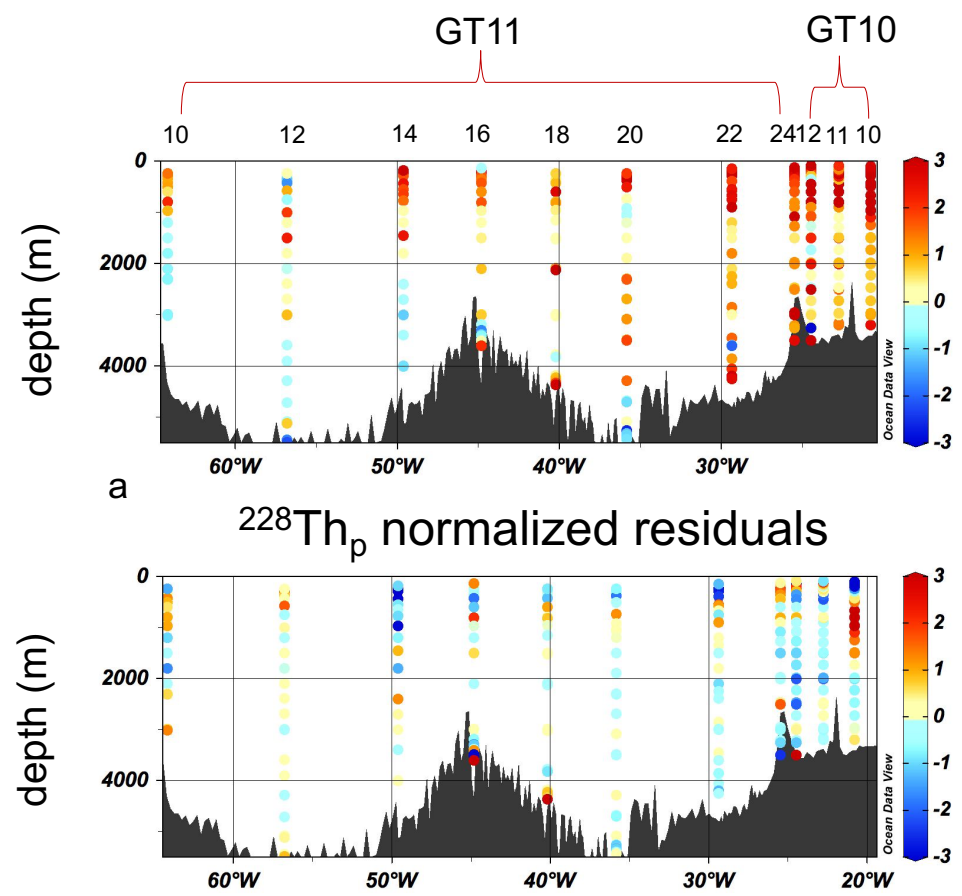

C
${ }^{228} \mathrm{Th}_{\mathrm{d}}$ (interpolated from data)
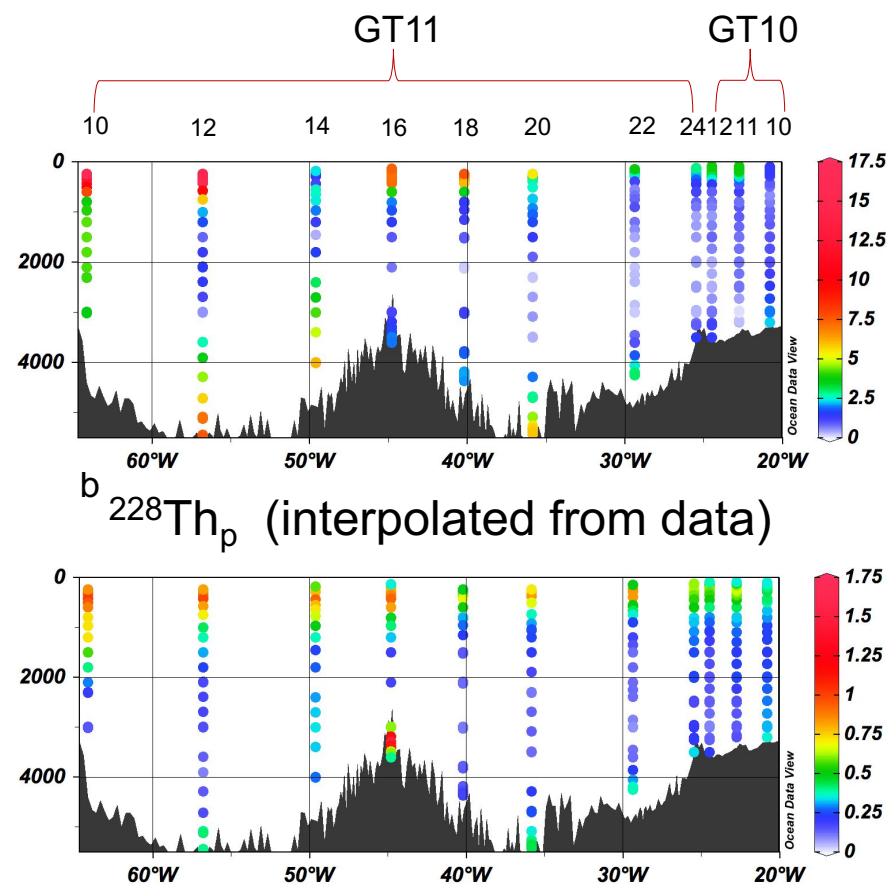

d

Figure 9: Same as Figure 7, but for ${ }^{228} \mathrm{Th}\left(\mathrm{dpm} \mathrm{m}^{-3}\right)$. 

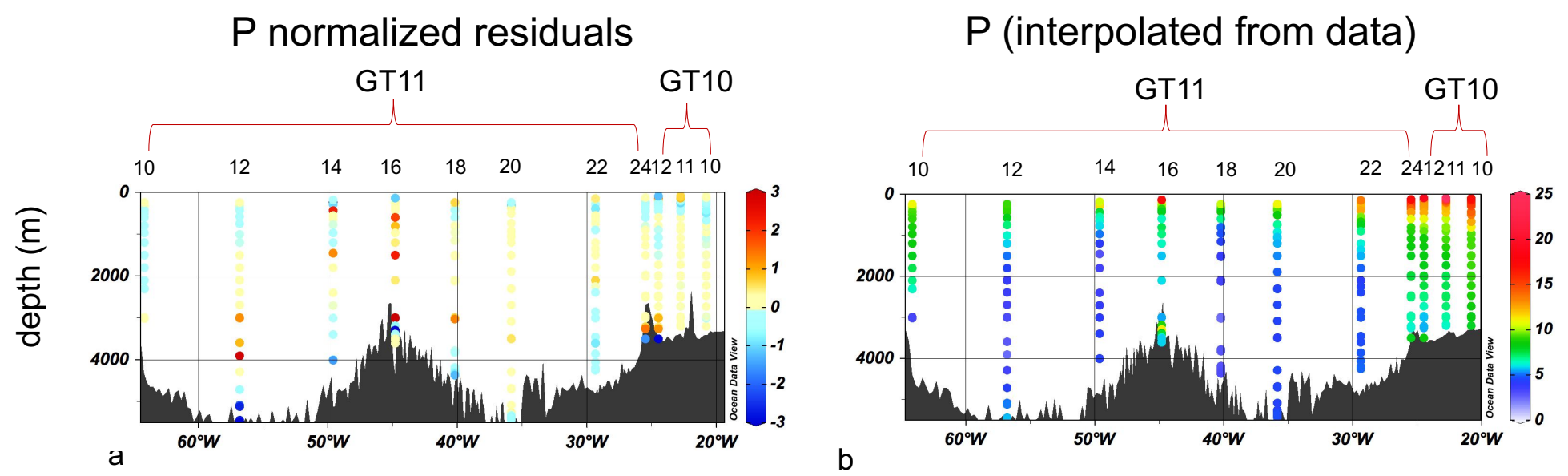

Figure 10: Same as Figure 7, but for $P\left(\mathrm{mg} \mathrm{m}^{-3}\right)$. 

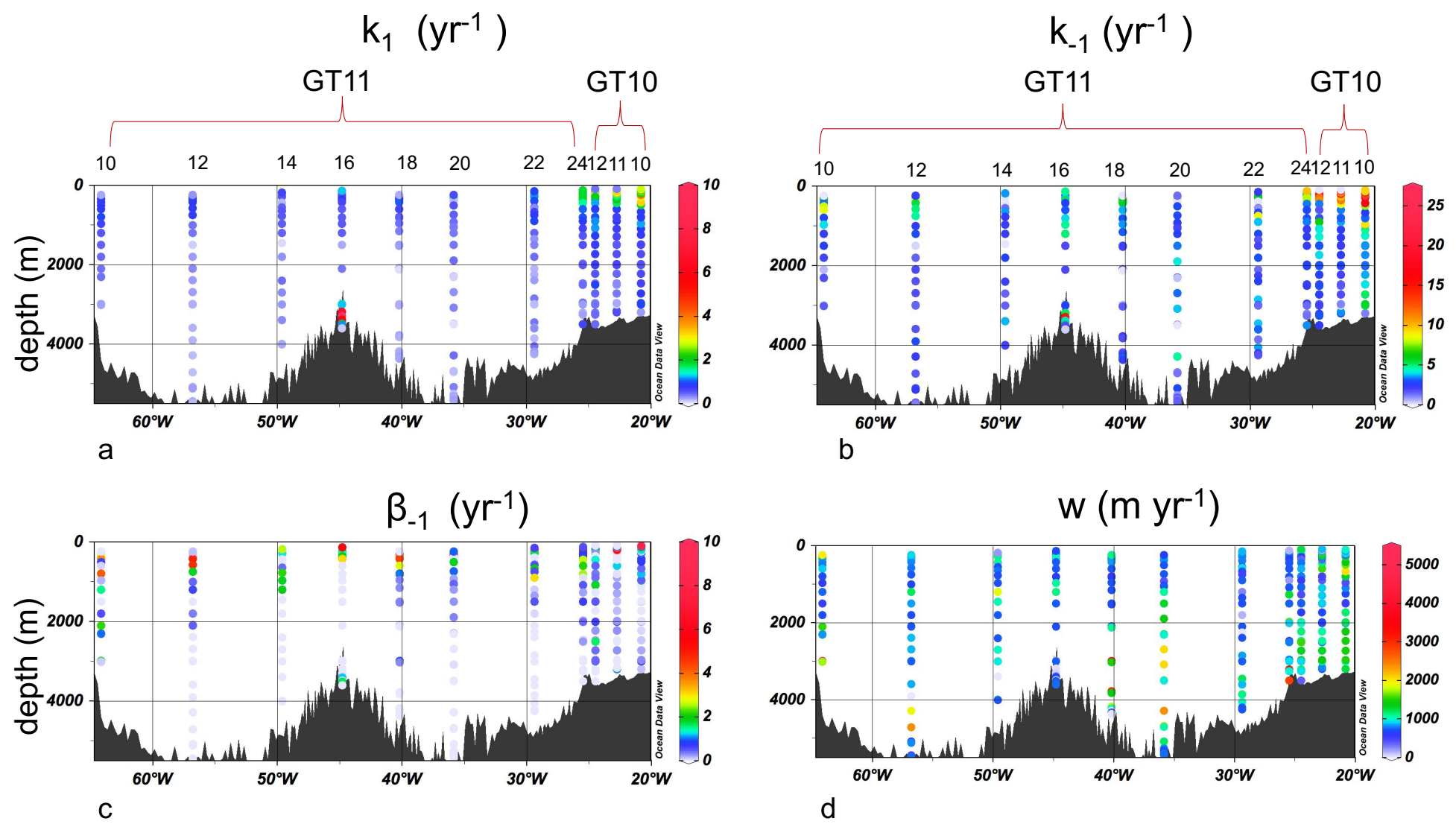

Figure 11: Posterior estimates of the rate parameters of Th and particle cycling along GA03 (legs 1-2). The rate constants for Th adsorption $\left(k_{1}\right)$, Th desorption $\left(k_{-1}\right)$, and particle degradation $\left(\beta_{-1}\right)$ are in $\mathrm{yr}^{-1}$, and the particle sinking speed $(w)$ is in $\mathrm{m} \mathrm{yr}^{-1}$. Notice that the largest value inferred for $k_{1}\left(21 \mathrm{yr}^{-1}\right.$ at $3200 \mathrm{~m}$ at station GT11-16) is not shown so that individual values of $k_{1}$ are more easily distinguished. The third and fourth stations from the right of each panel (GT10-12 and GT11-24, respectively) are actually at the same geographic location $\left(17^{\circ} 23^{\prime} \mathrm{N}, 24^{\circ} 30^{\prime} \mathrm{W}\right)$. 

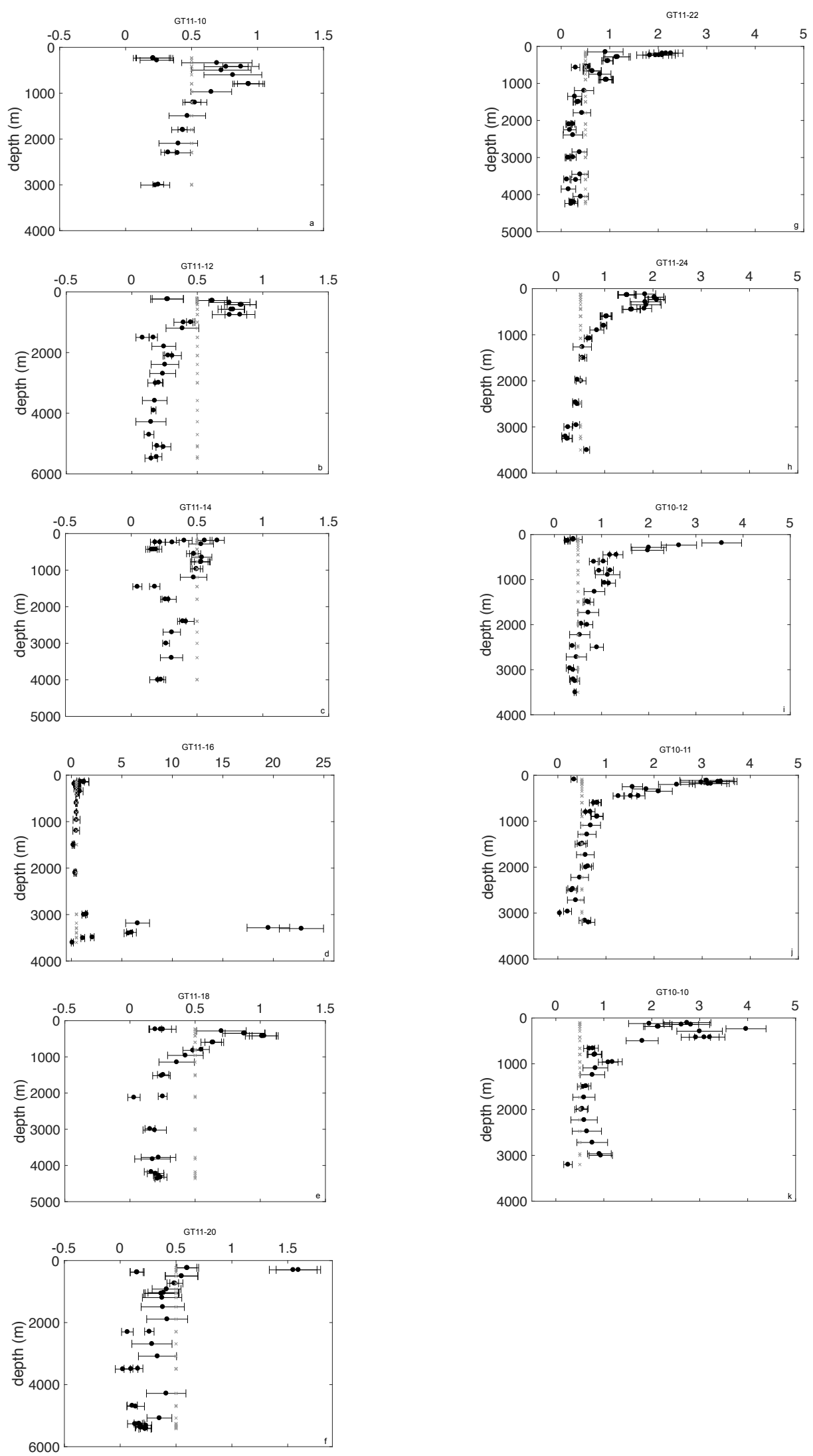

Figure 12: Vertical profile of the Th adsorption rate constant, $k_{1}$, in $\mathrm{yr}^{-1}$ (solid circles, error bars indicate \pm 1 standard deviation) at our selected stations along GA03:(a) GT11-10, (b) GT11-12, (c) GT11-14, (d) GT11-16, (e) GT11-18, (f) GT11-20, (g) GT11-22, (h) GT11-24, (i) GT10-12, (j) GT10-11, and (k) GT10-10. The grey asterisks show the prior estimate of $k_{1}=0.5 \pm 5 \mathrm{yr}^{-1}$. 

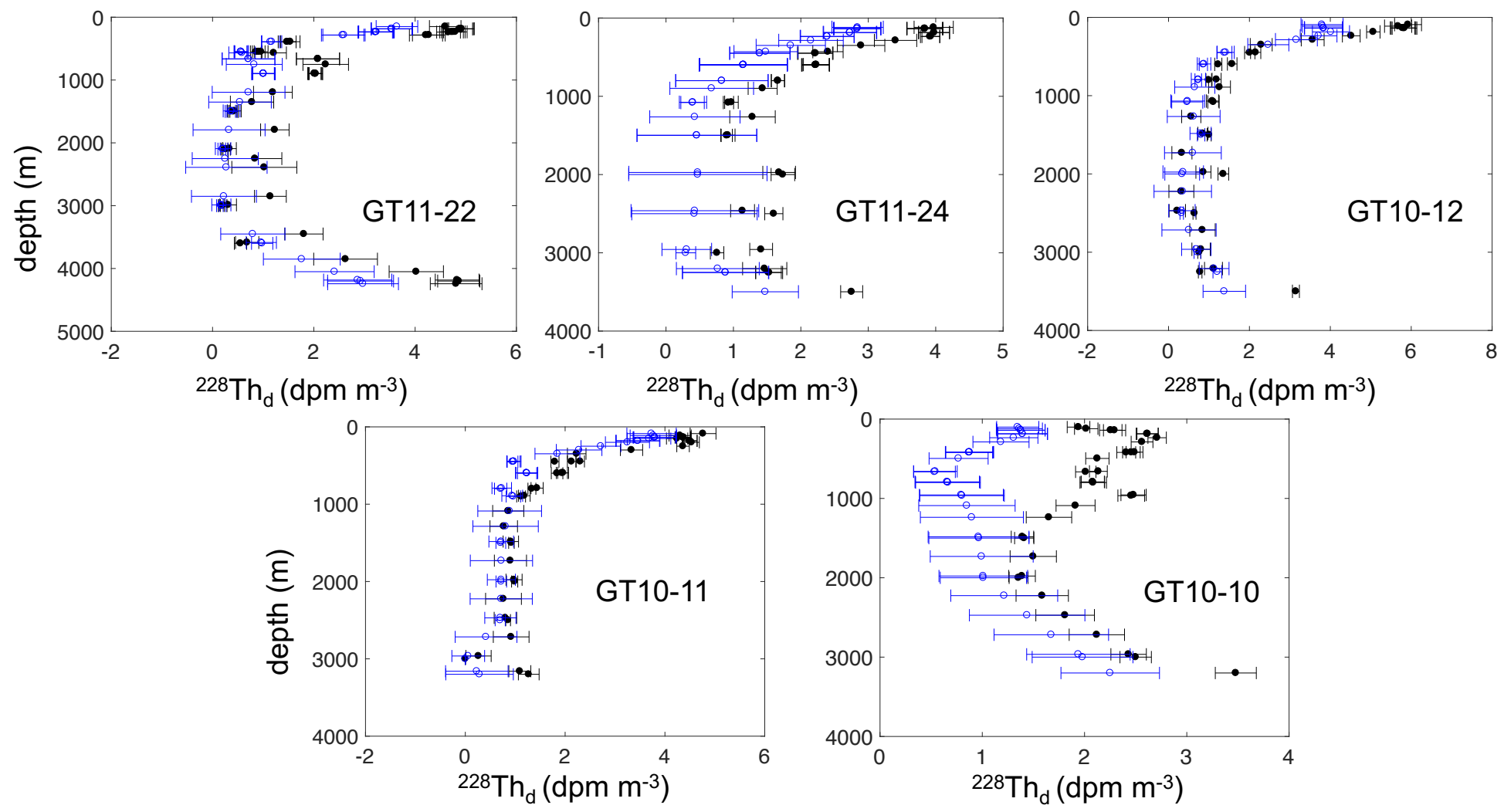

Figure 13: ${ }^{228} \mathrm{Th}_{d}$ profiles at the five easternmost stations. The open circles represent the interpolated values, and the solid circles represent the posterior estimates (error bars are \pm 1 standard deviation). 

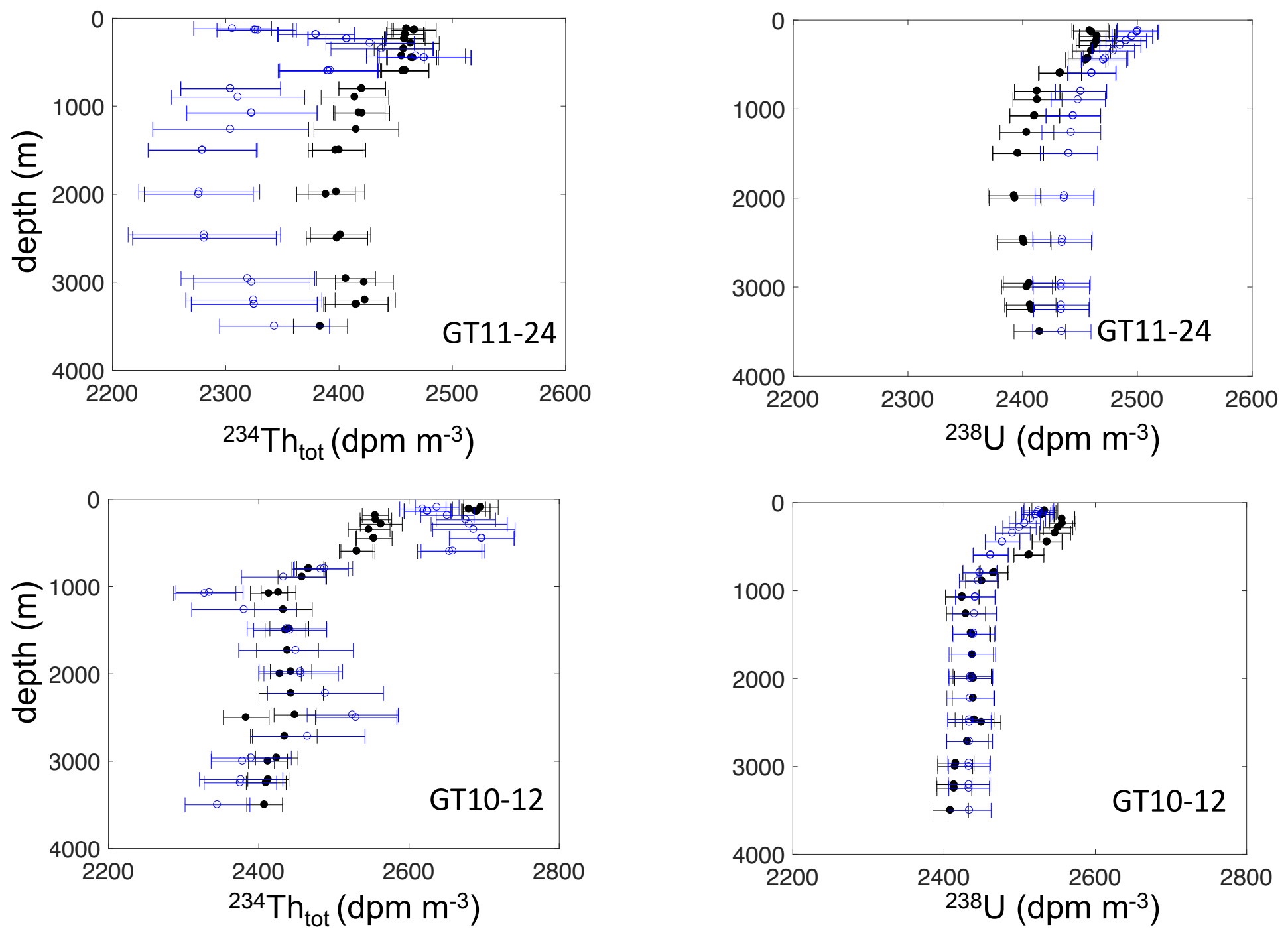

Figure 14: ${ }^{234} \mathrm{Th}_{\text {tot }}$ and ${ }^{238} \mathrm{U}$ profiles at the crossover station GT11-24/GT10-12. The open circles represent the interpolated values, and the solid circles represent the posterior estimates (error bars are \pm 1 standard deviation). 

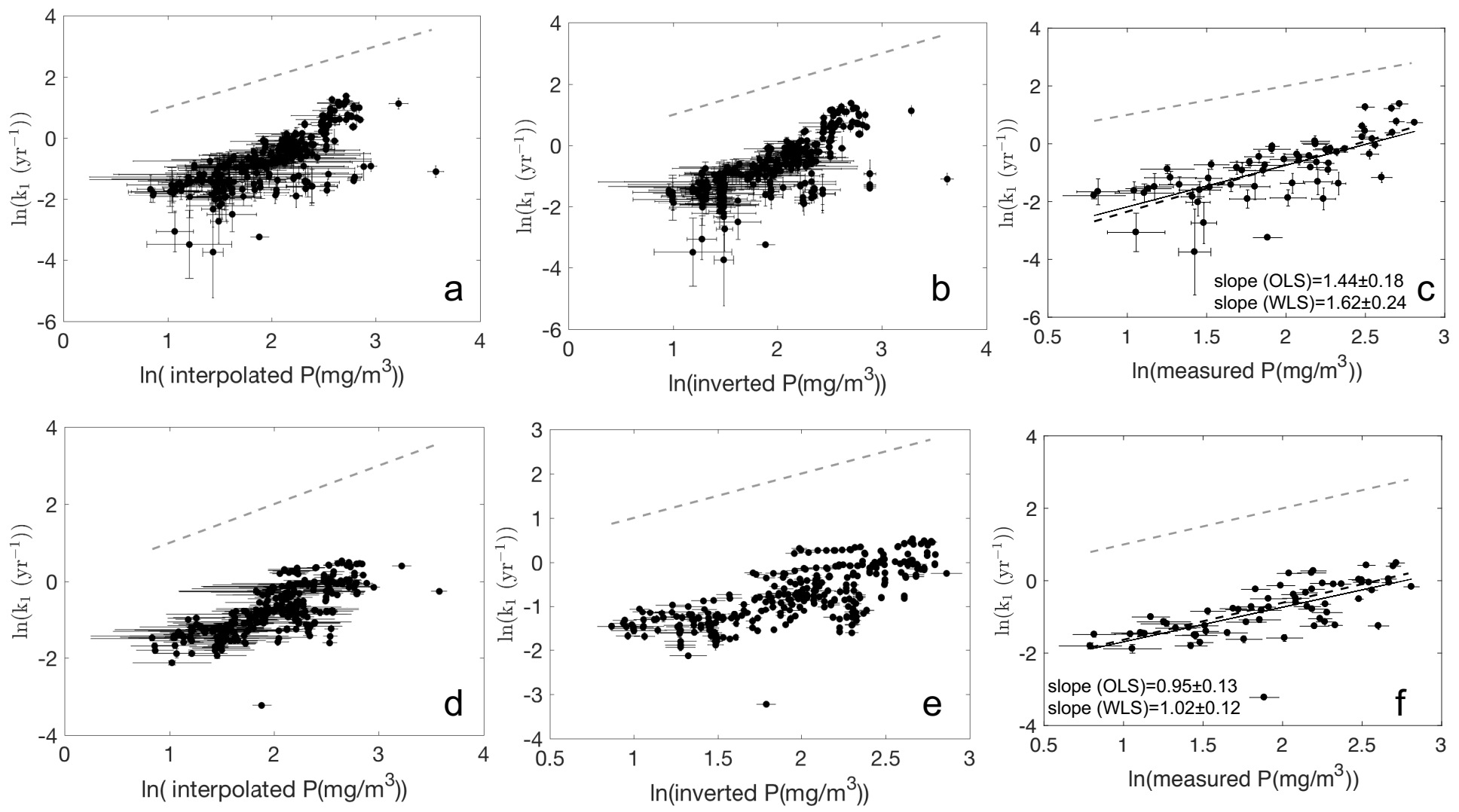

Figure 15: Variation of Th adsorption rate constant with particle concentration. Panels (a-c) show plots of $\ln k_{1}$ estimated by inversion vs. $\ln P$ obtained from interpolation (a), inversion (b), and measurements (c). The error bars are \pm 1 standard deviation, and the light dashed line is the 1:1 line. In panel (c), the solid (dark dashed) line is the best fit obtained by OLS (WLS). Panels (d-f) are the same as panels (a-c), except that $k_{1}$ is estimated from an inversion that assumes a smooth vertical distribution of the rate parameters $(\gamma=1$; see text). Note that none of the panels include the very large $k_{1}$ values from station GT11-16. 


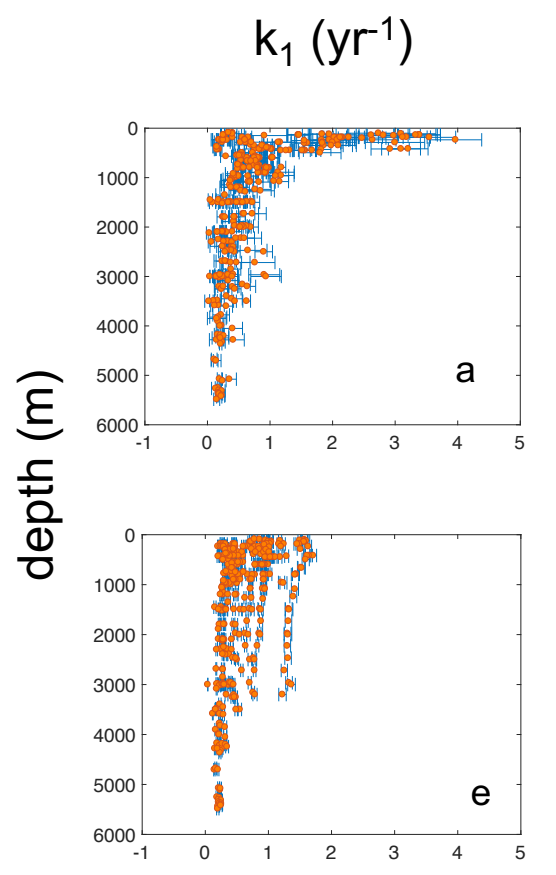

\section{$k_{-1}\left(y r^{-1}\right)$}
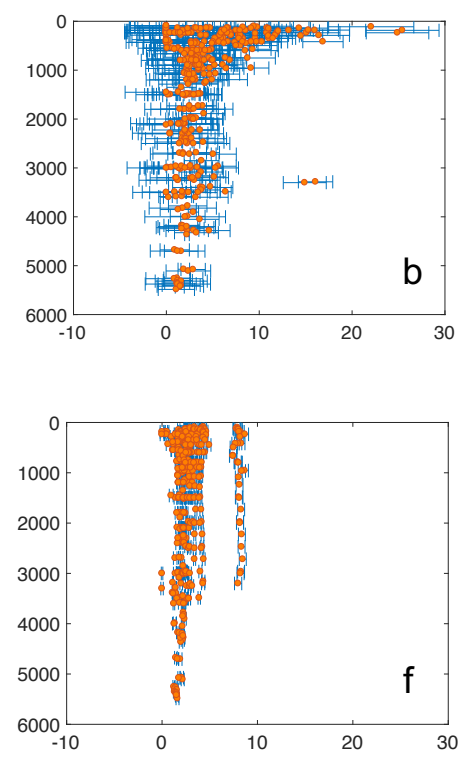

\section{$\beta_{-1}\left(y r^{-1}\right)$}
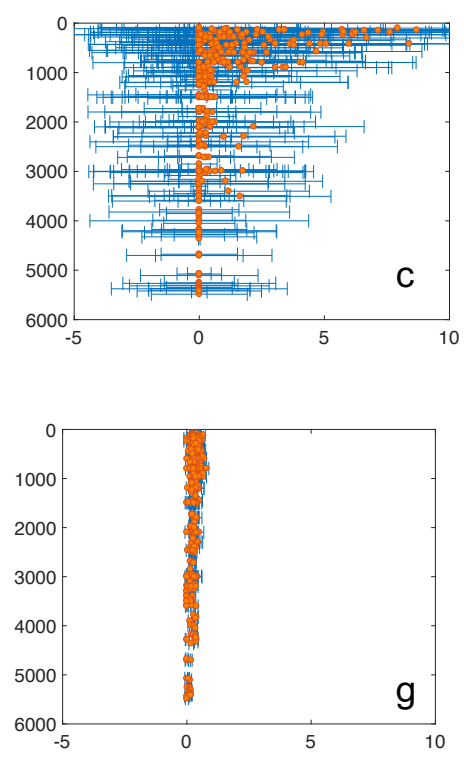

$\mathrm{w}\left(\mathrm{m} \mathrm{yr}^{-1}\right)$
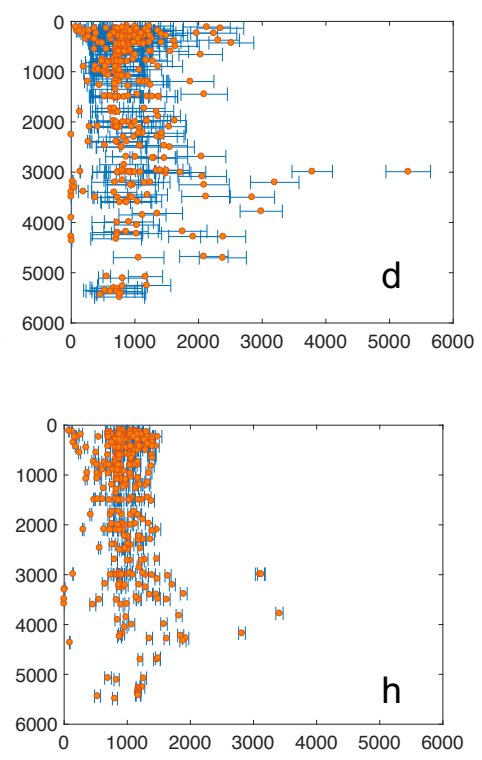

Figure 16: Posterior estimates of $k_{1}, k_{-1}, \beta_{-1}$, and $w$ at all selected stations of GA03 obtained from the inversion without smoothing (panels a-d) and with smoothing with $\gamma=1$ (panels e-h). Panels (a,e) do not include $k_{1}$ values from station GT11-16, which include extremely large values of $k_{1}$ present near the TAG hydrothermal vent. Different colors are used to denote the estimates (orange) and their errors (blue; \pm 1 standard deviation). The separate cluster of large $k_{-1}$ values in panel (f) (around 8 $\mathrm{yr}^{-1}$ ) includes values mostly from stations GT11-24, GT10-12, GT10-11, and GT10-10. 

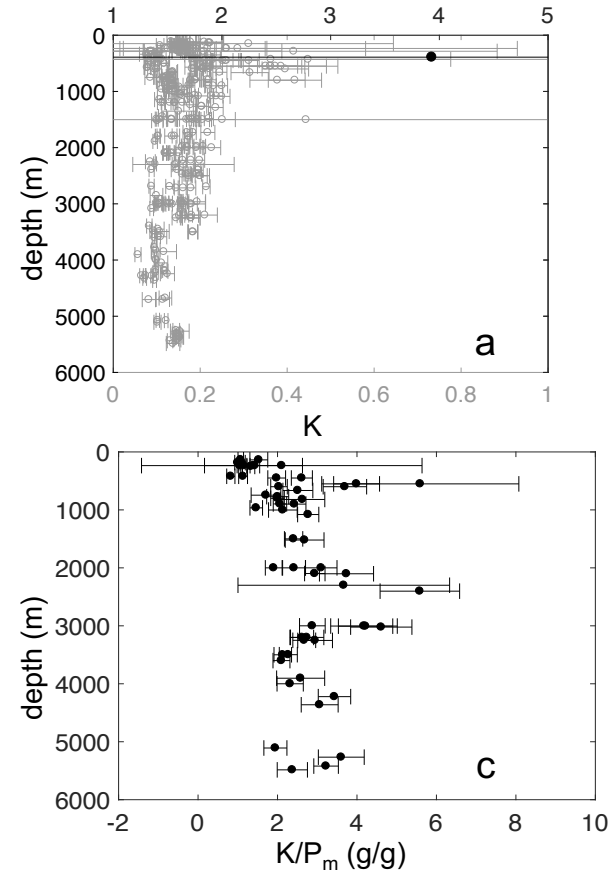
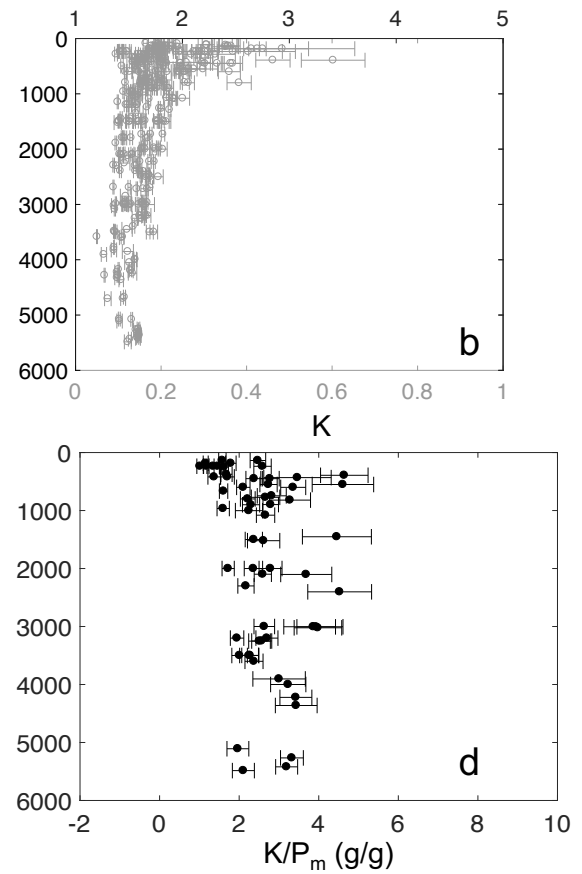

Figure 17: Panels (a,b): posterior estimates of the rate constant ratio $K$ derived from the inversion (a) without smoothing and (b) with smoothing $(\gamma=1)$, at all selected stations and all depths where $k_{-1}+\beta_{-1}>0.1 \mathrm{yr}^{-1}$. Two scales are used to isolate the large values of $K>1$ and better show the vertical structure of $K$. The black circles (top axis) show $K$ values $>1$, while the grey circles (bottom axis) show the $K$ values $\leq$ 1. Panels (c,d): Estimates of $K / P_{m}$, where $K$ is derived from the inversion (a) without smoothing and (b) with smoothing $(\gamma=1)$, at all selected stations and depths where $P$ is measured and where $k_{-1}+\beta_{-1}>0.1 \mathrm{yr}^{-1}$. None of the panels include values estimated at station GT11-16. 

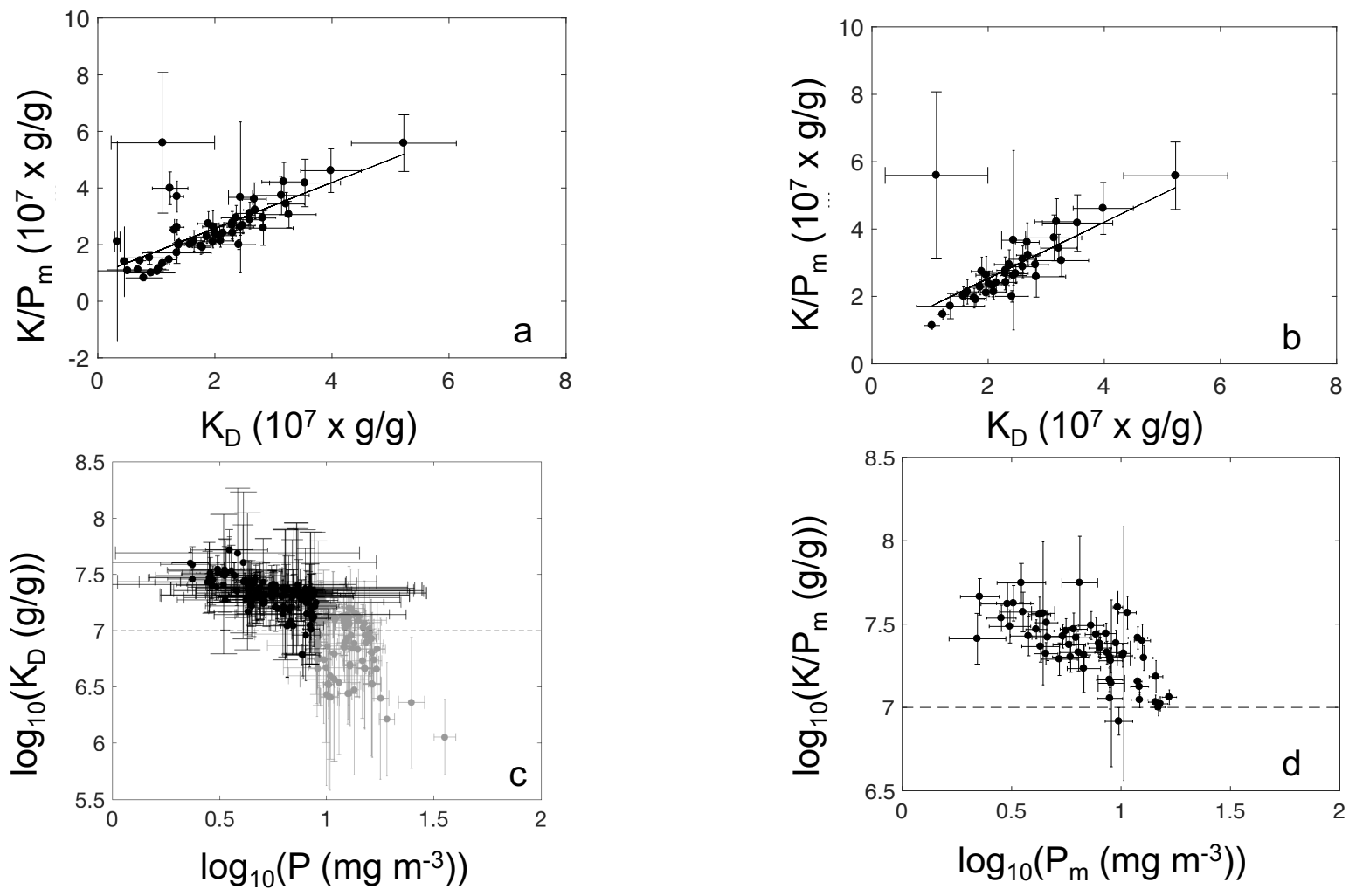

Figure 18: (a) $\log _{10}\left(K / P_{m}\right)$ vs. $\log _{10} K_{D}$. The dashed line is the 1:1 line. (b) Same as (a), except excluding $\left(K_{D}, K / P_{m}\right)$ pairs for which $P_{m}<9 \mathrm{mg} \mathrm{m}^{-3}$. (c) $\log _{10} K_{D}$ vs. $\log _{10} P$ for interpolated ${ }^{230} \mathrm{Th}$ and $P$. The grey circles show values for which $P_{m} \geq 9 \mathrm{mg}$ $\mathrm{m}^{-3}$, and the black circles show values for which $P_{m}<9 \mathrm{mg} \mathrm{m}^{-3}$. (d) $\log _{10}\left(K / P_{m}\right)$ vs. $\log _{10} P_{m}$, where $K$ is estimated by inversion and $P_{m}$ is measured particle concentration. For panels (c) and (d), the dashed line is the slope expected in the absence of a particle concentration effect (slope is 0 ). In all panels, error bars are \pm 1 standard deviation, and values of $K_{D}$ and $K / P_{m}$ at station GT11-16 are not included. 


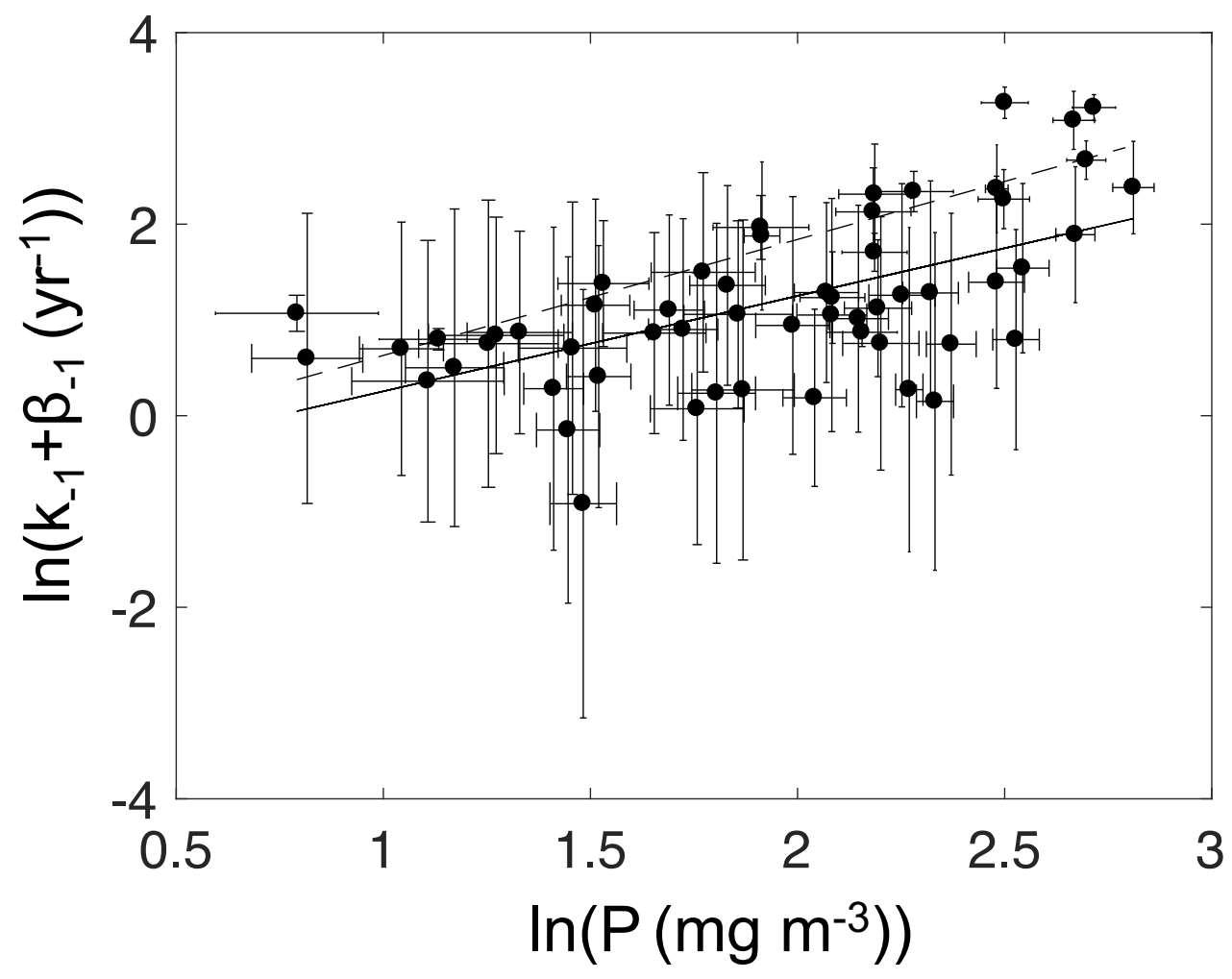

Figure 19: $\ln \left(k_{-1}+\beta_{-1}\right)$ estimated by inversion vs. $\ln P_{m}$, excluding $\left(k_{-1}+\beta_{-1}, P\right)$ pairs for which $k_{-1}+\beta_{-1}<0.1 \mathrm{yr}^{-1}$. The error bars are \pm 1 standard deviation and the solid (dashed) line is the best fit using OLS (WLS). 


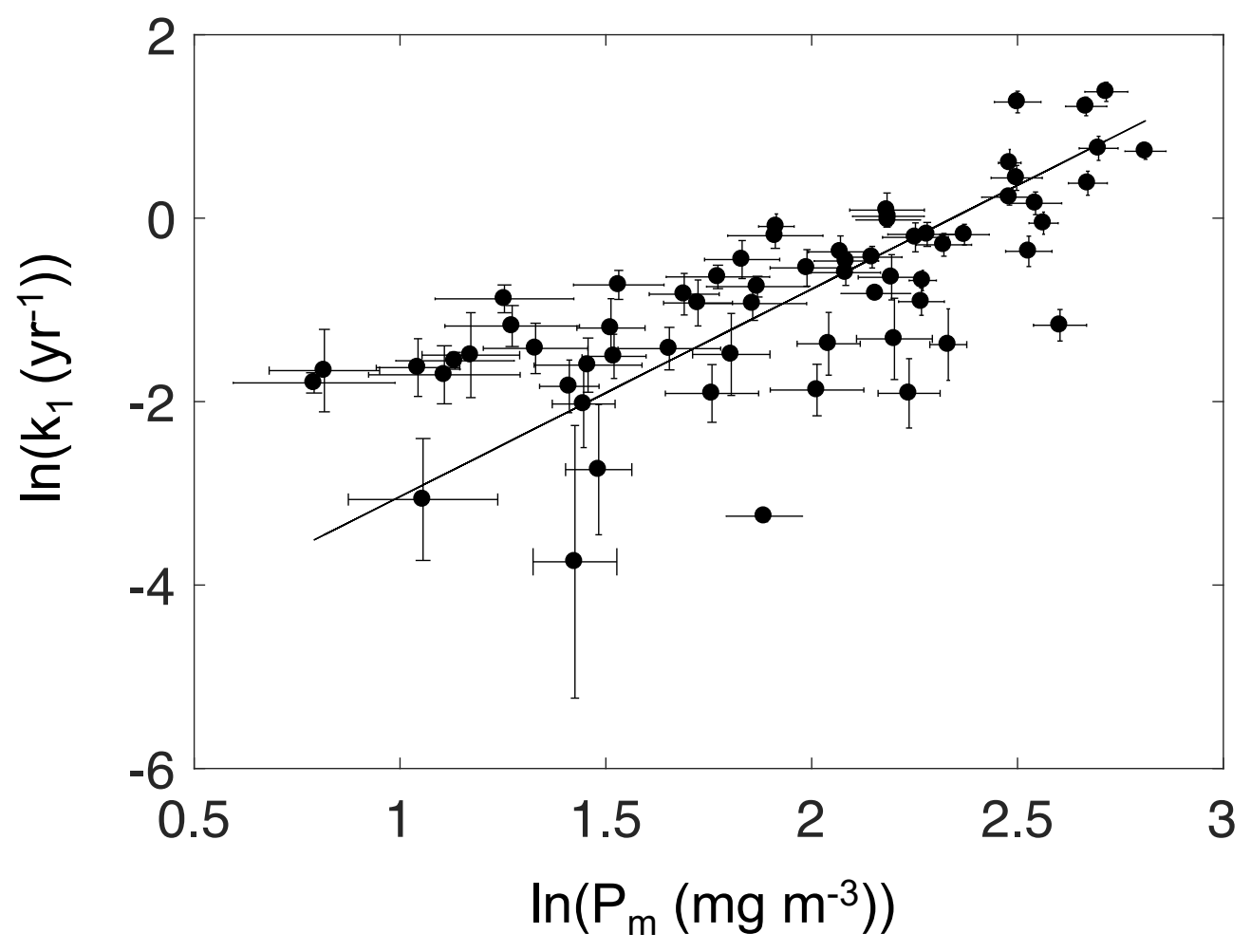

Figure B.1: $\ln k_{1}$ estimated by inversion vs. $\ln P_{m}$. The error bars are \pm 1 standard deviation and the solid line is the best fit obtained from the ATI. The figure does include very large $k_{1}$ values from station GT11-16. 

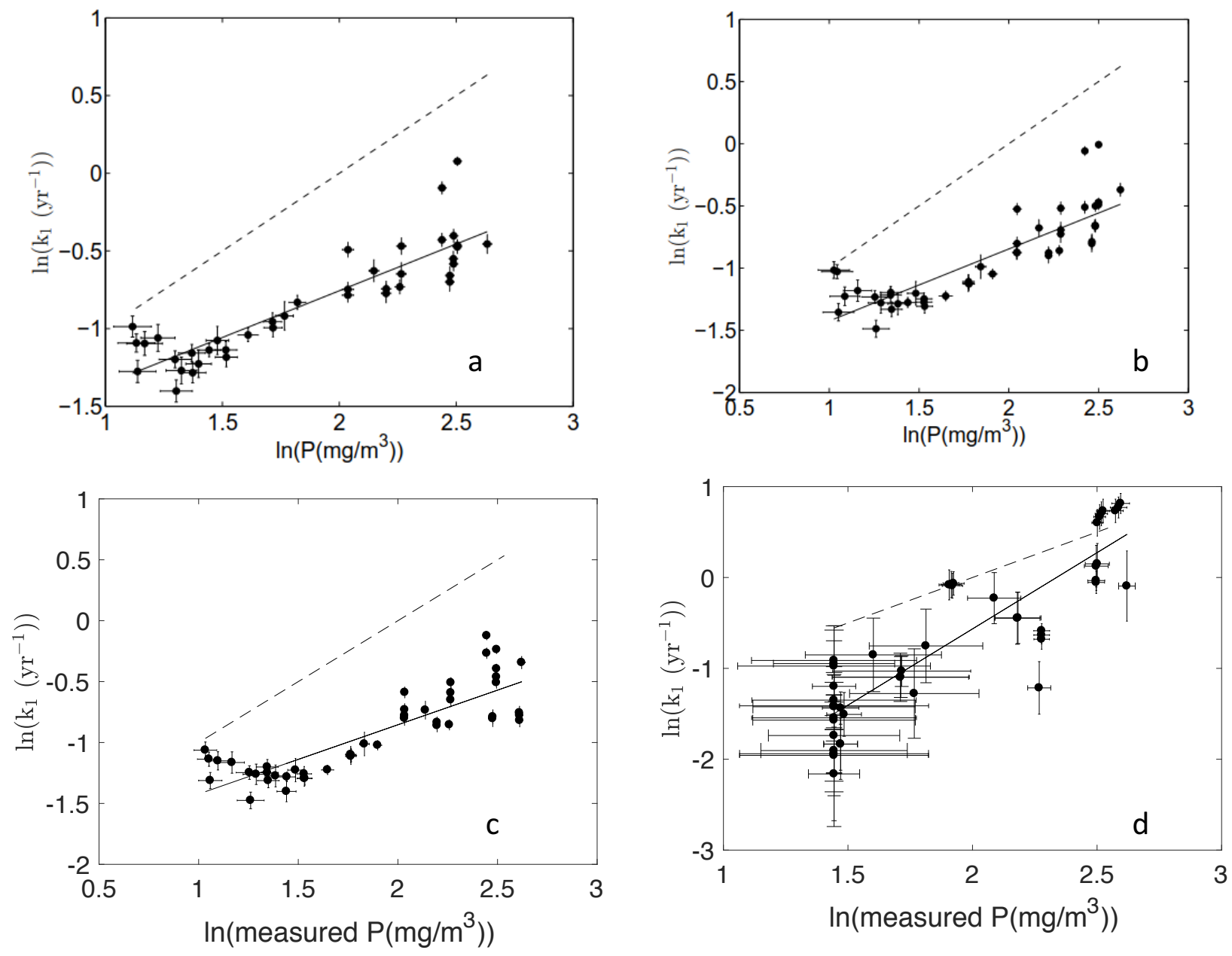

Figure C.1: $\ln k_{1}$ vs. $\ln P$ for station GT11-22 using (a) ATI with smoothing and total ${ }^{230} \mathrm{Th}_{p}$ (adsorbed $+{ }^{230} \mathrm{Th}$ locked in mineral lattices; Lerner et al. (2016)), (b) ATI with smoothing and adsorbed ${ }^{230} \mathrm{Th}_{p}$, (c) FMINCON with smoothing, and (d) FMINCON without smoothing. In each panel, the solid line is the best fit using OLS, the dashed line is the 1:1 line (no particle concentration effect), and error bars are \pm 1 standard deviation. 